\title{
P-Heterocyclic Building Blocks: Application to the Stereoselective Synthesis of Phosphono Sugars.
}

Diana S. Stoianova, Alan Whitehead and Paul R. Hanson*

Paul R. Hanson

Department of Chemistry

University of Kansas, 1251 Wescoe Hall Drive, Lawrence, KS 66045-7582

phanson@KU.edu (785) 864-3094

FAX (785) 864-5396

http://www.chem.ukans.edu/phansongroup/

\section{Supporting Information}

\section{Table of Contents}

General Experimental Methods

NMR spectra for compounds

S 3

17b-43

X-ray data for compound $\mathbf{2 3}$

S 58 


\section{General Methods.}

All air and moisture sensitive reactions were carried out in flame-dried glassware under argon. THF and $\mathrm{CH}_{2} \mathrm{Cl}_{2}$ was purified by passage through a purification system employing activated $\mathrm{Al}_{2} \mathrm{O}_{3}$. $\mathrm{MeOH}$ and $\mathrm{HMPA}$ were distilled from $\mathrm{CaH}_{2}$. DME was distilled from $\mathrm{Na}$ /benzophenone. Flash column chromatography was performed with silica gel (230-400 mesh). Thin layer chromatography was performed out on silica gel $60 \mathrm{~F}_{254}$ plates. ${ }^{1} \mathrm{H},{ }^{13} \mathrm{C}$ and ${ }^{31} \mathrm{P}$ NMR spectra were recorded in $\mathrm{CDCl}_{3}$ (unless otherwise mentioned) on a DRX-400 spectrometer operating at $400 \mathrm{MHz}, 100 \mathrm{MHz}$, and $162 \mathrm{MHz}$ respectively. High-resolution mass spectrometry (HRMS) and FAB spectra were obtained on a ZAB double-focusing mass spectrometer. Optical rotations were recorded on a Rudolph Automatic Polarimeter. 


\section{Compound 17b}

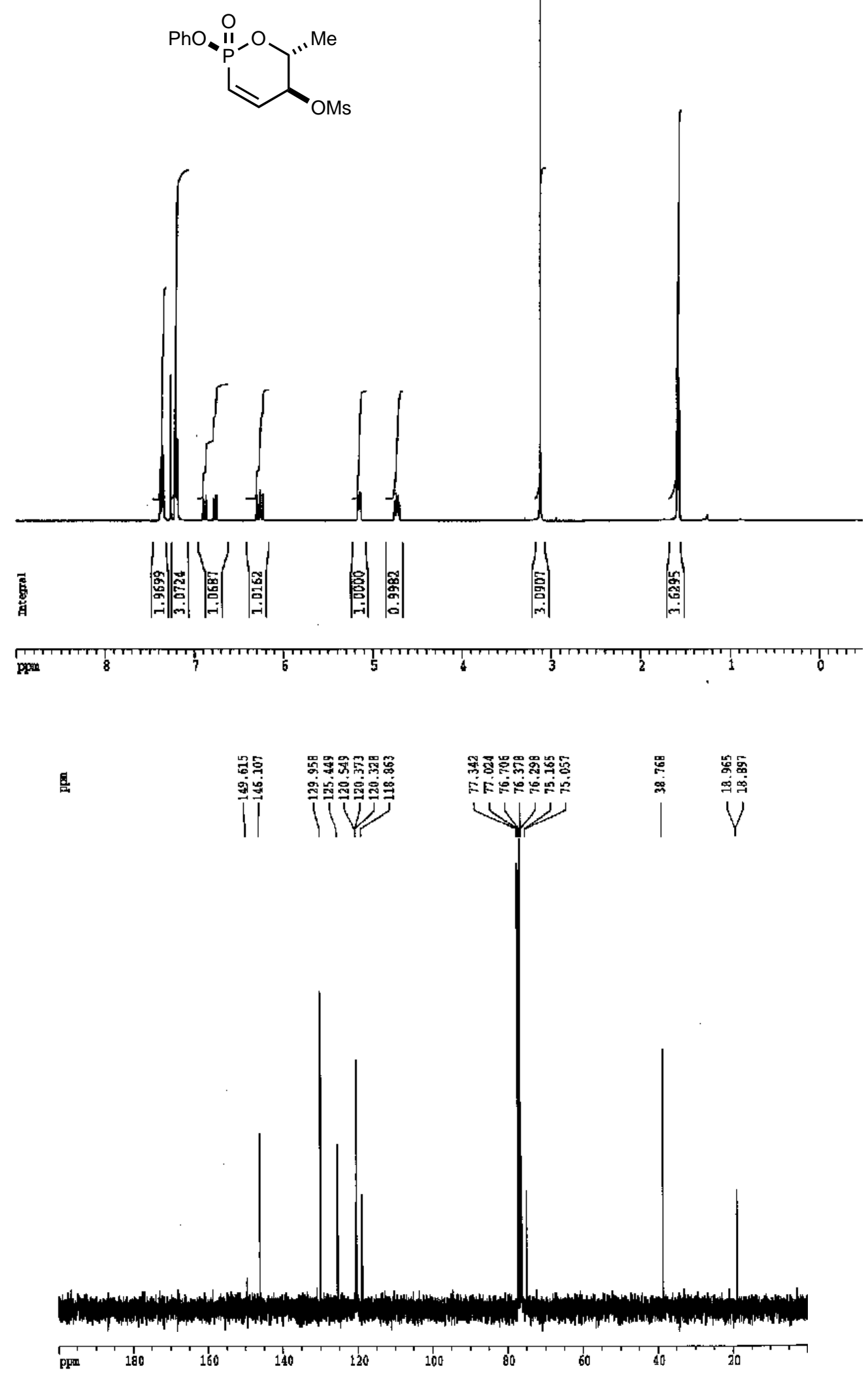


县

$\mathrm{PhO}{ }_{\mathrm{P}}^{\mathrm{II}}-\mathrm{O}>\mathrm{Me}$

$\varnothing_{\mathrm{OMs}}$
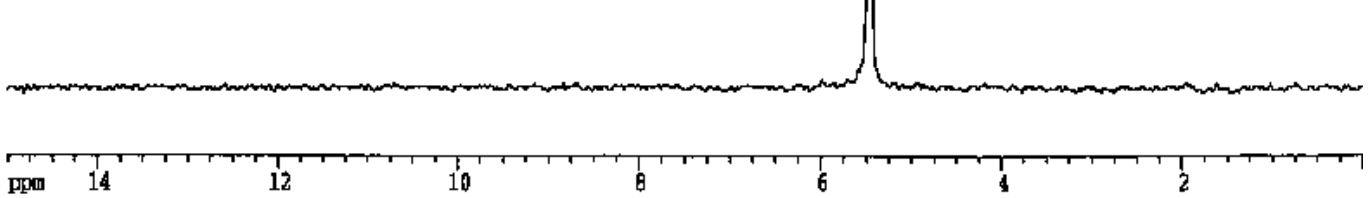


\section{Compound 18}
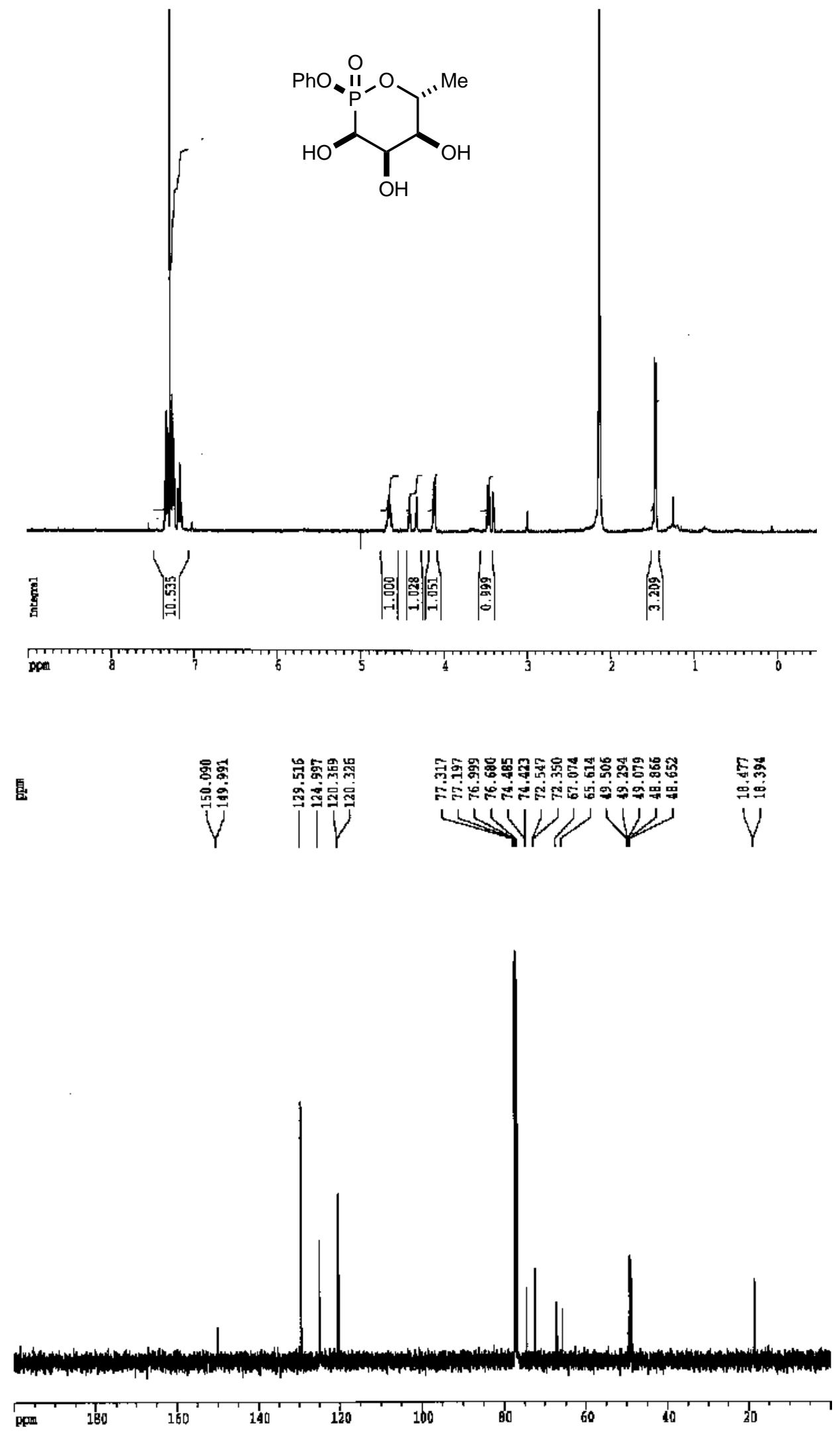
点

$\underset{3}{*}$

밈

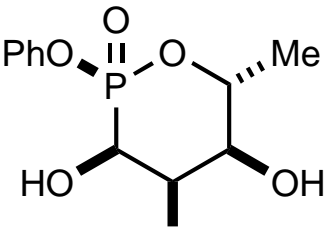

$\left.\right|_{18}$ 


\section{Compound 19}
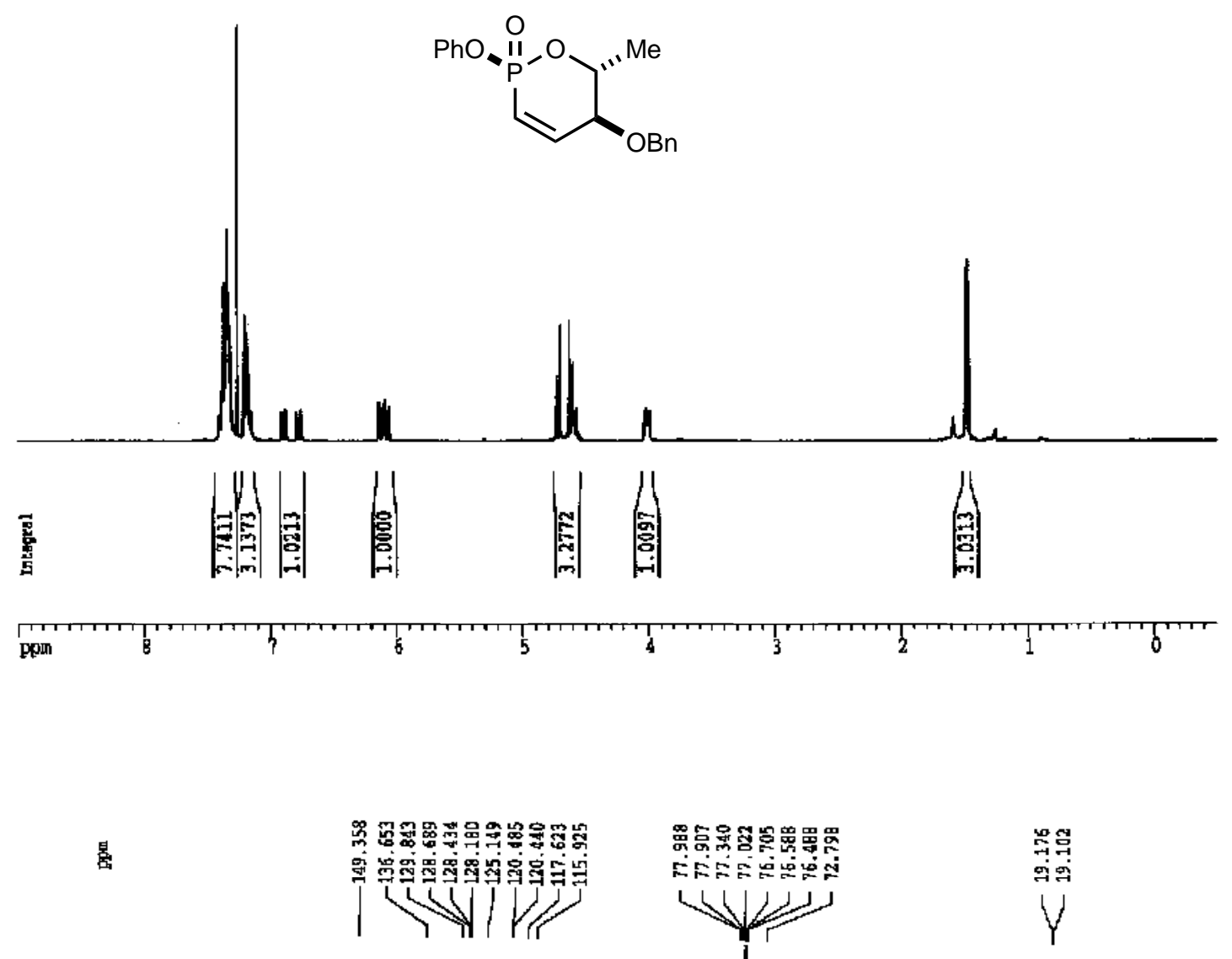

웍욜

ํำ

$y$
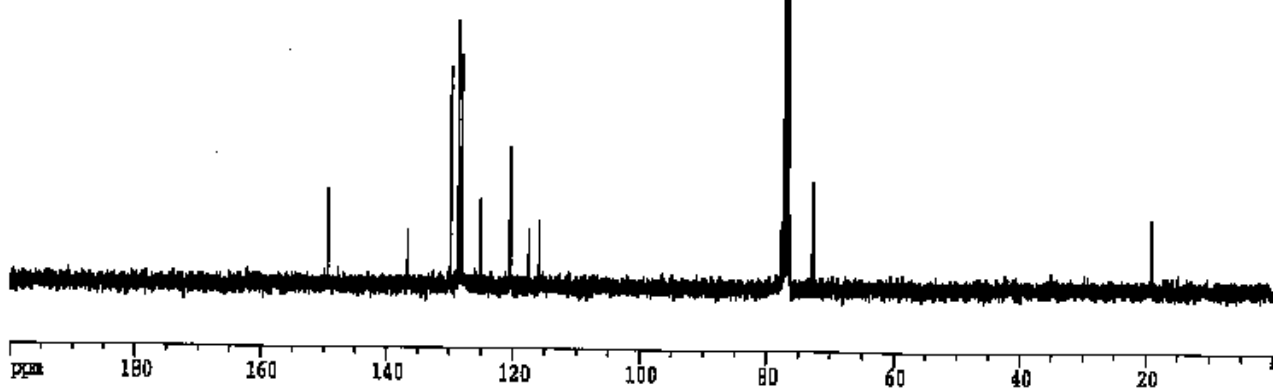

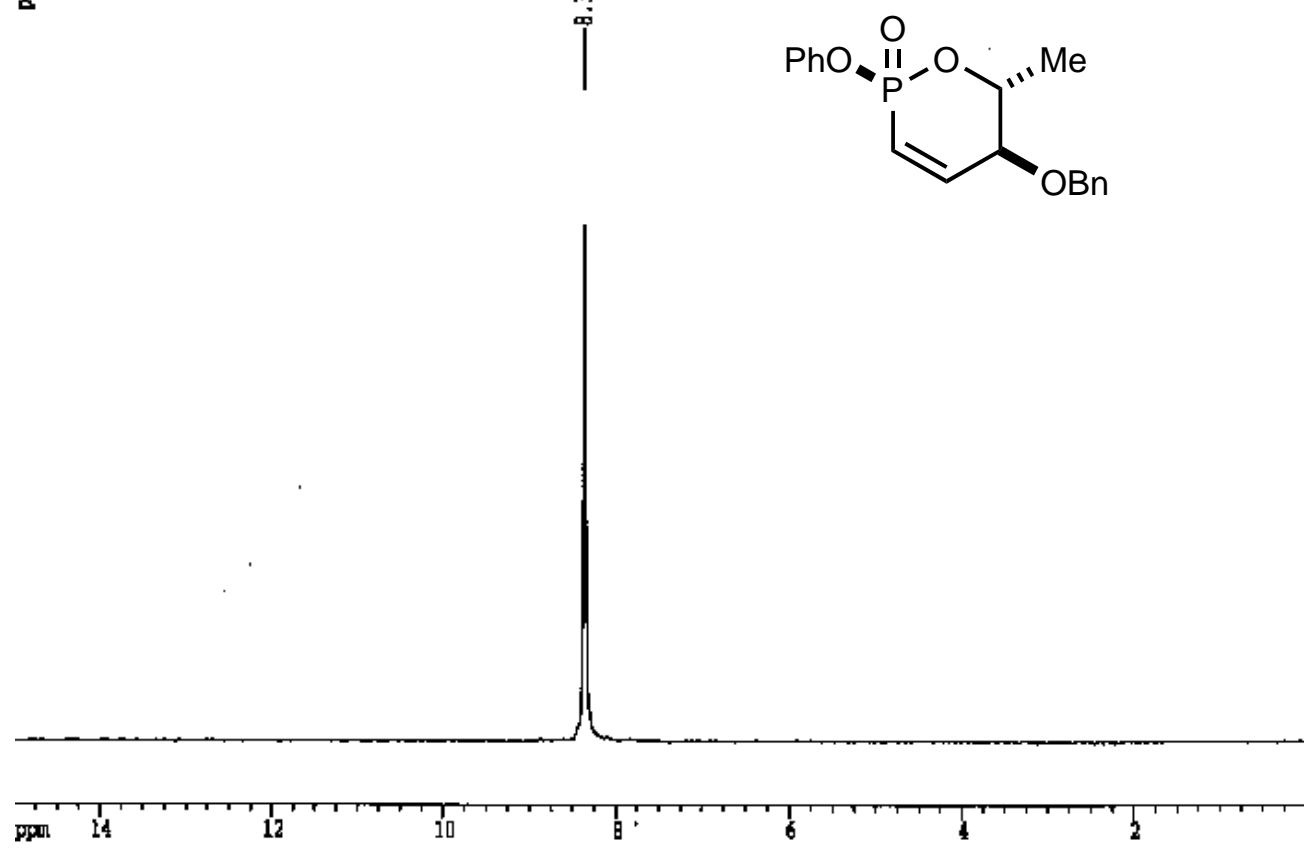


\section{Compound 20}
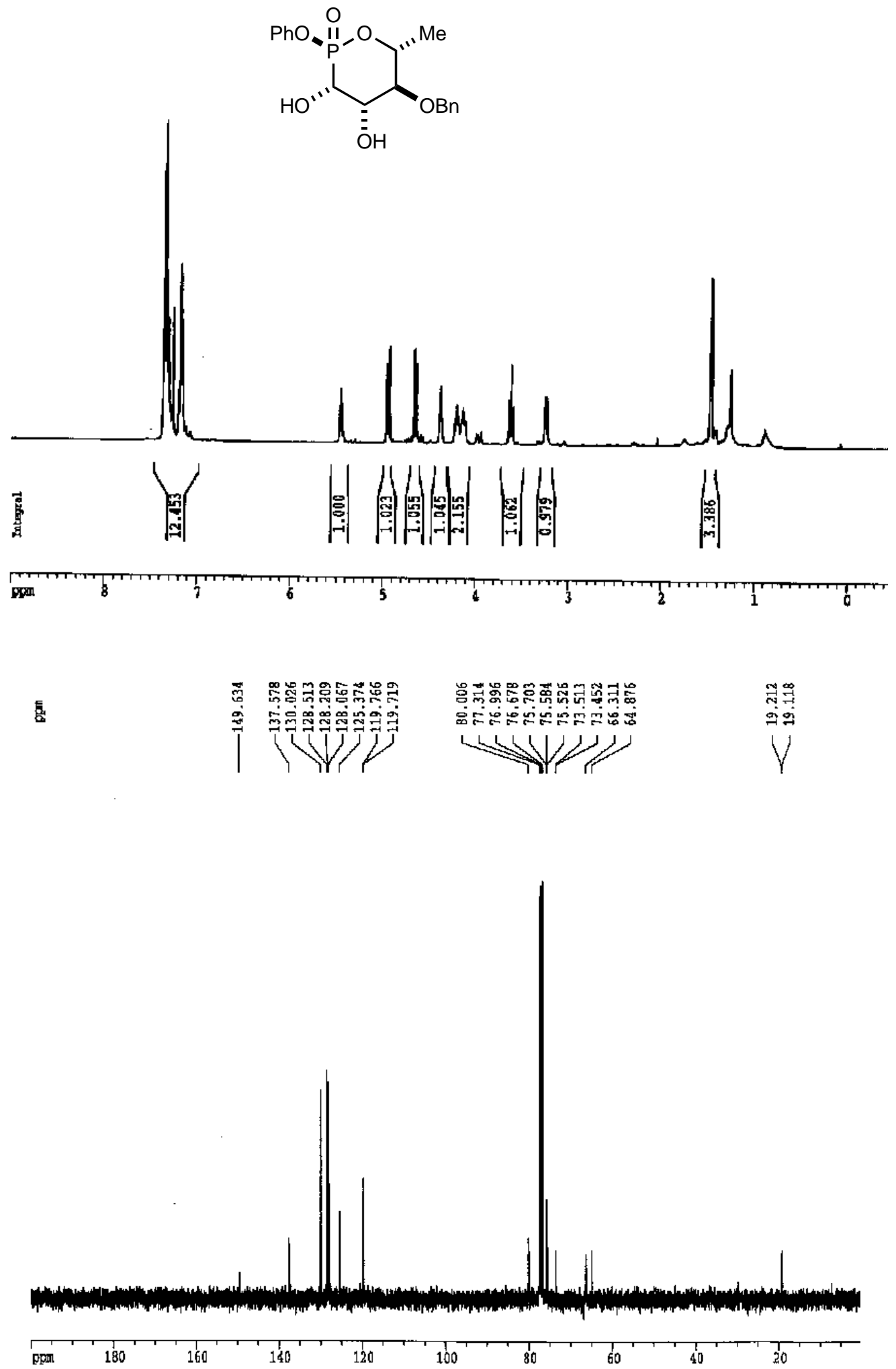


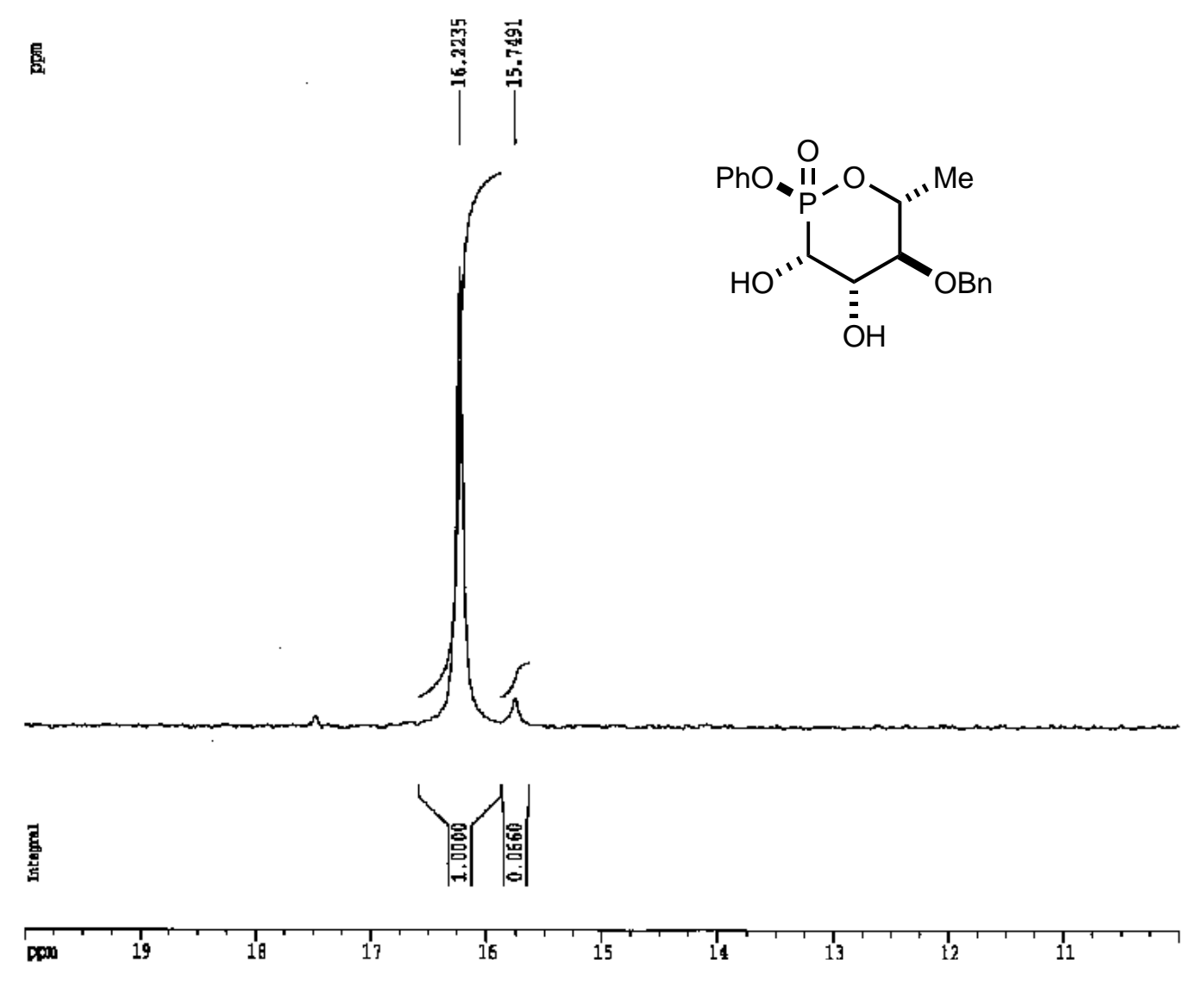




\section{Compound 21}

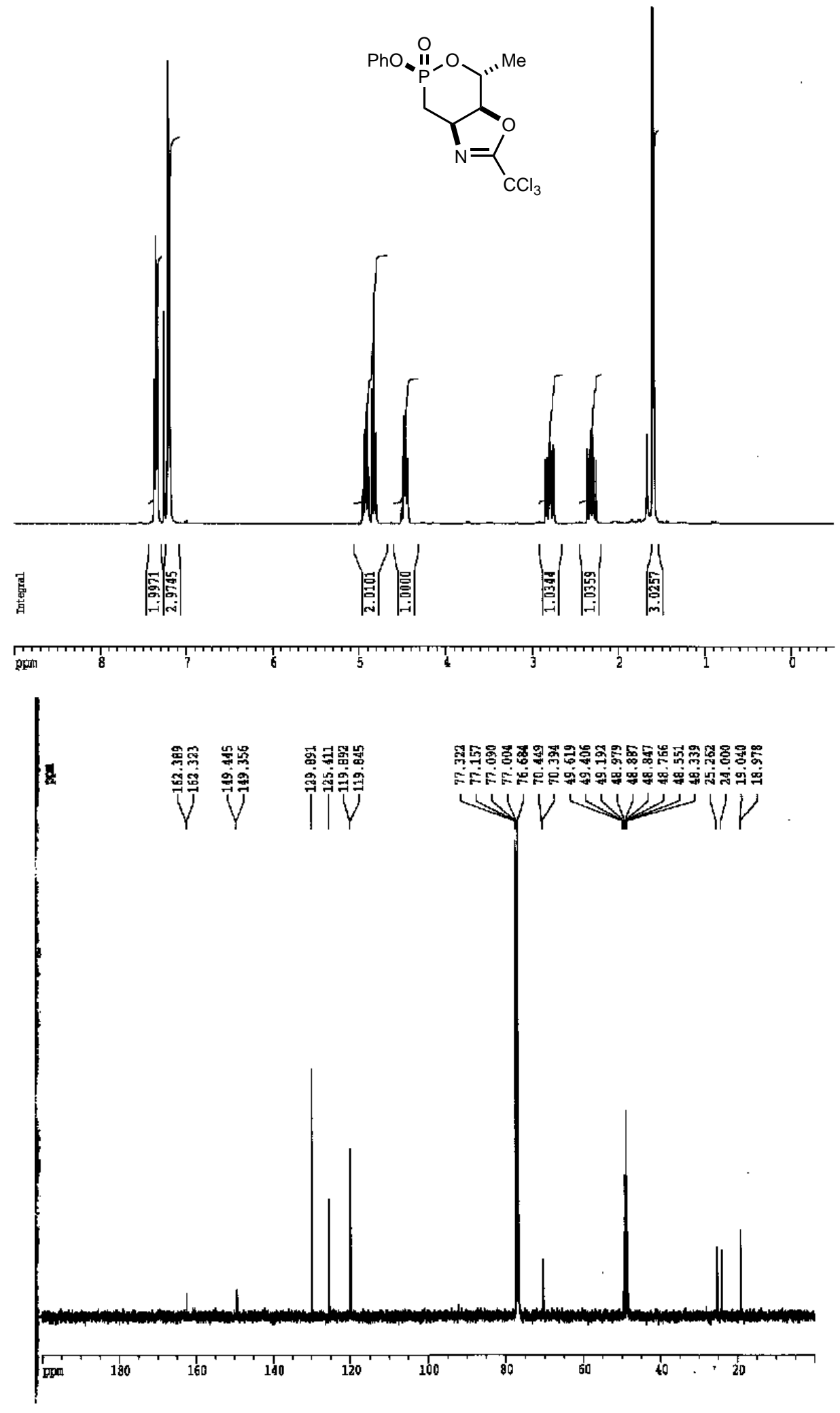




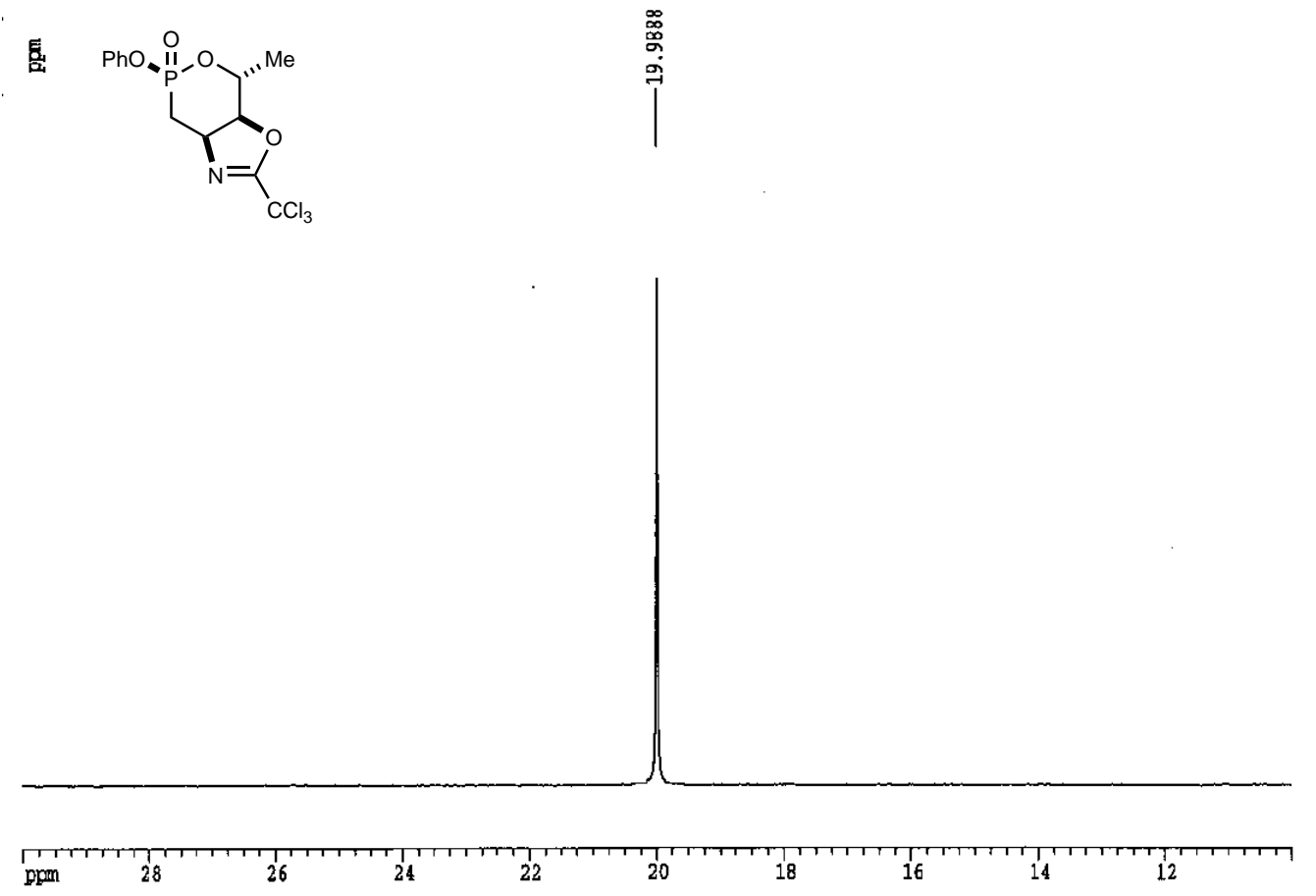

S 12 


\section{Compound 22}
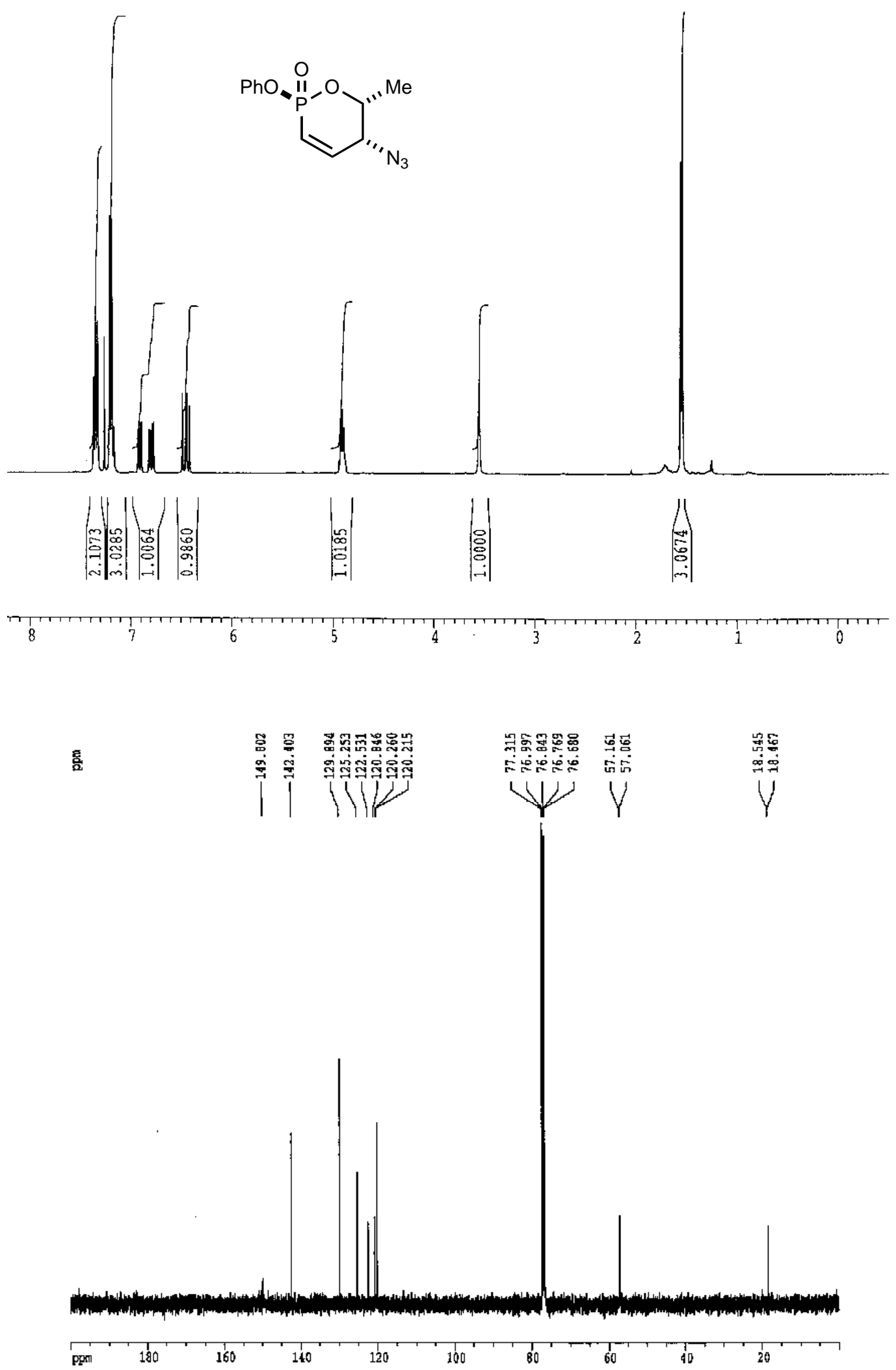

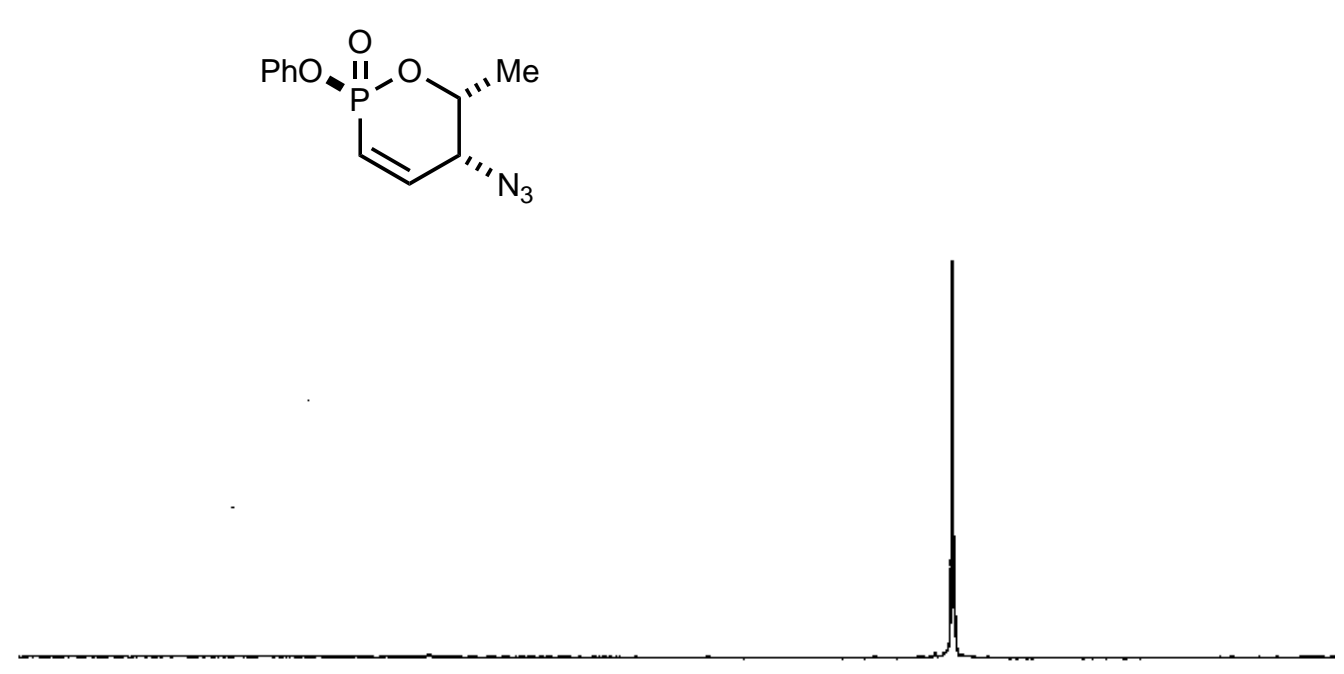

ppin

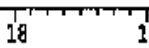

16

14

12

10 19 17 $1+111+110$ 


\section{Compound 23}

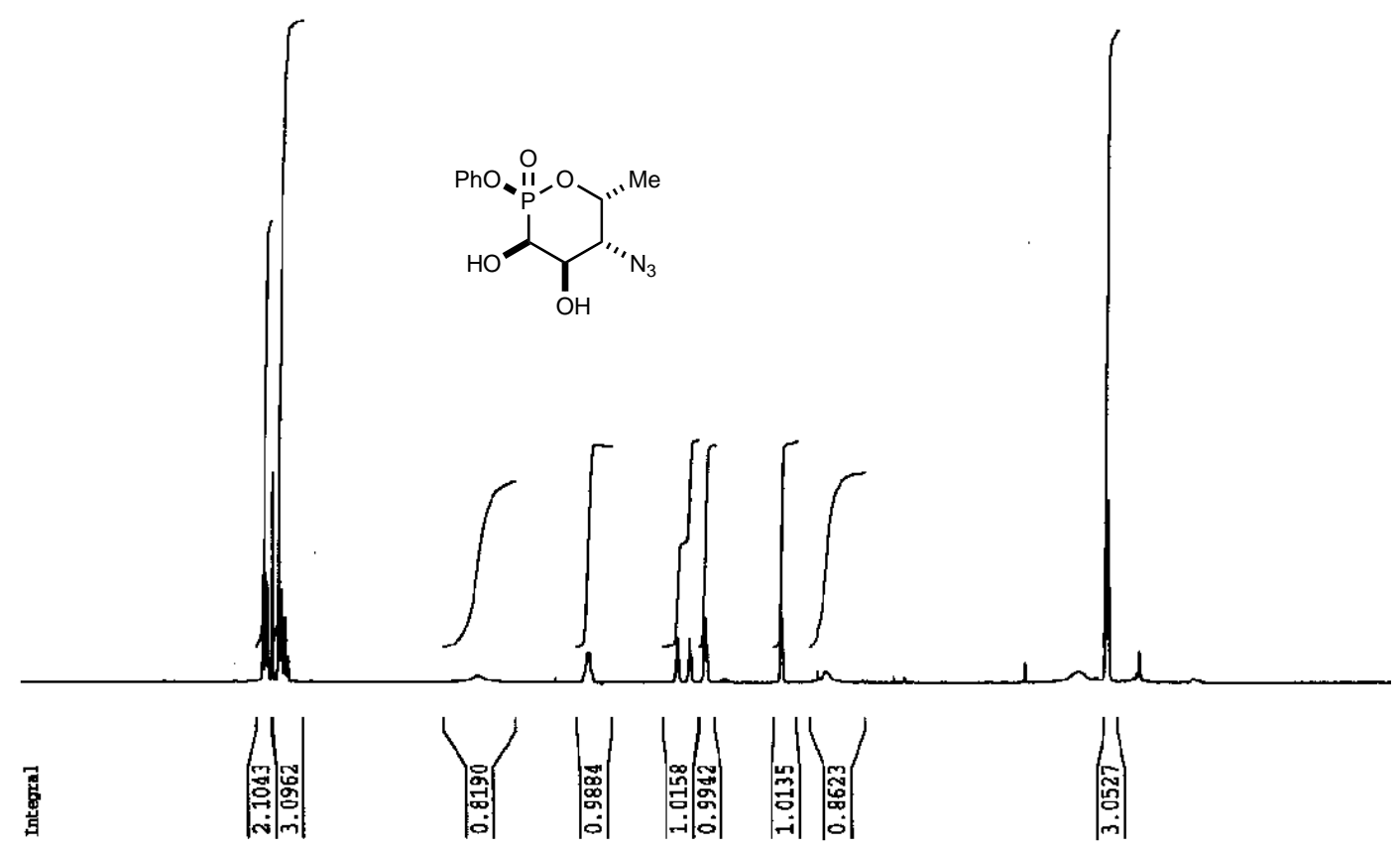

悬
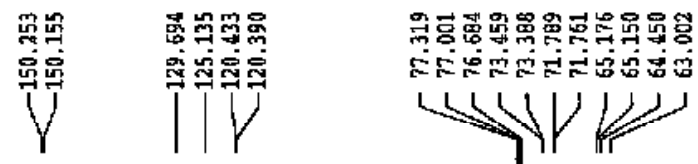

䛚器

걱

Y

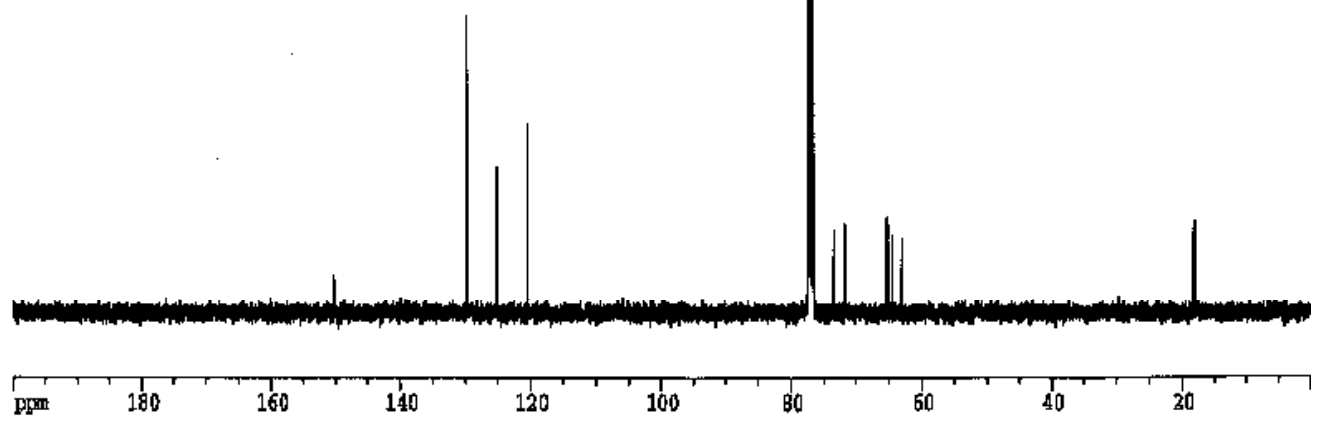


畐
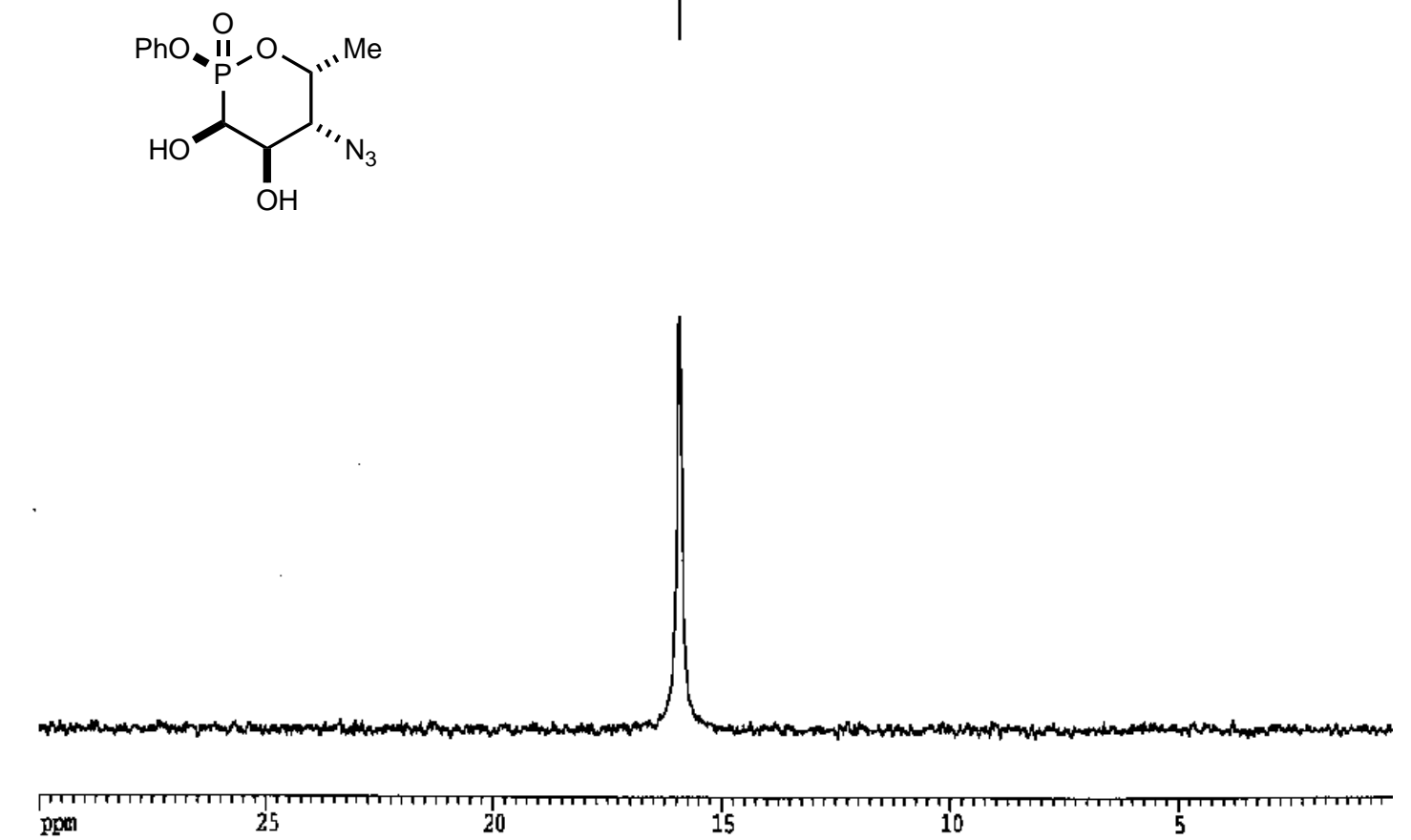


\section{Compound 24}
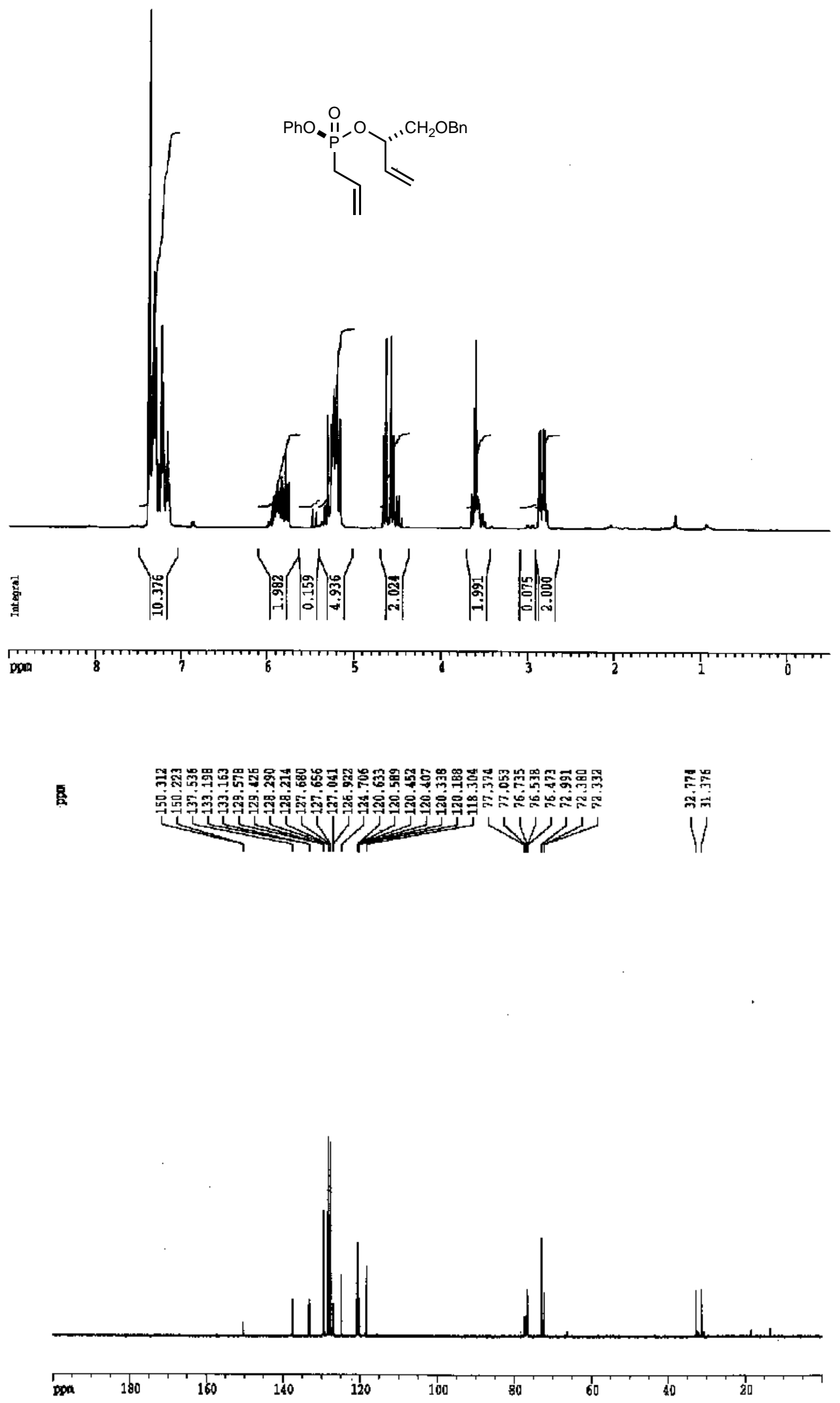


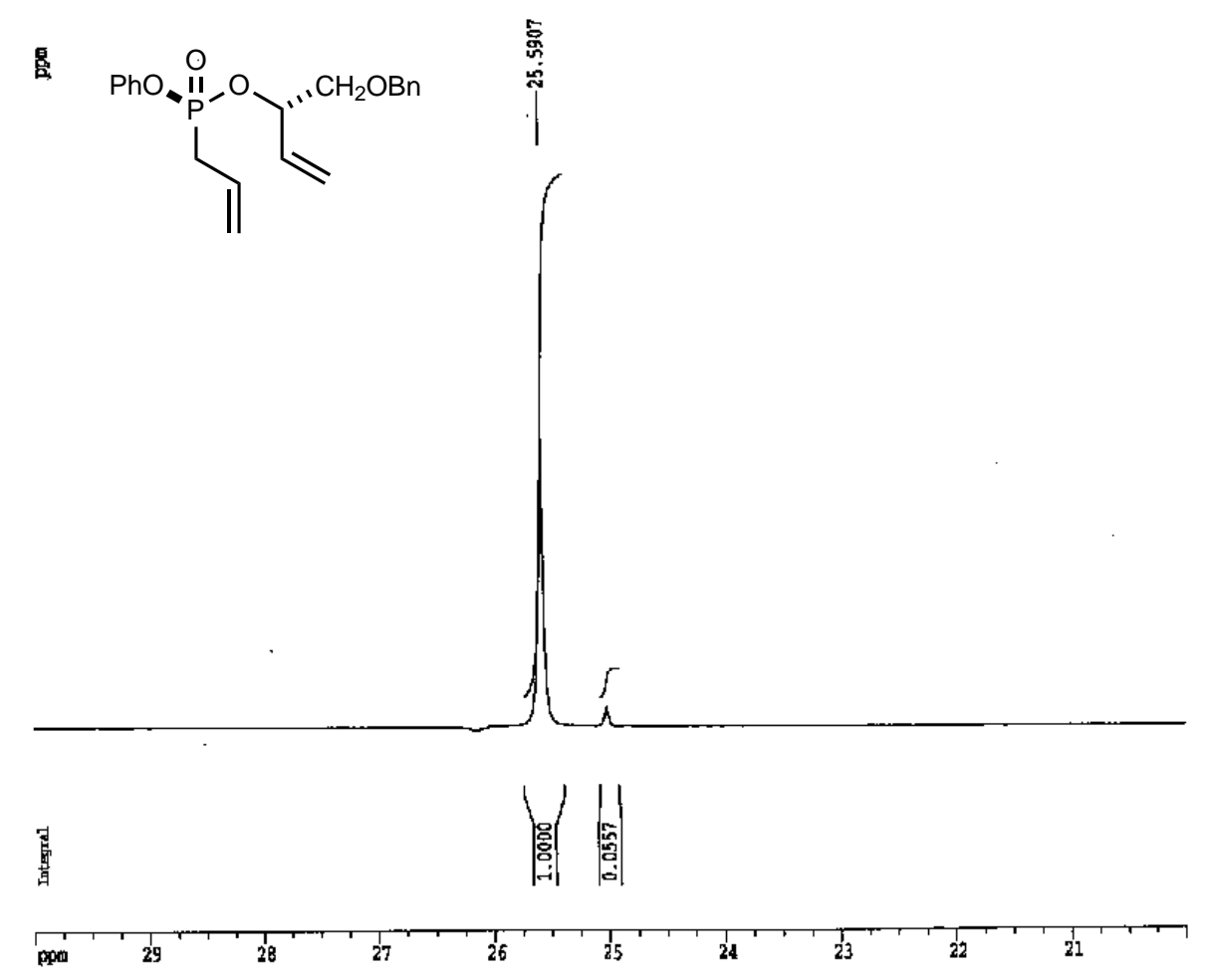




\section{Compound 25}

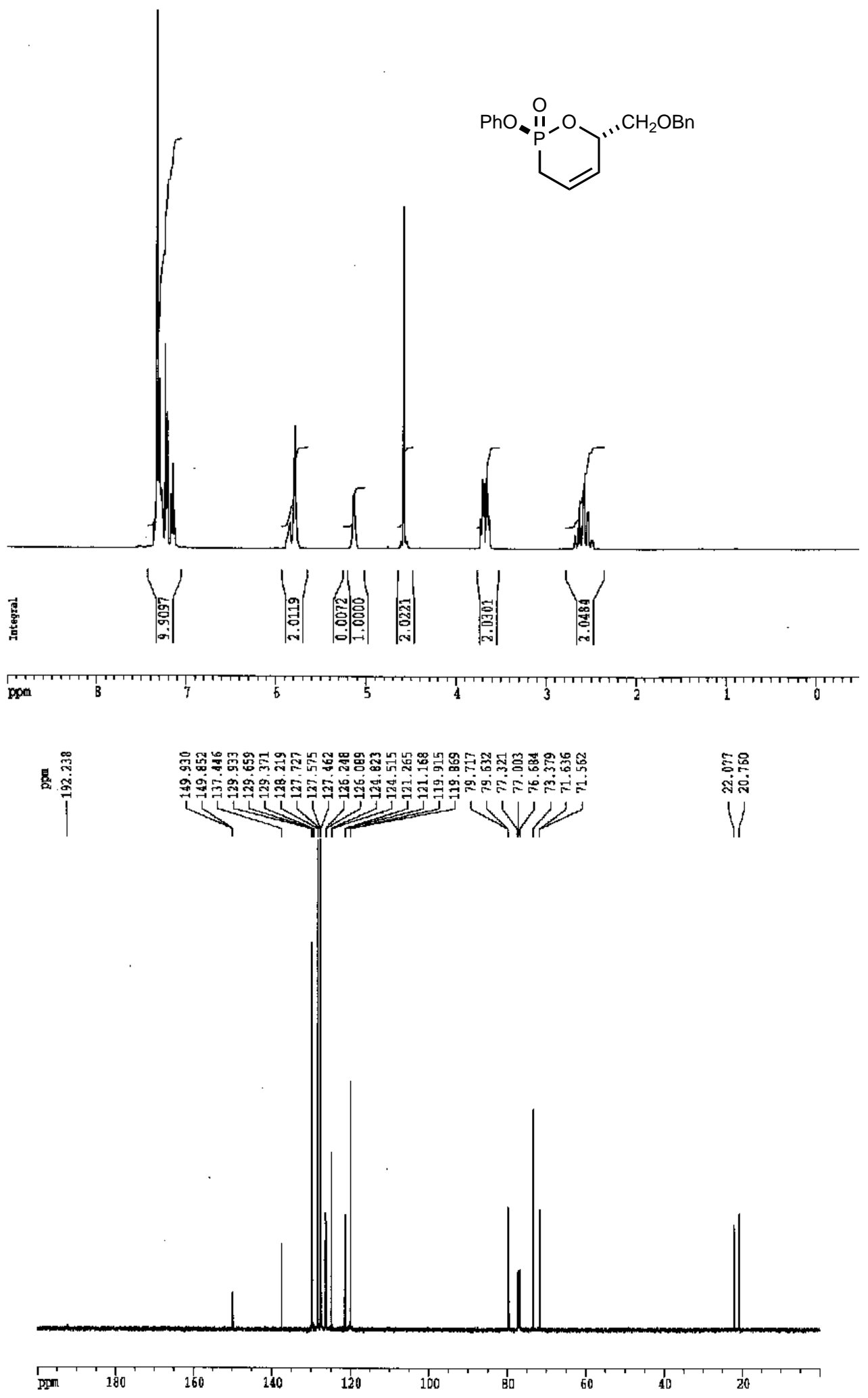



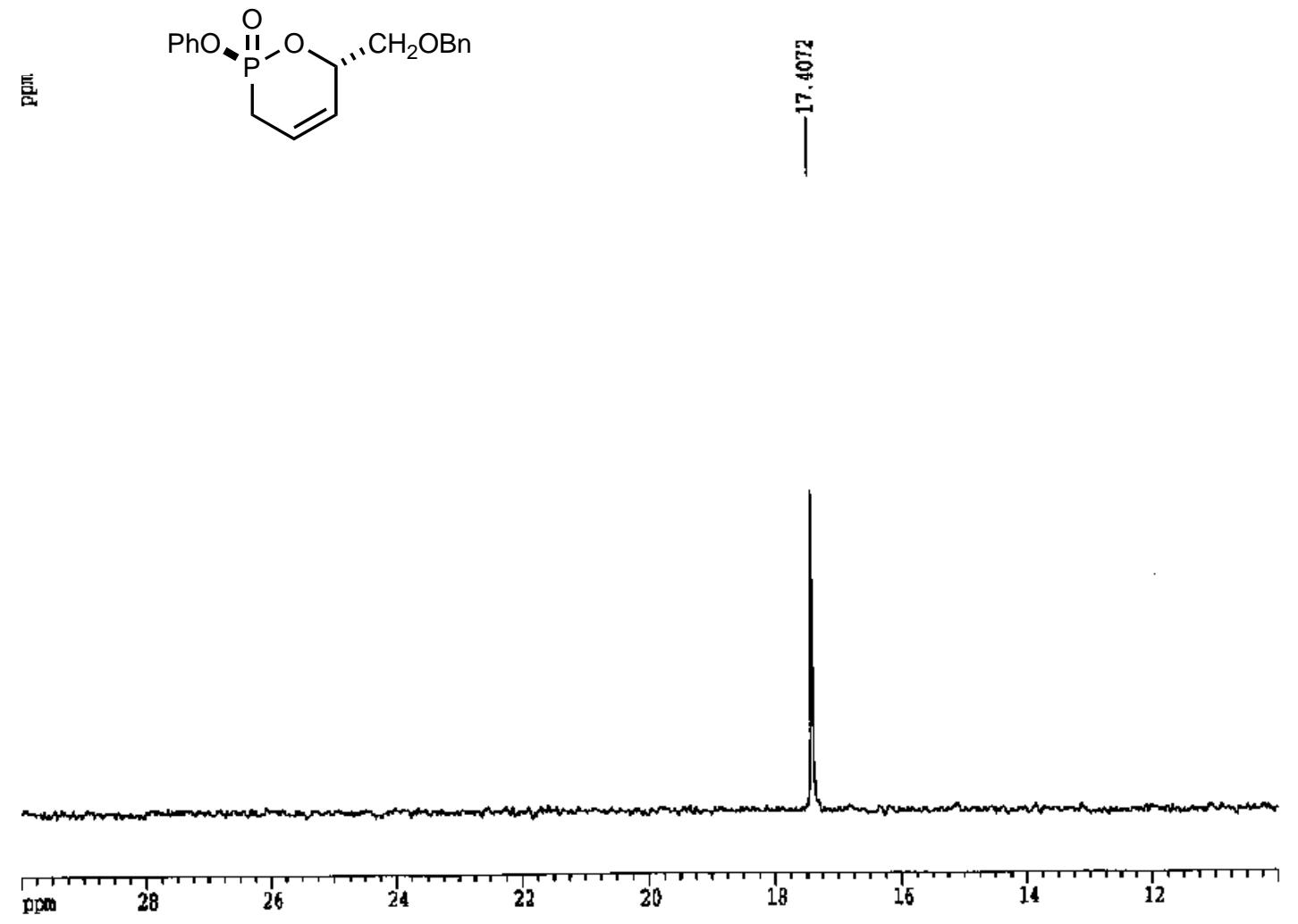


\section{Compound 26}

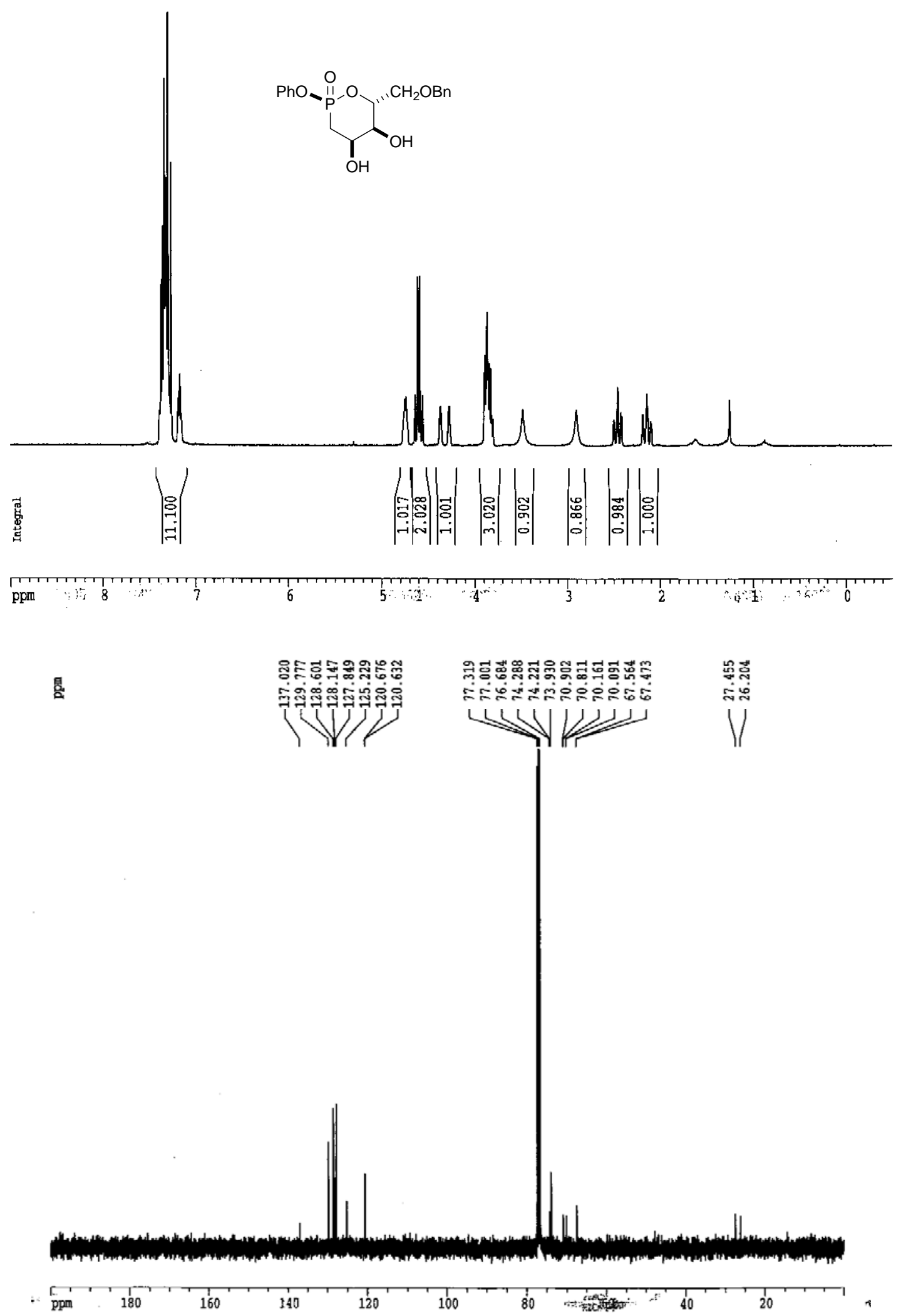


용

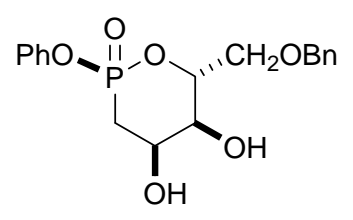

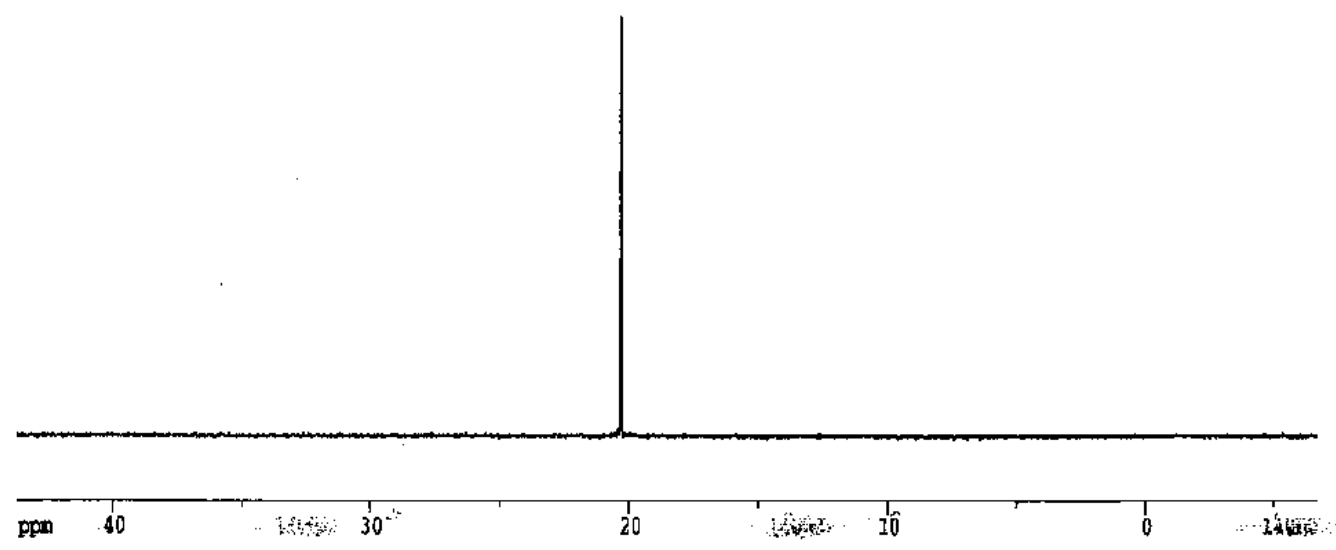

S 22 


\section{Compound 27}

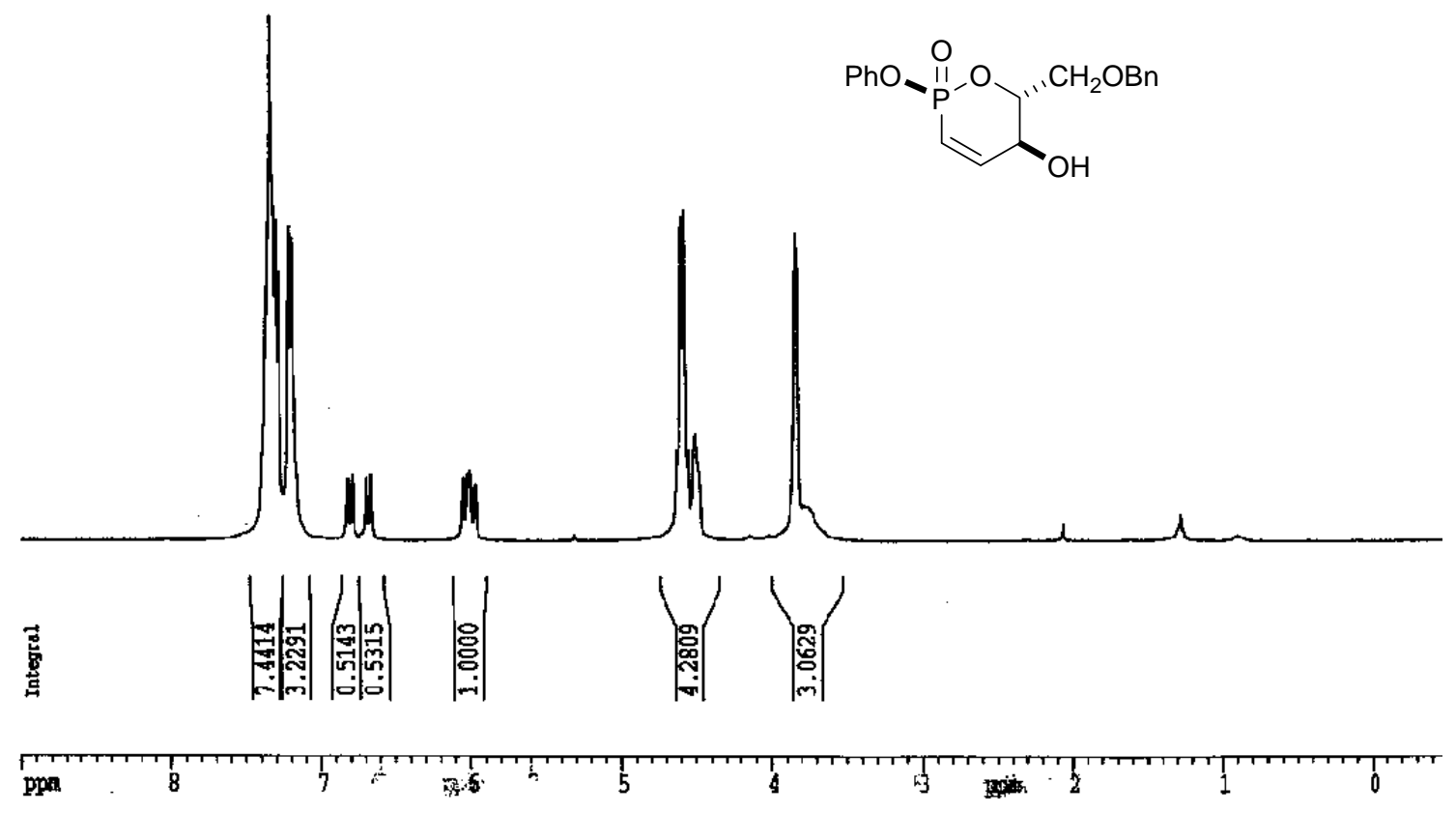

高

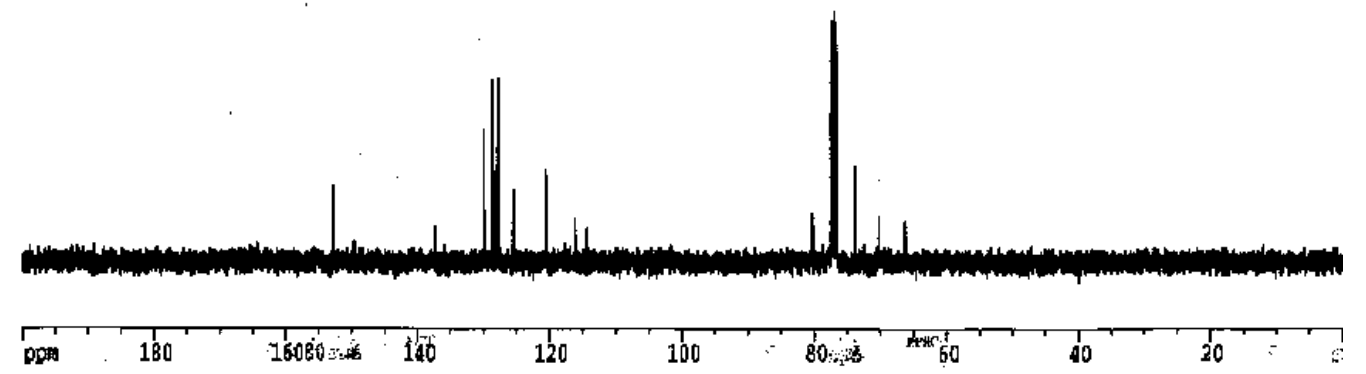


|ं
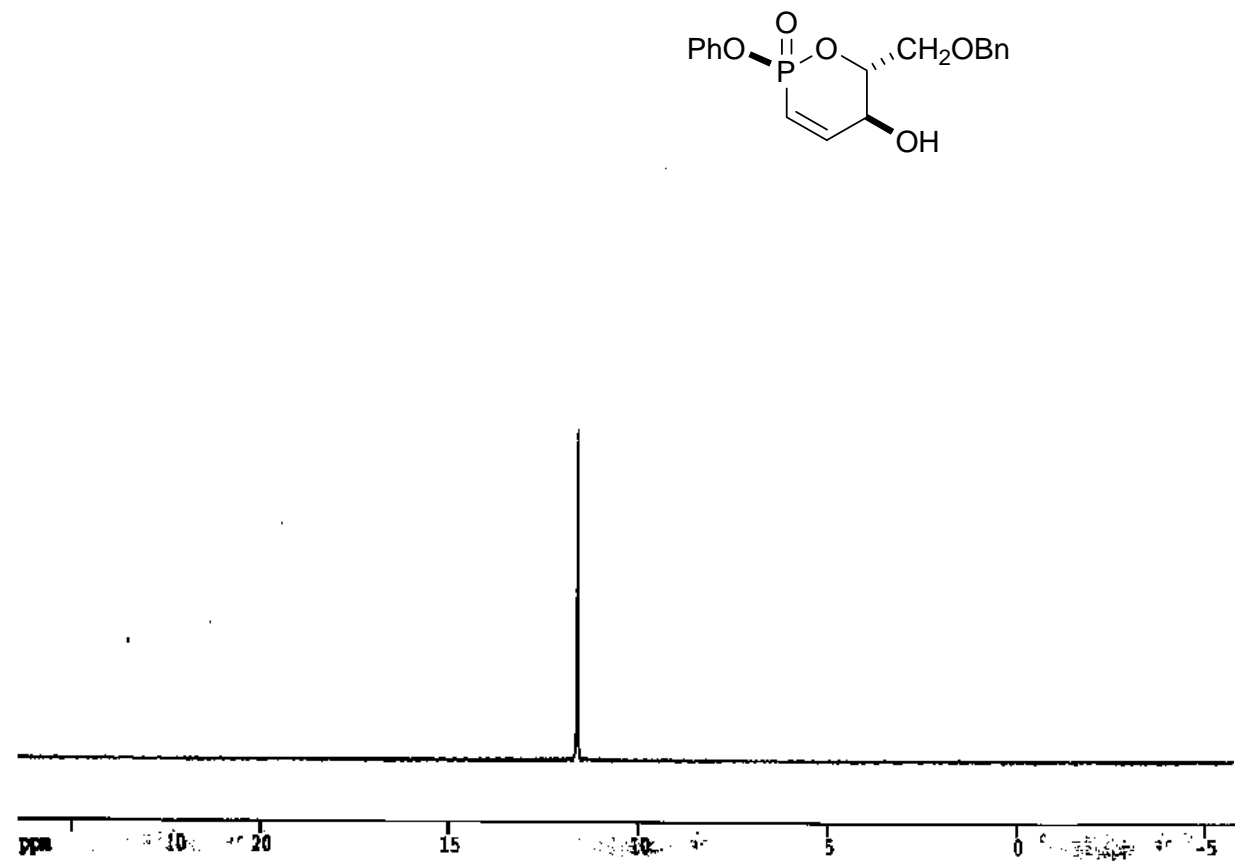


\section{Compound 28}

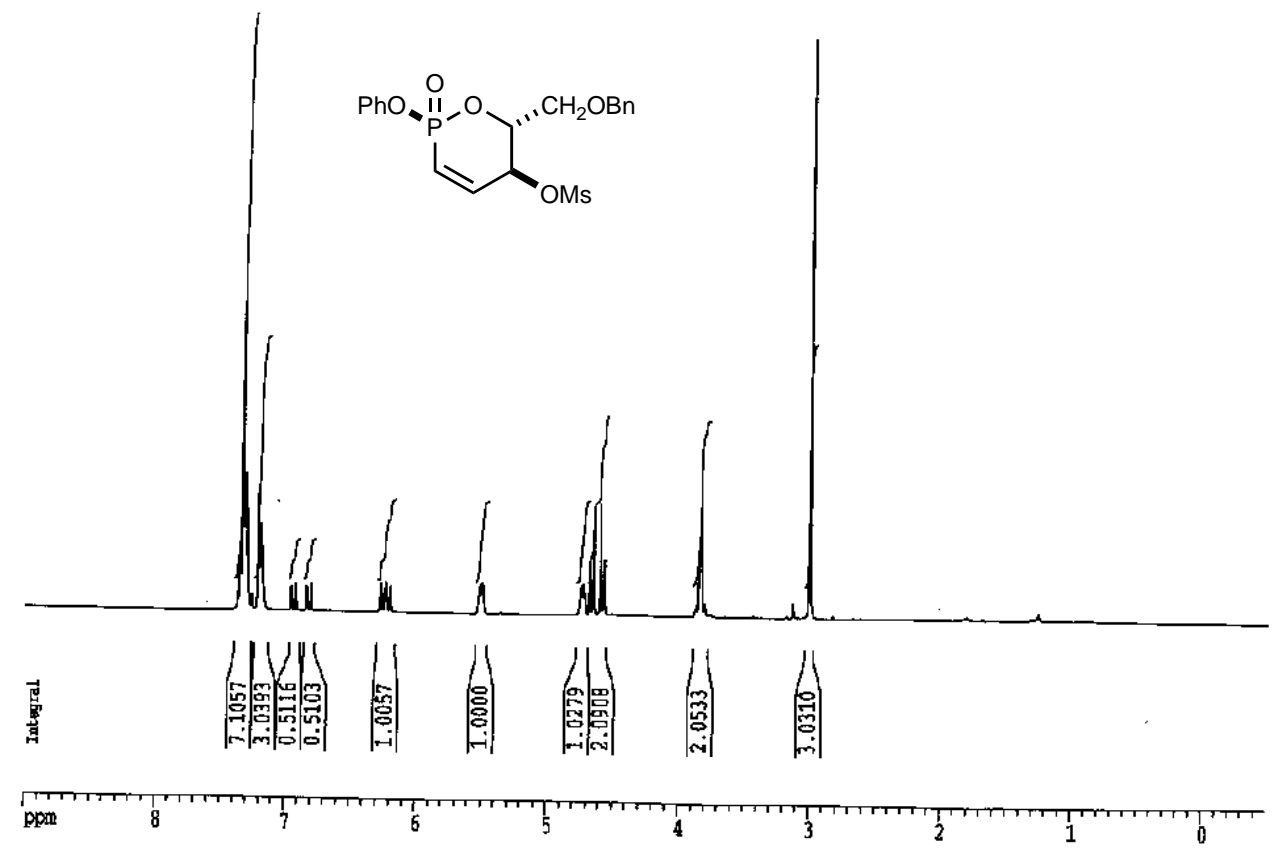

魴
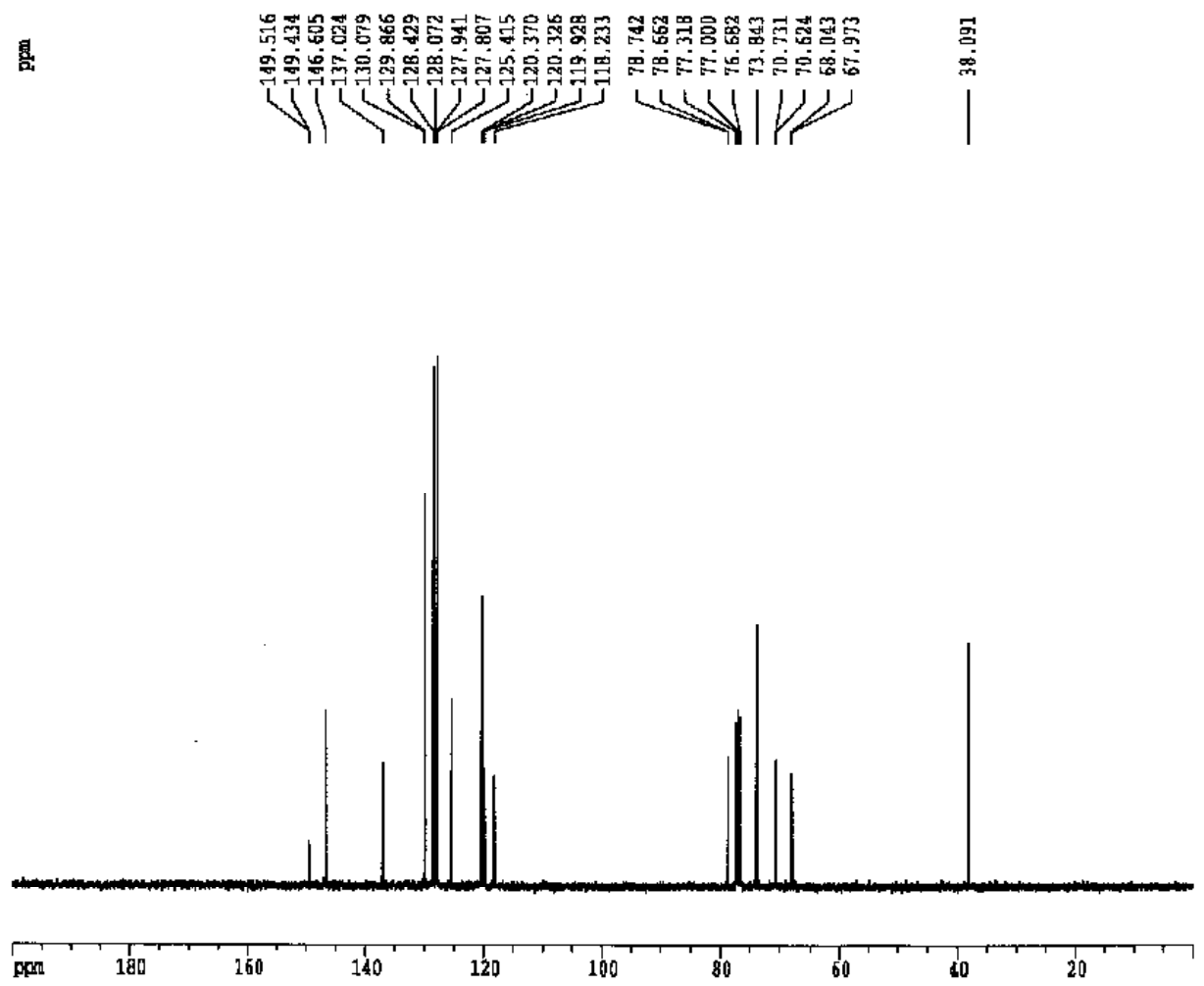

S 25 
E

愛

PhO

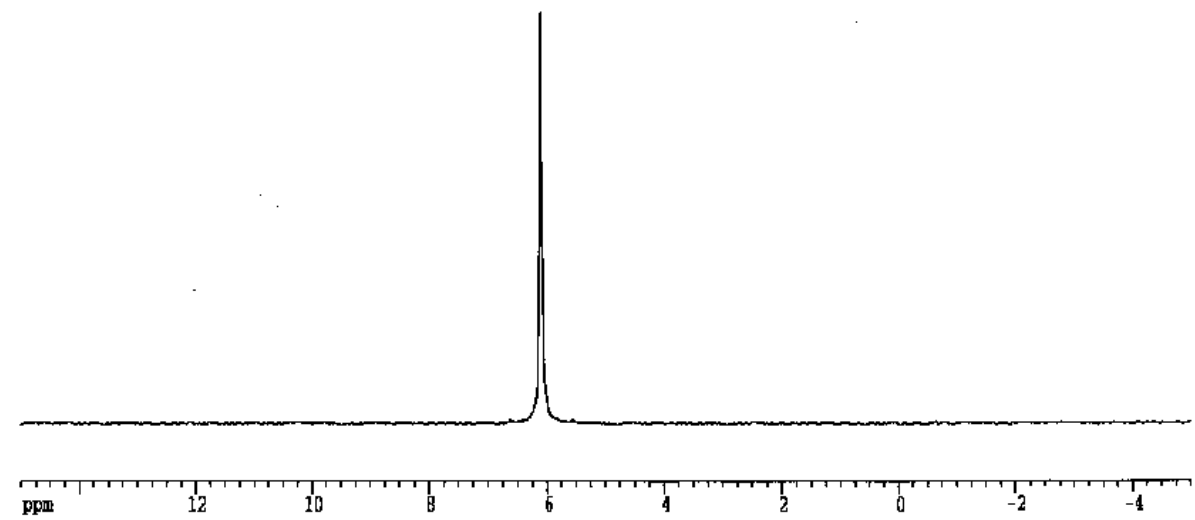

S 26 


\section{Compound 29}

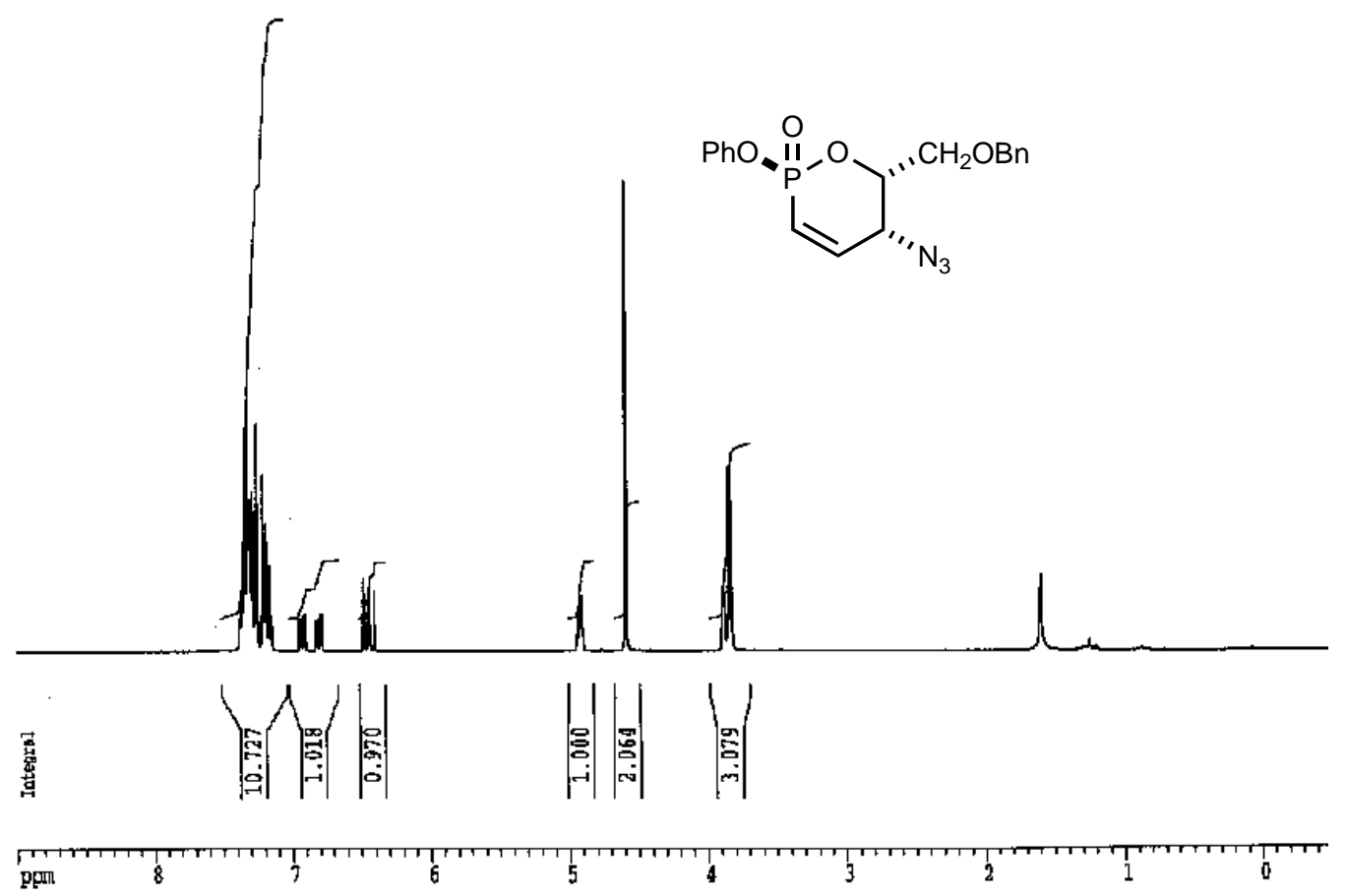

悬

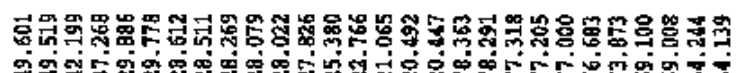

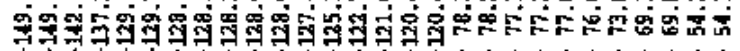

in

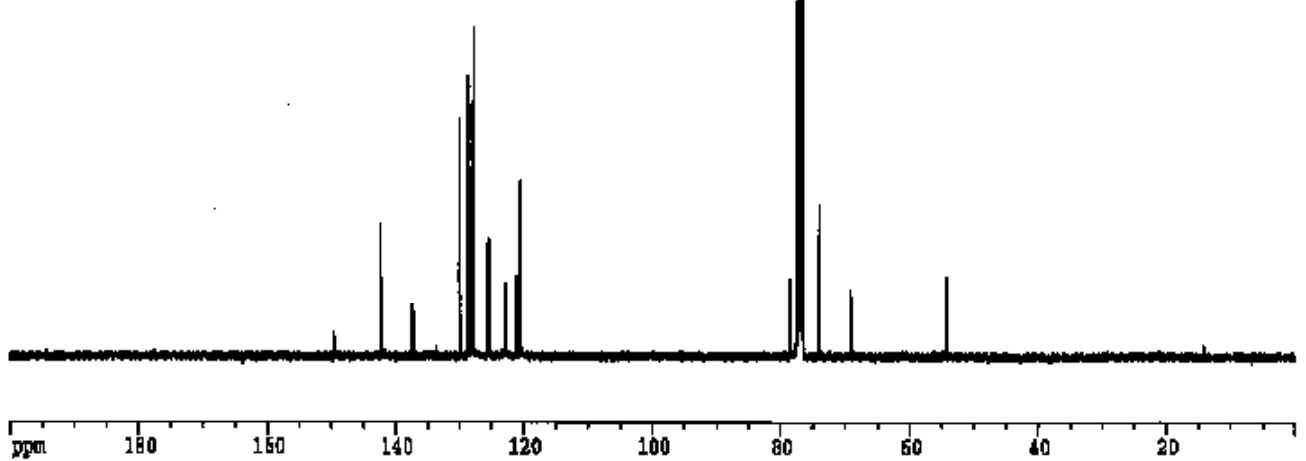

S 27 
量<smiles>N[C@@H]1C=C[P@@](=O)(O)O[C@@H]1CCOCc1ccccc1</smiles>

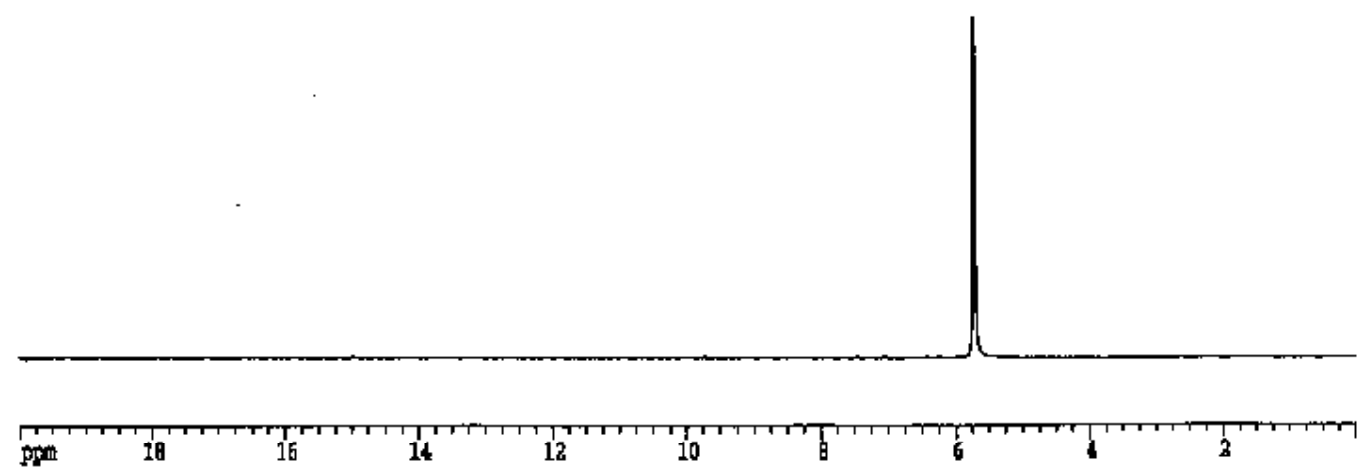




\section{Compound 30}

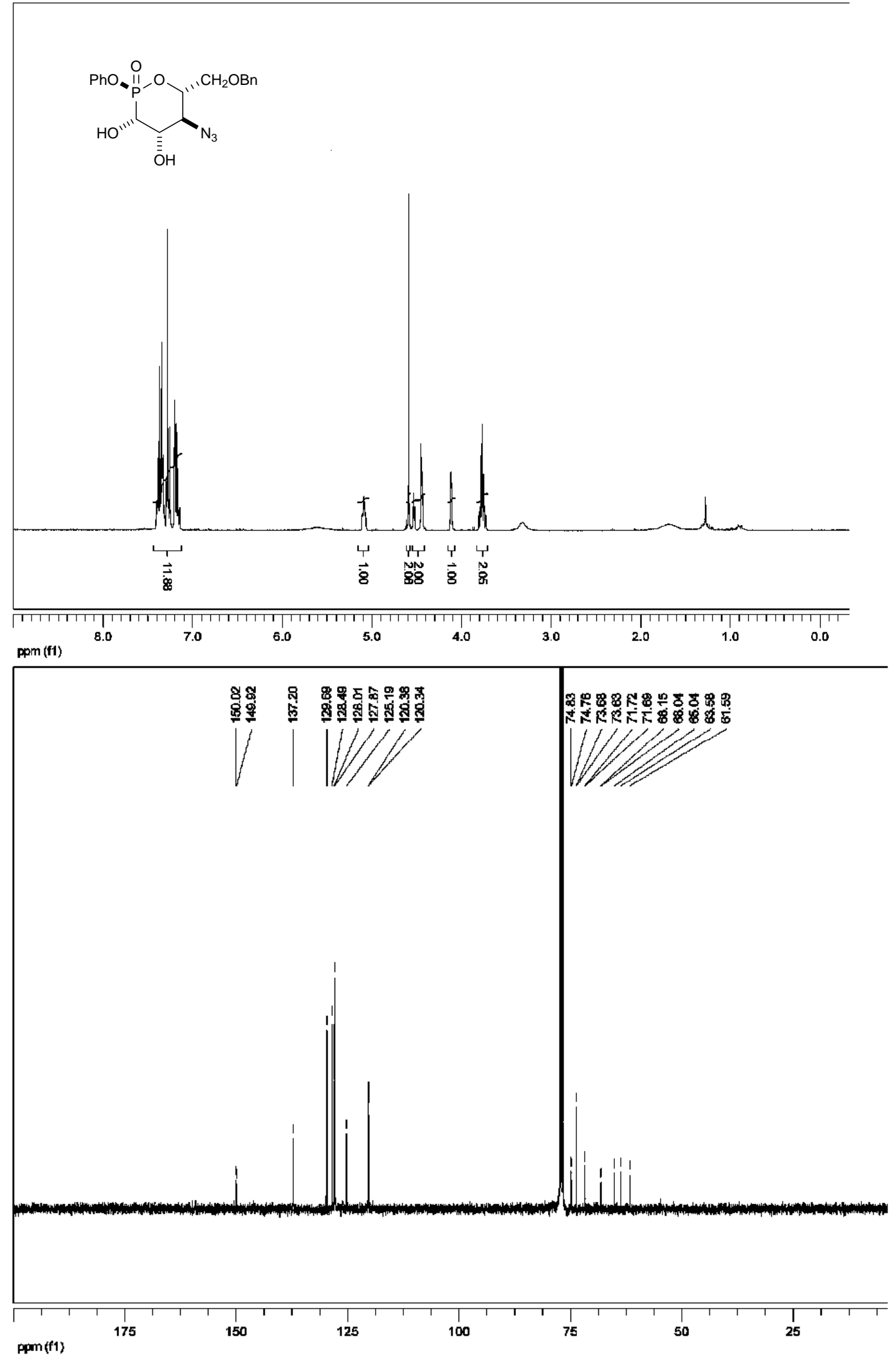




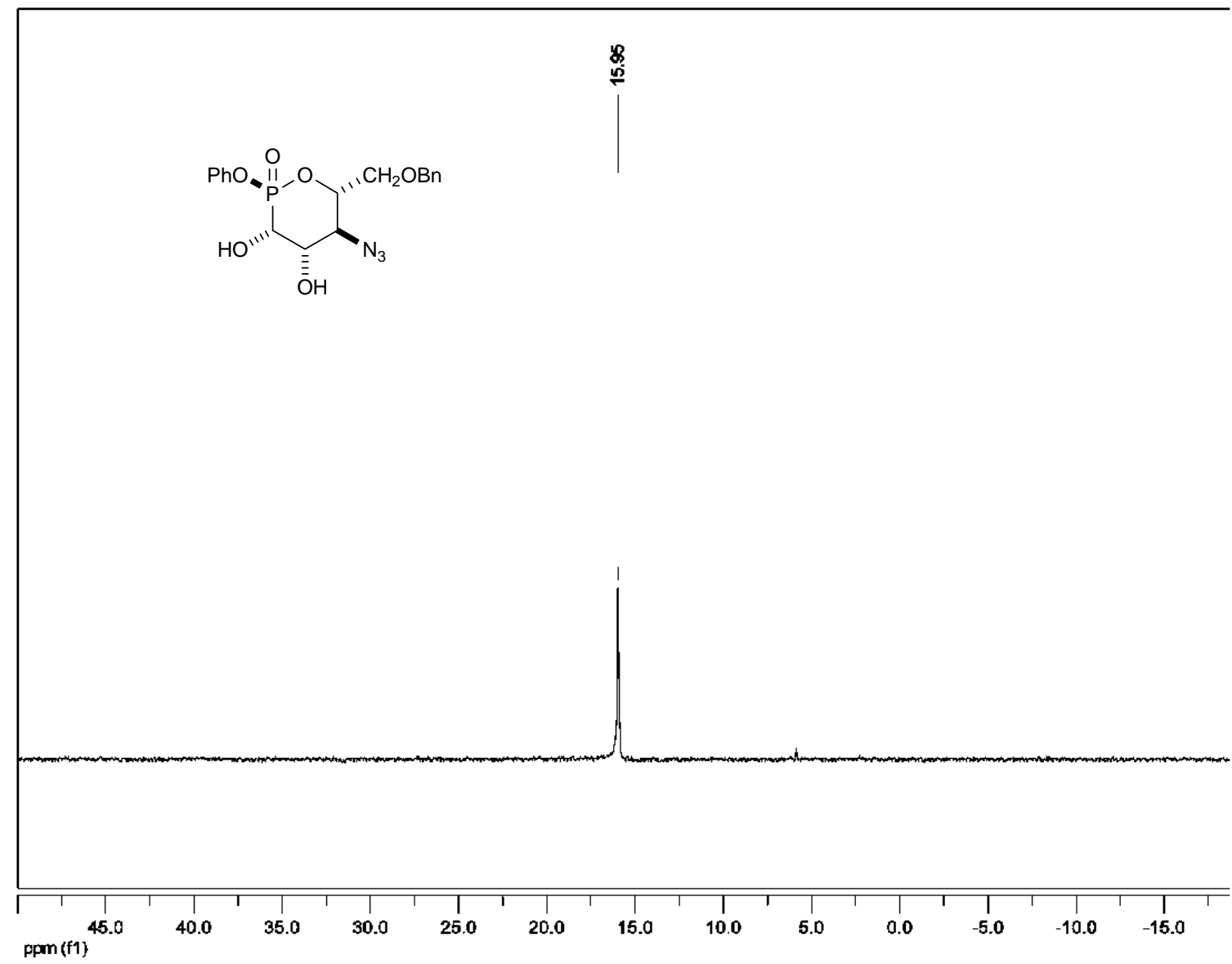




\section{Compound 31}
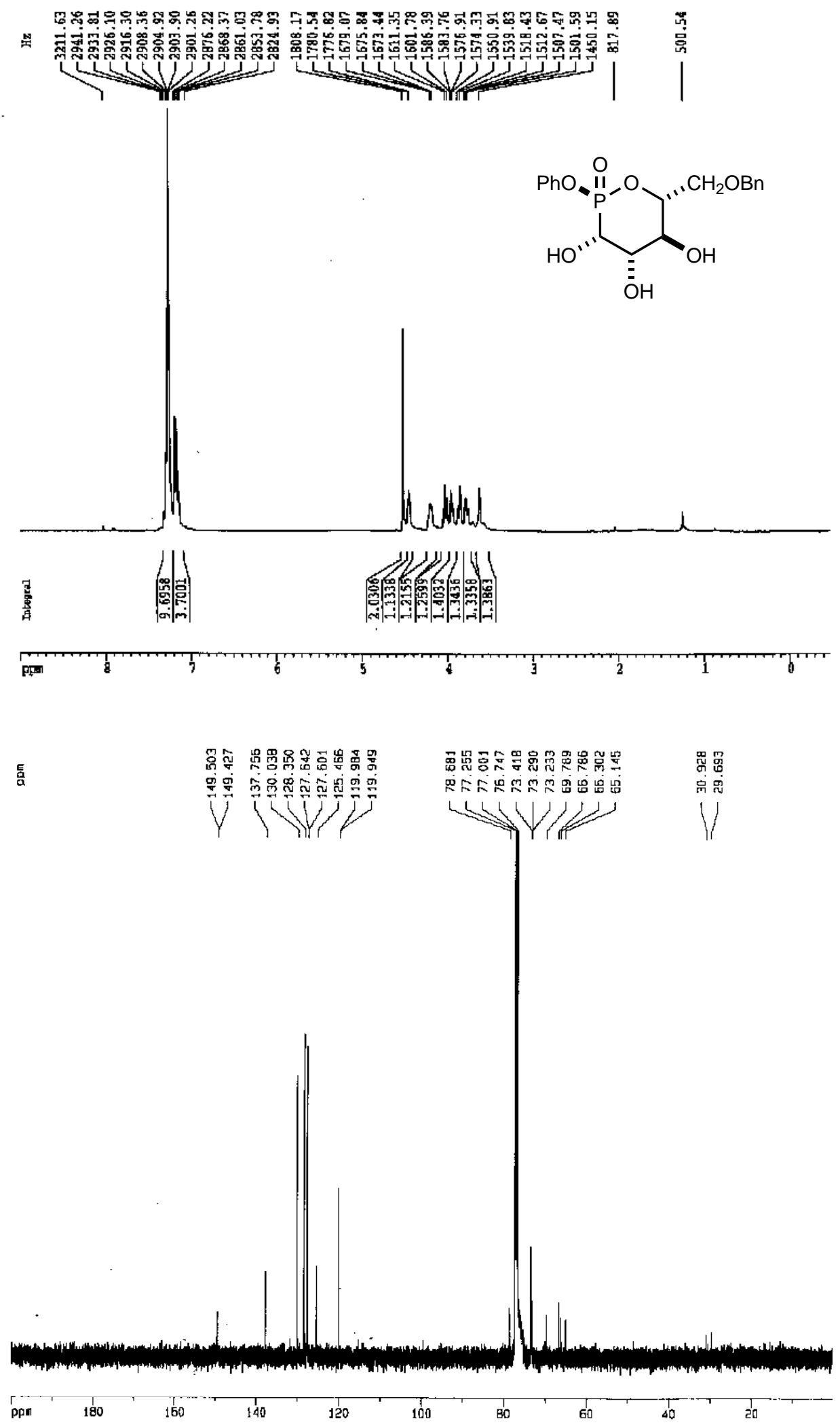
貼<smiles>O=P1(O)O[C@H](COCc2ccccc2)[C@@H](O)[C@H](O)[C@H]1O</smiles>

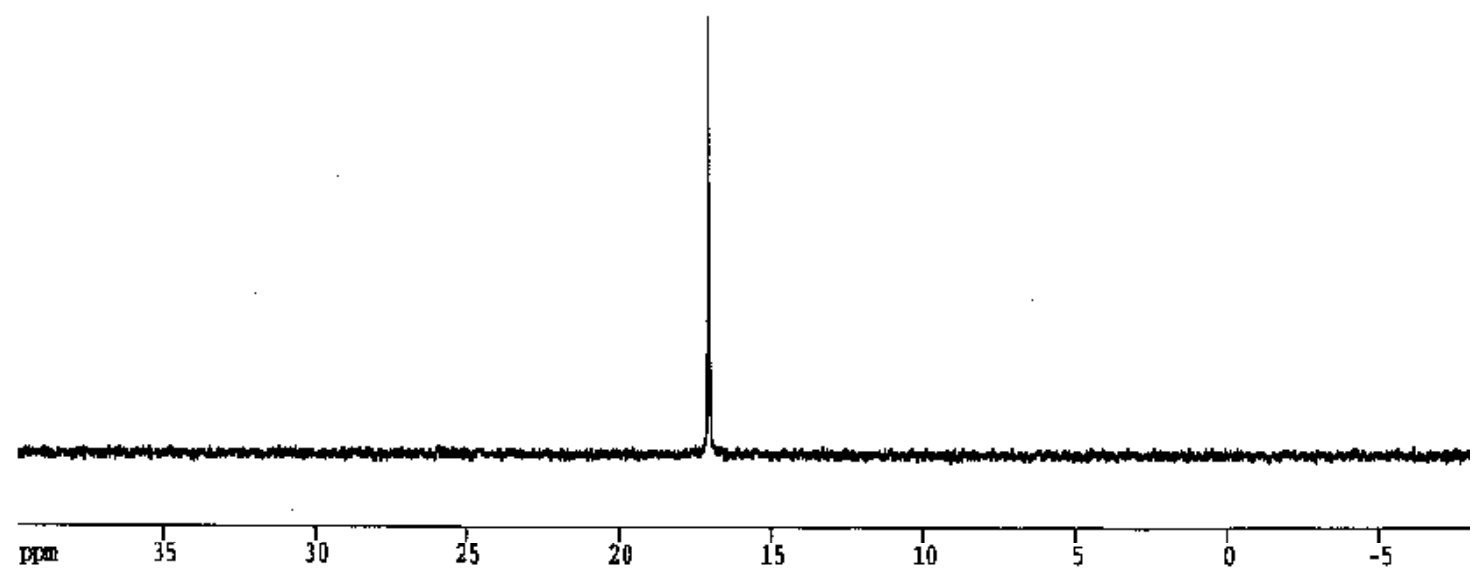




\section{Compound 32}

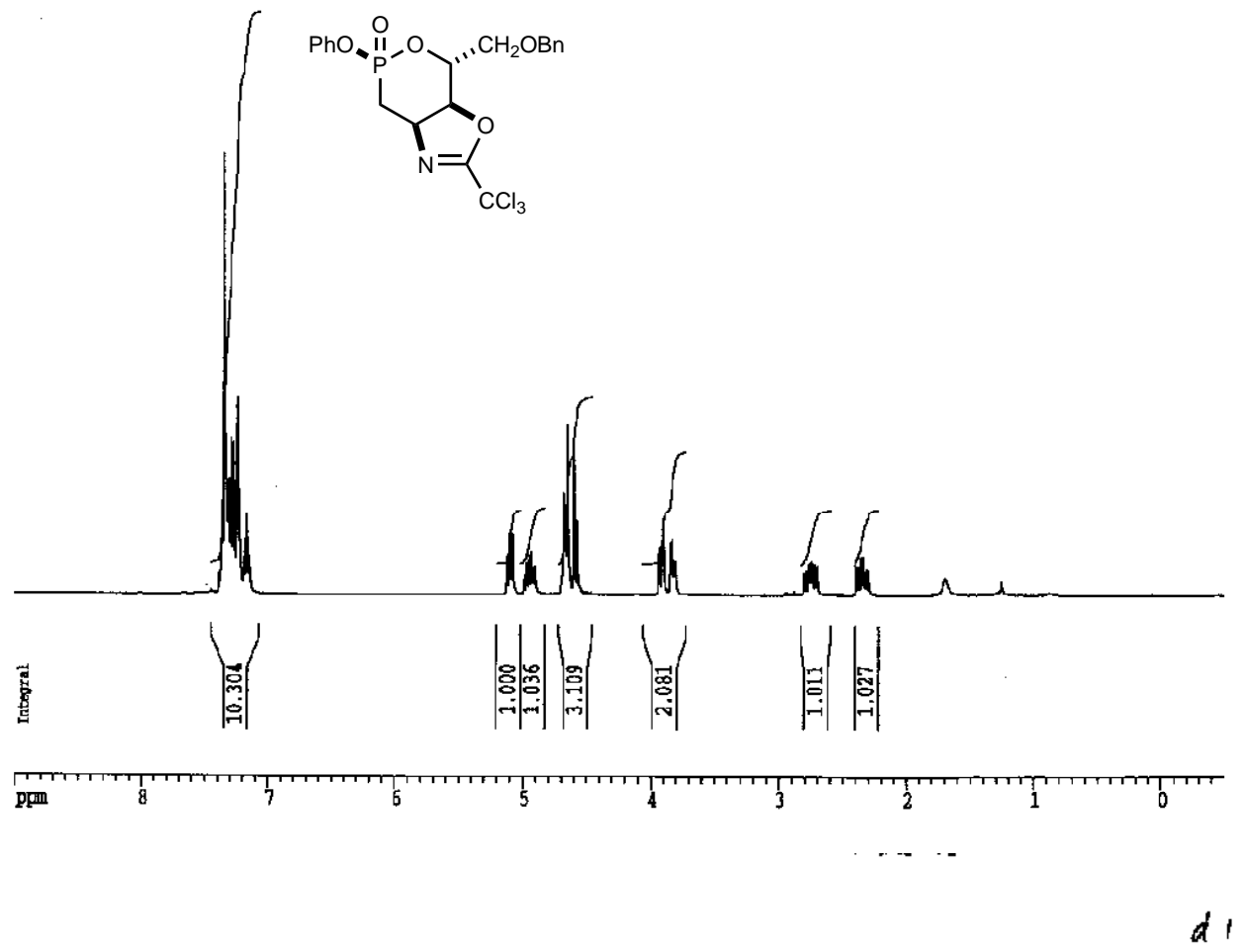

基
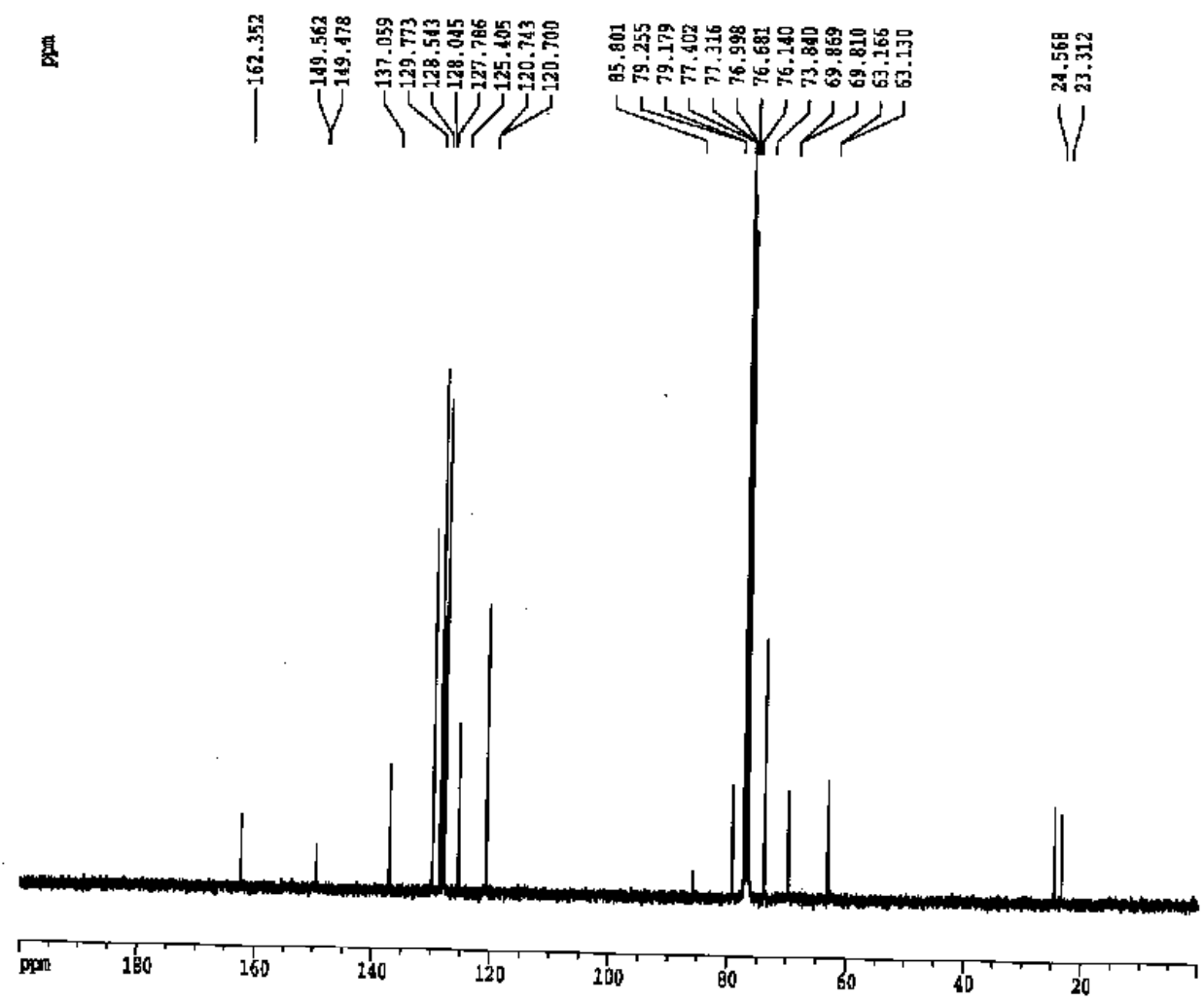

S 33 

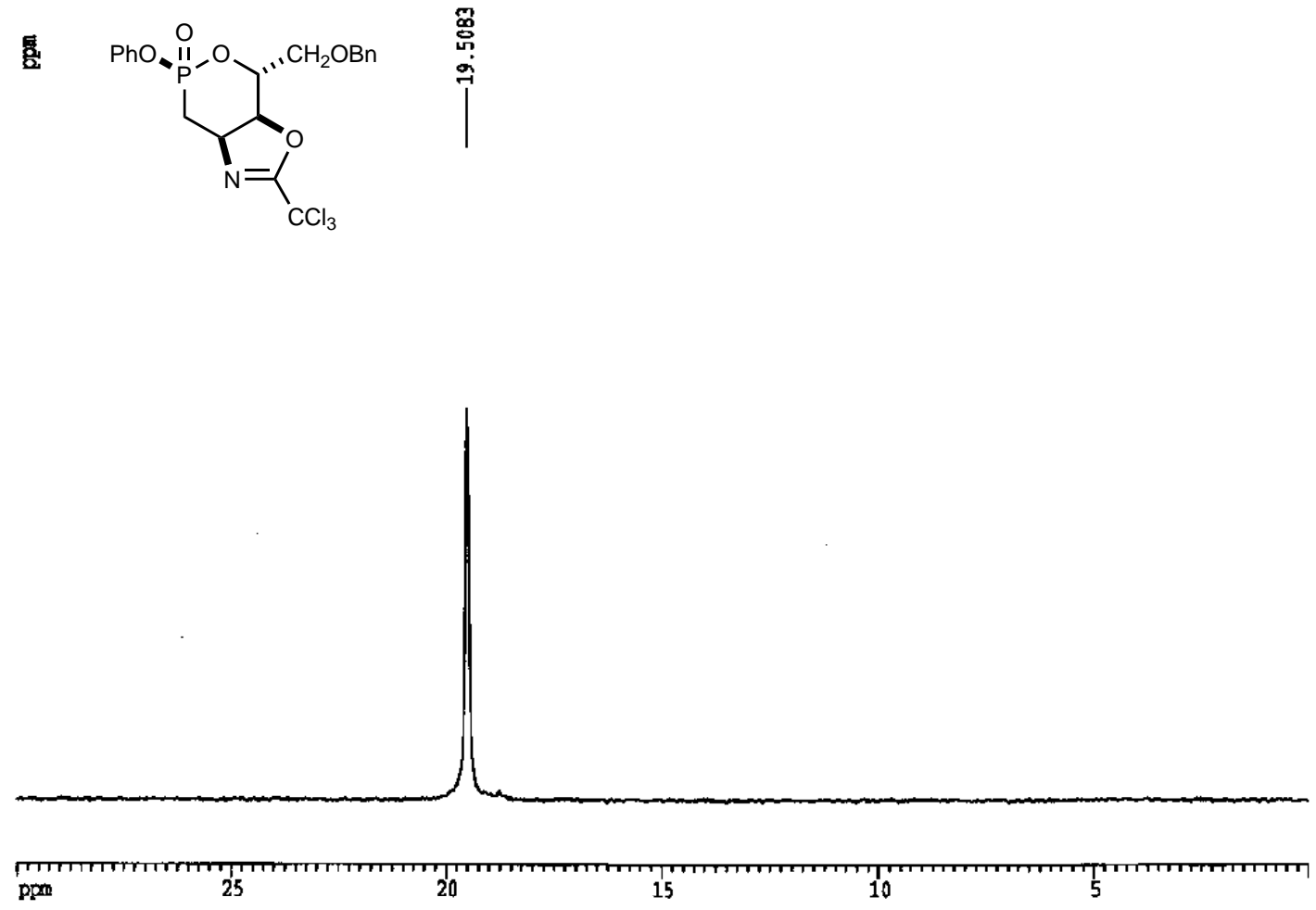


\section{Compound 33}

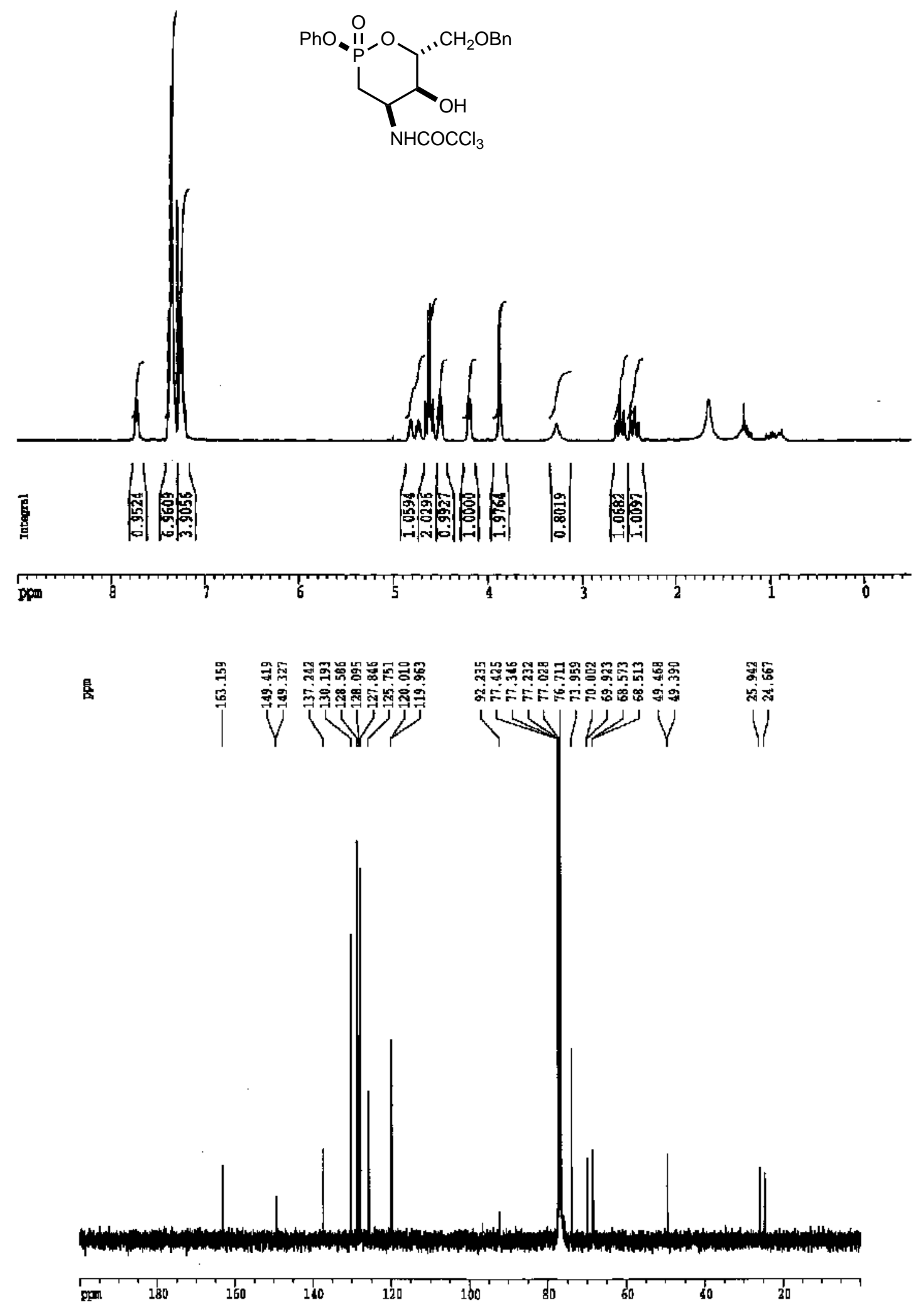


홈

音

$\infty$
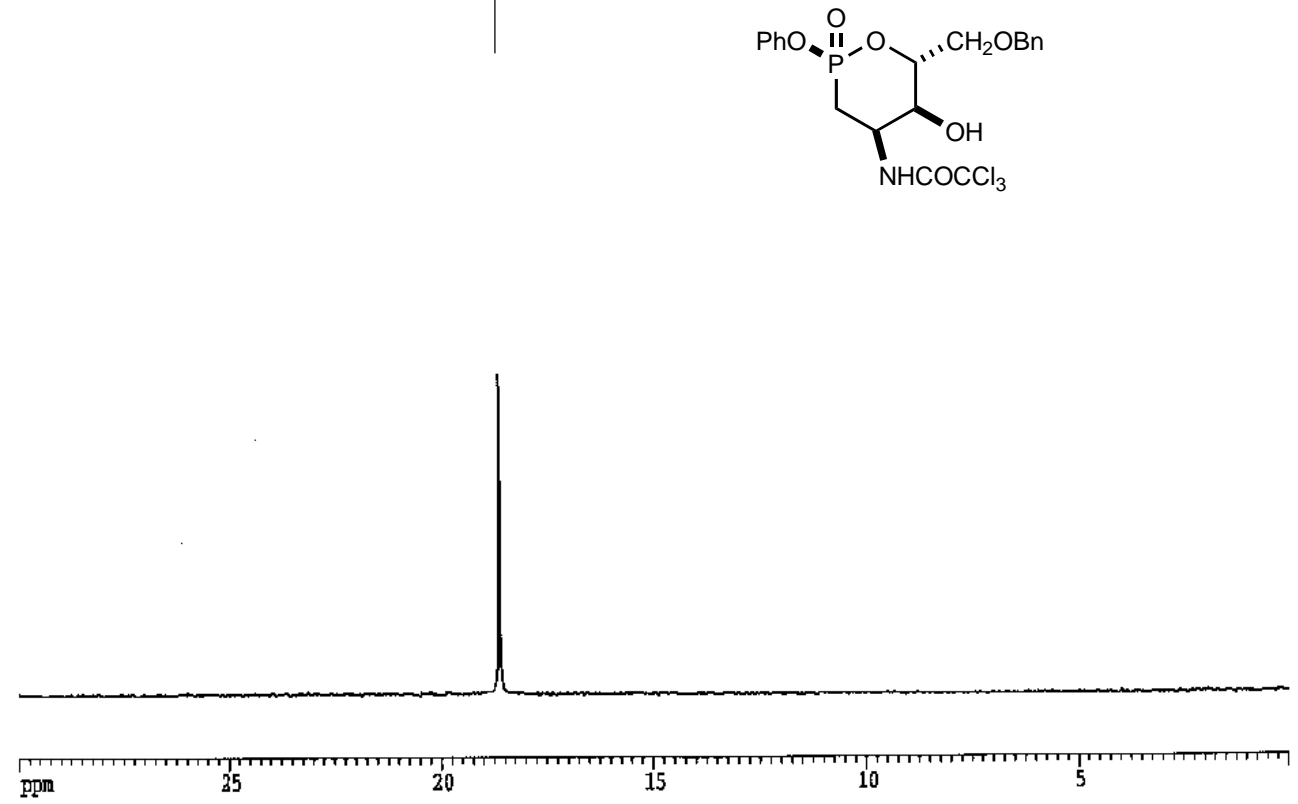

S 36 


\section{Compound 34}

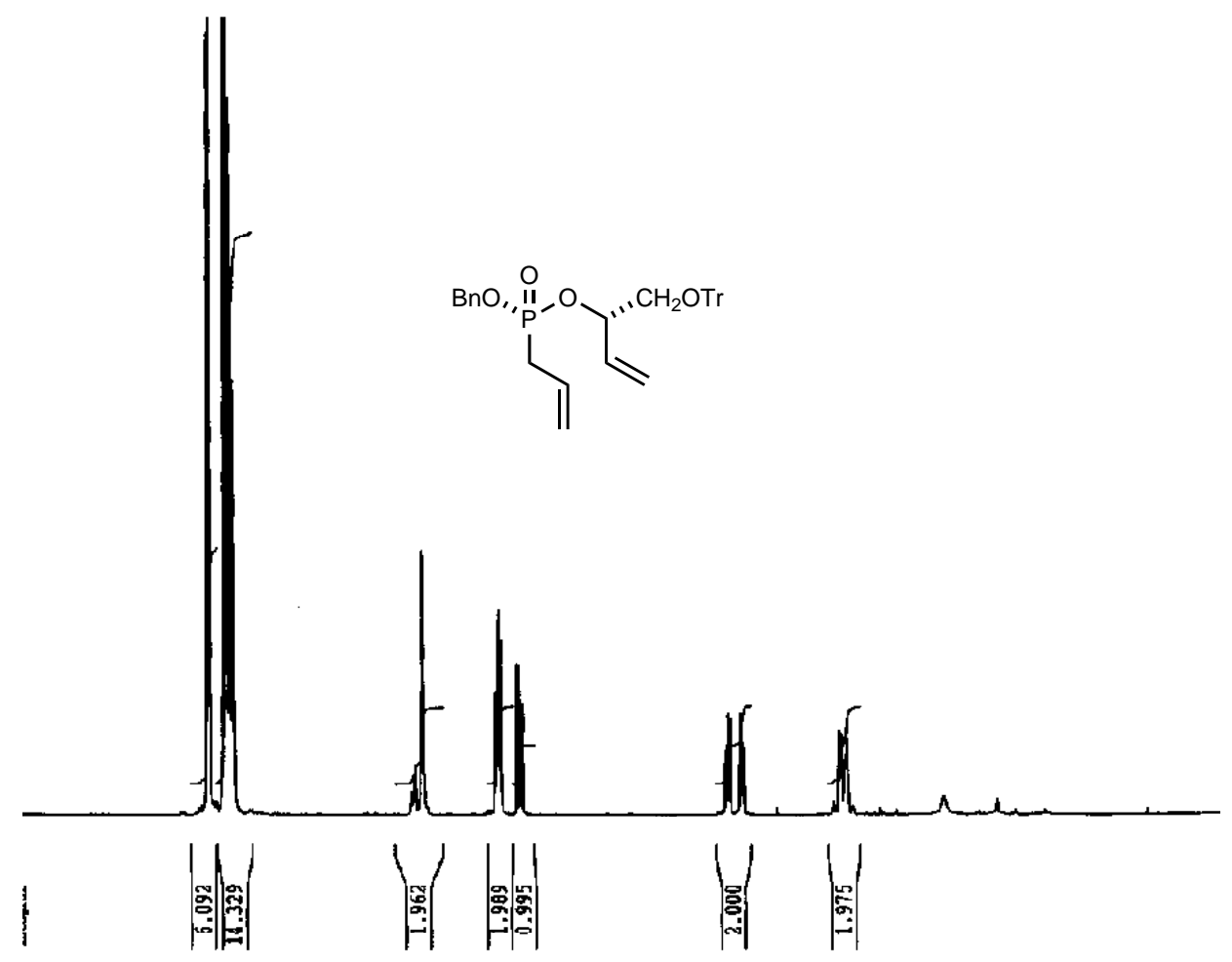

镸

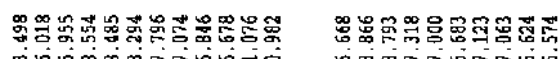

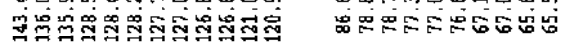

WW

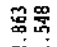

ส่ง

V

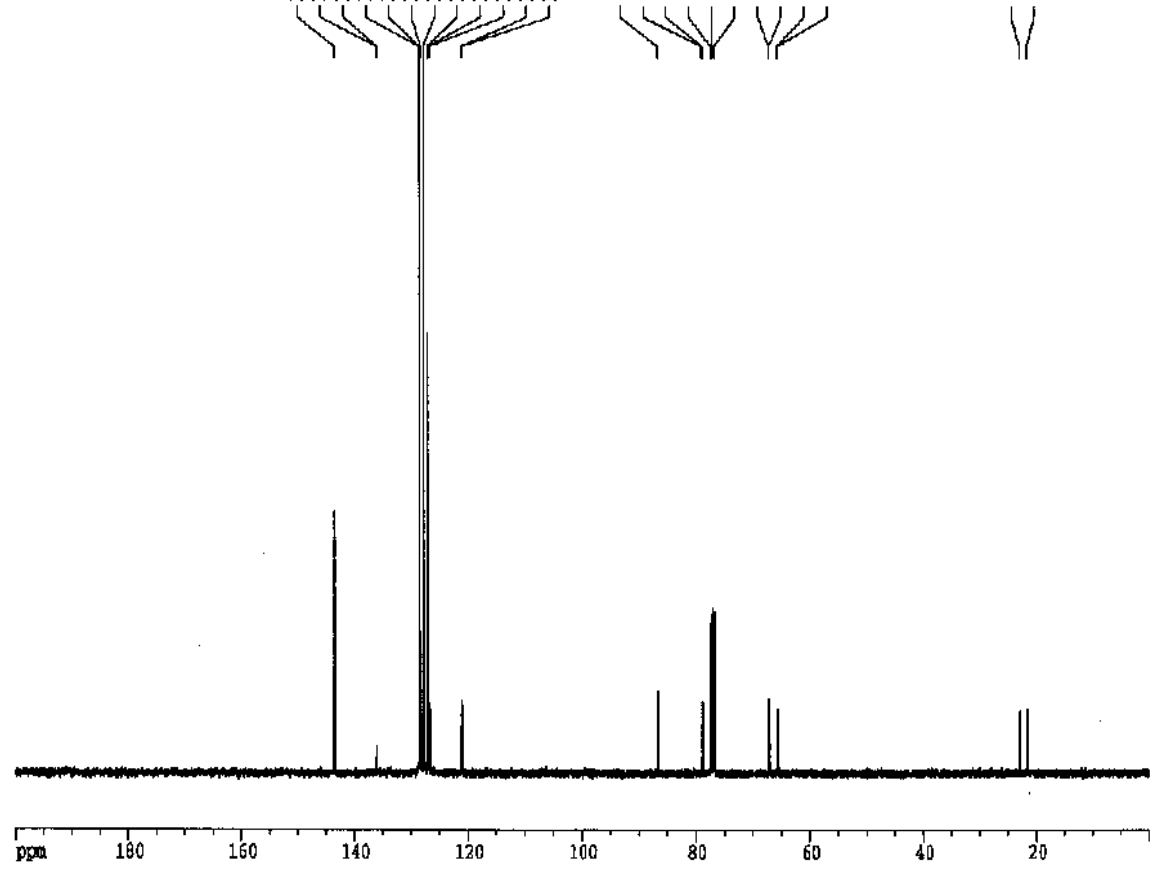



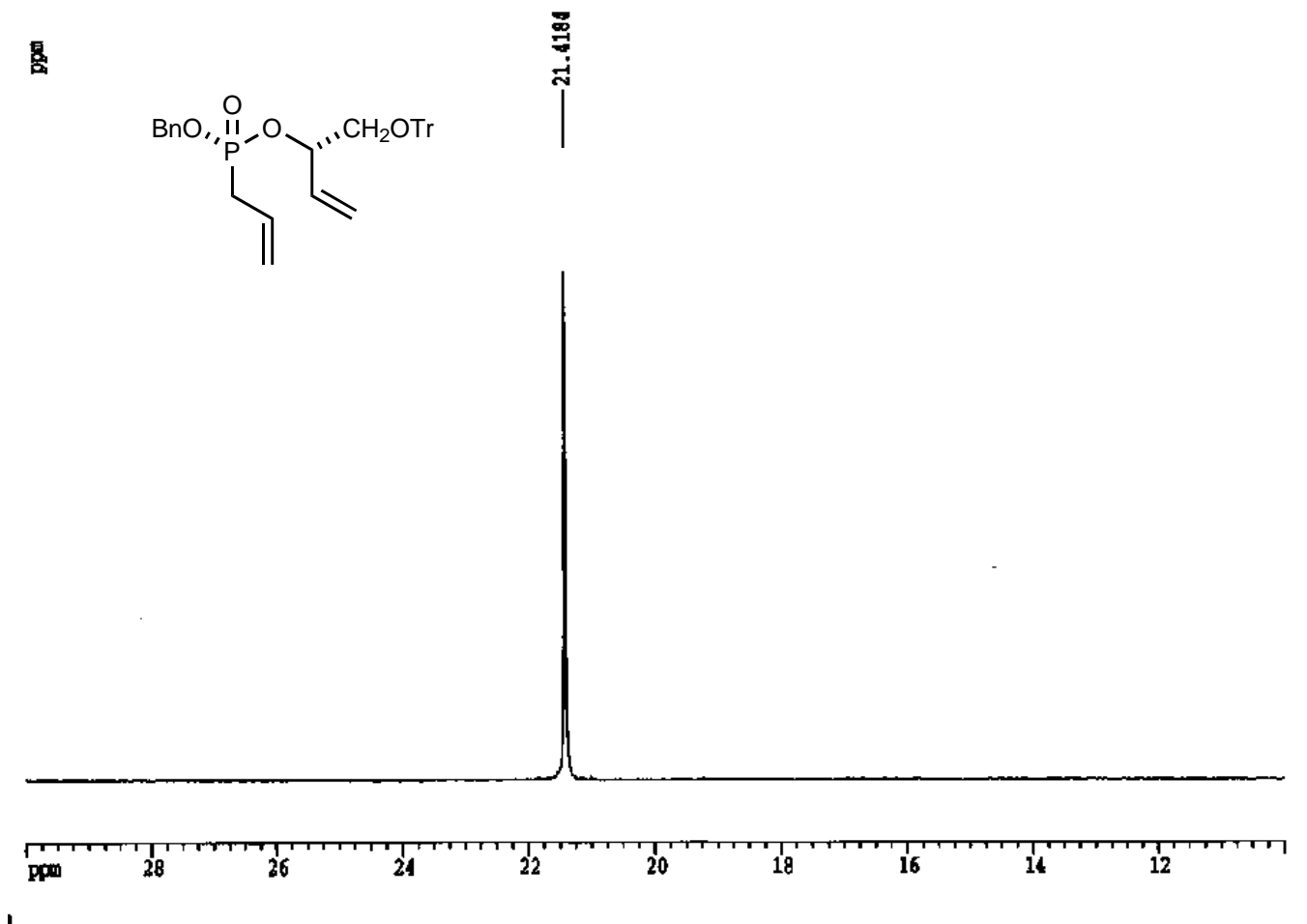

I 


\section{Compound 35}

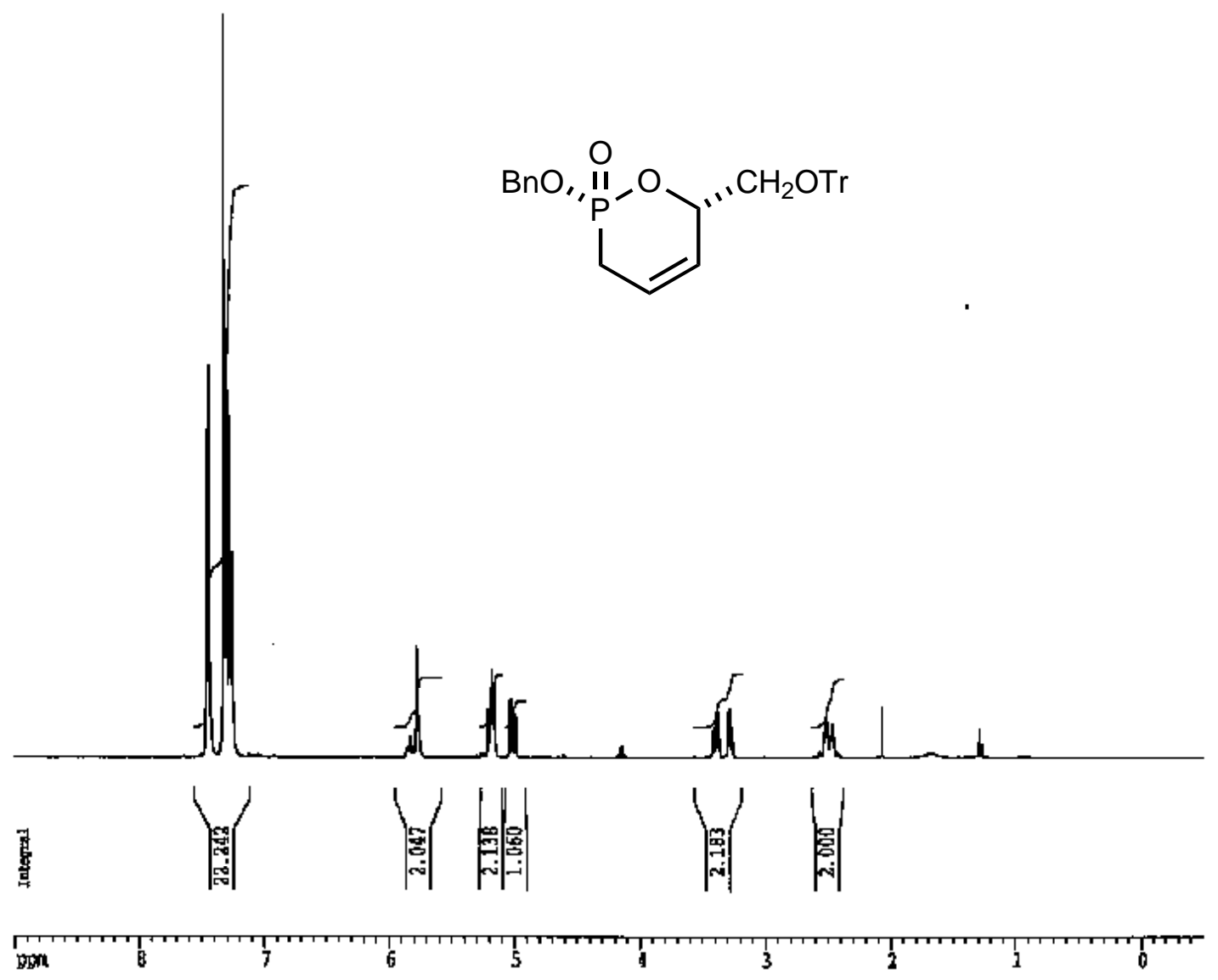


宫

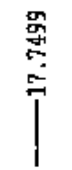<smiles>O=P1(O[Ga])CC=C[C@@H](C[OH+])O1</smiles>

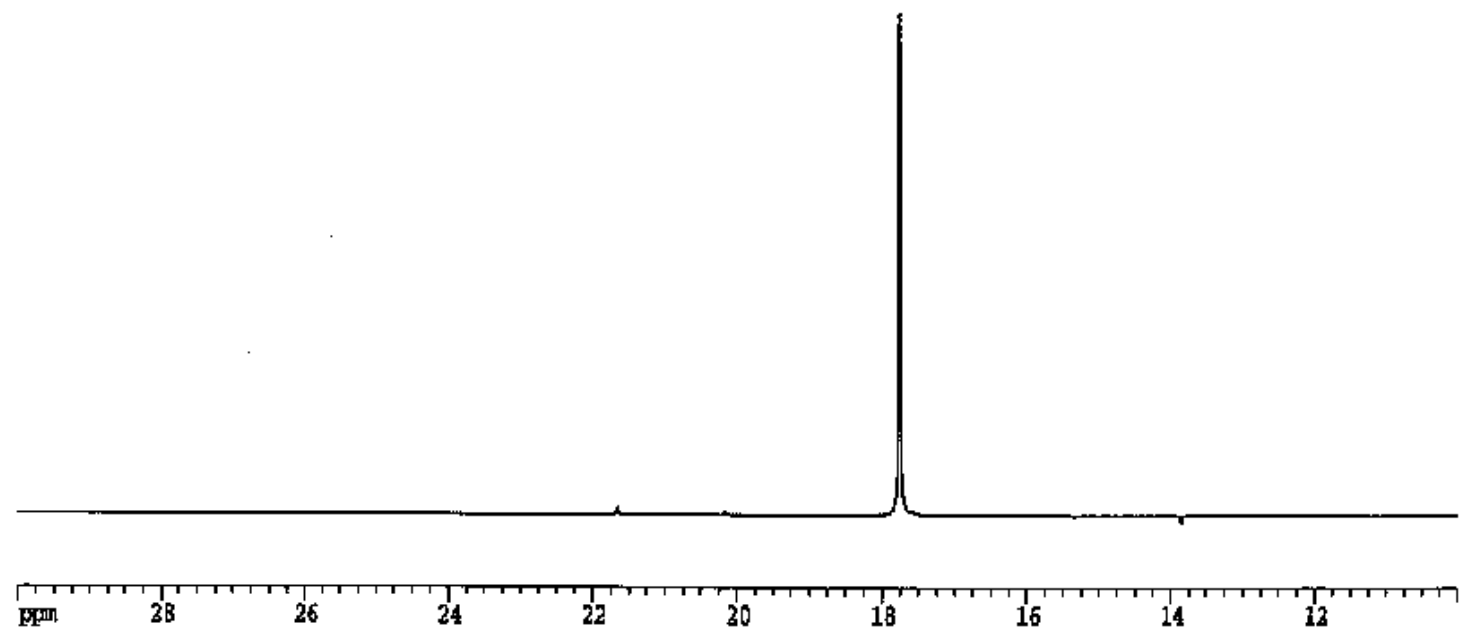




\section{Compound 36}

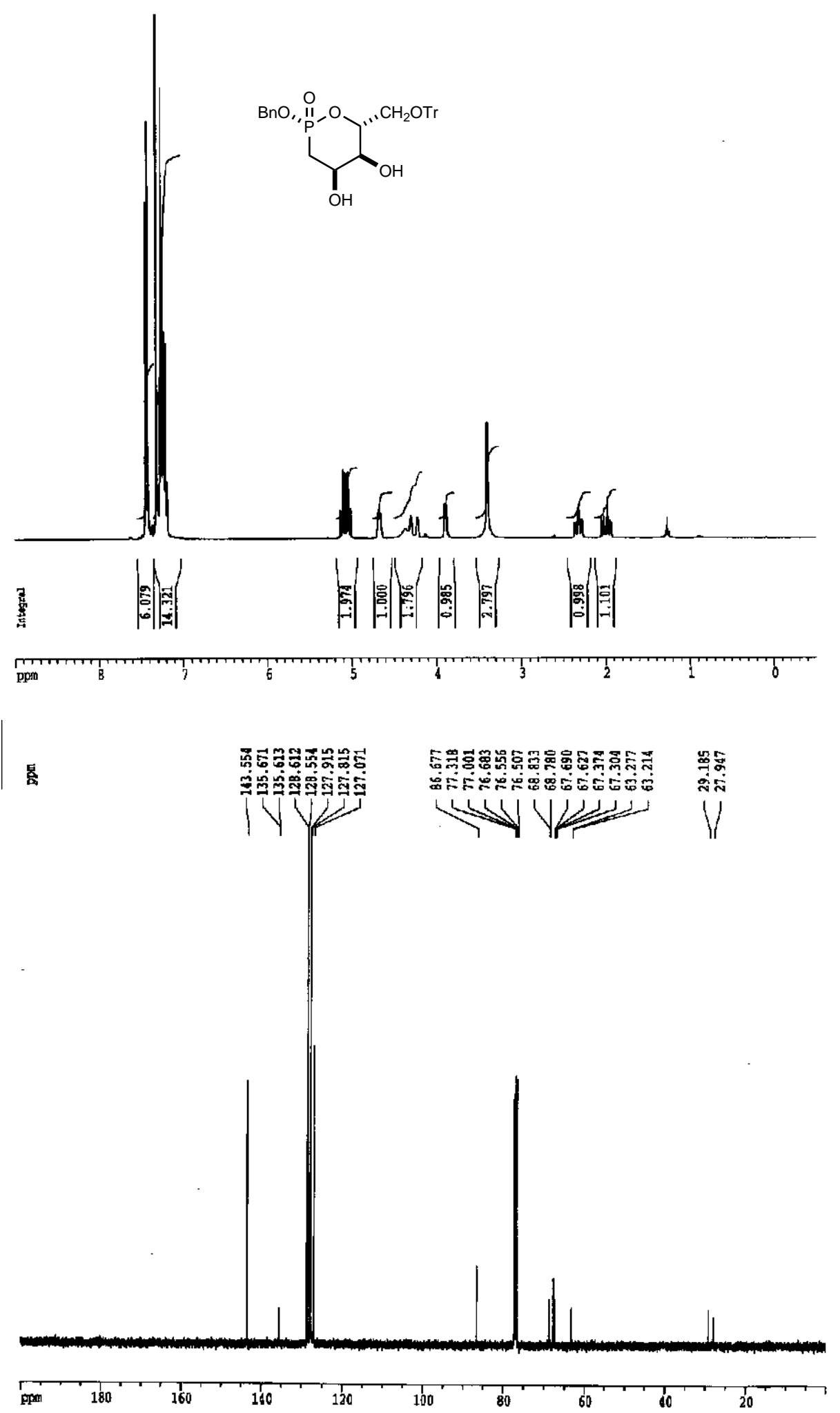



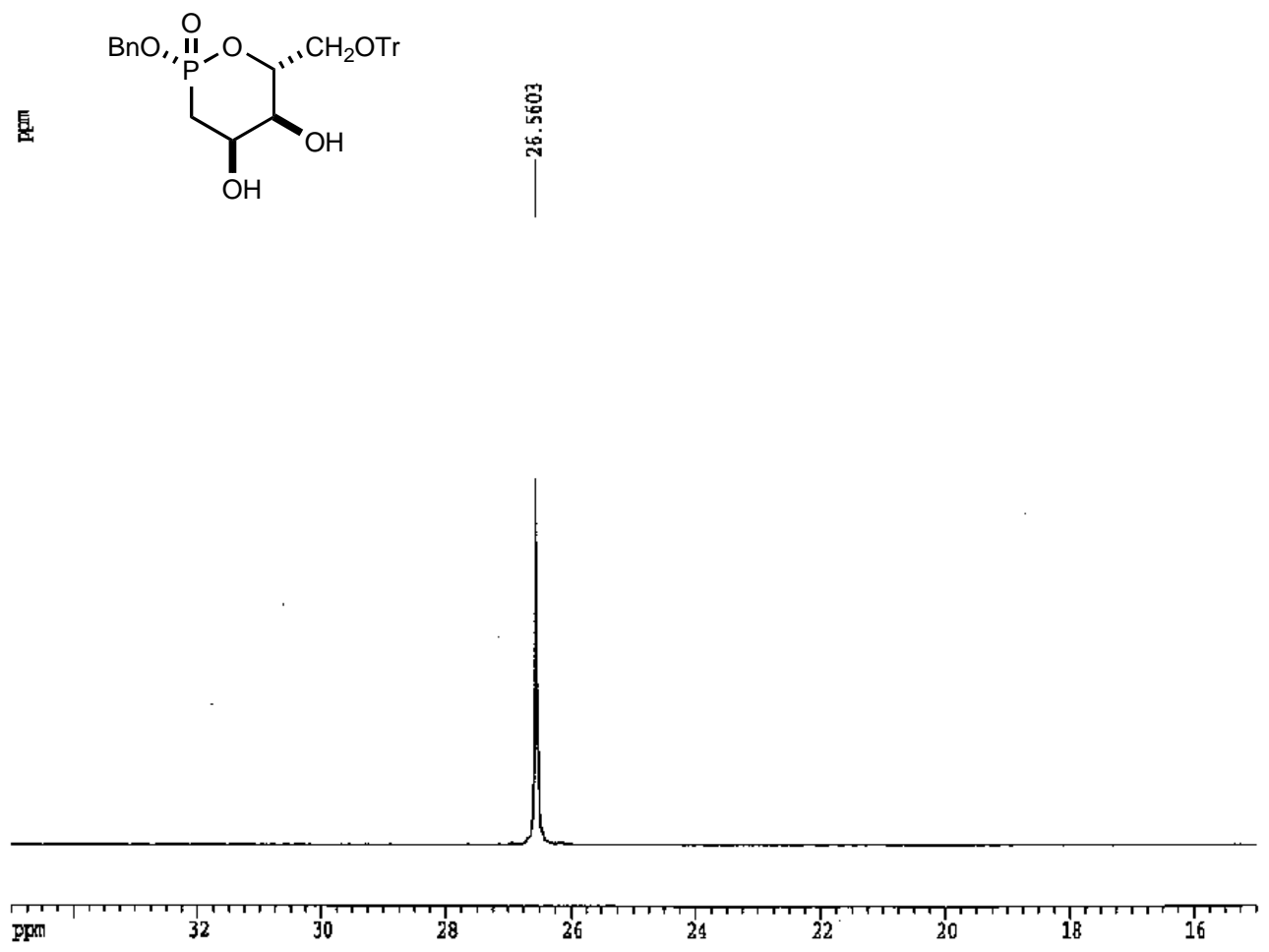

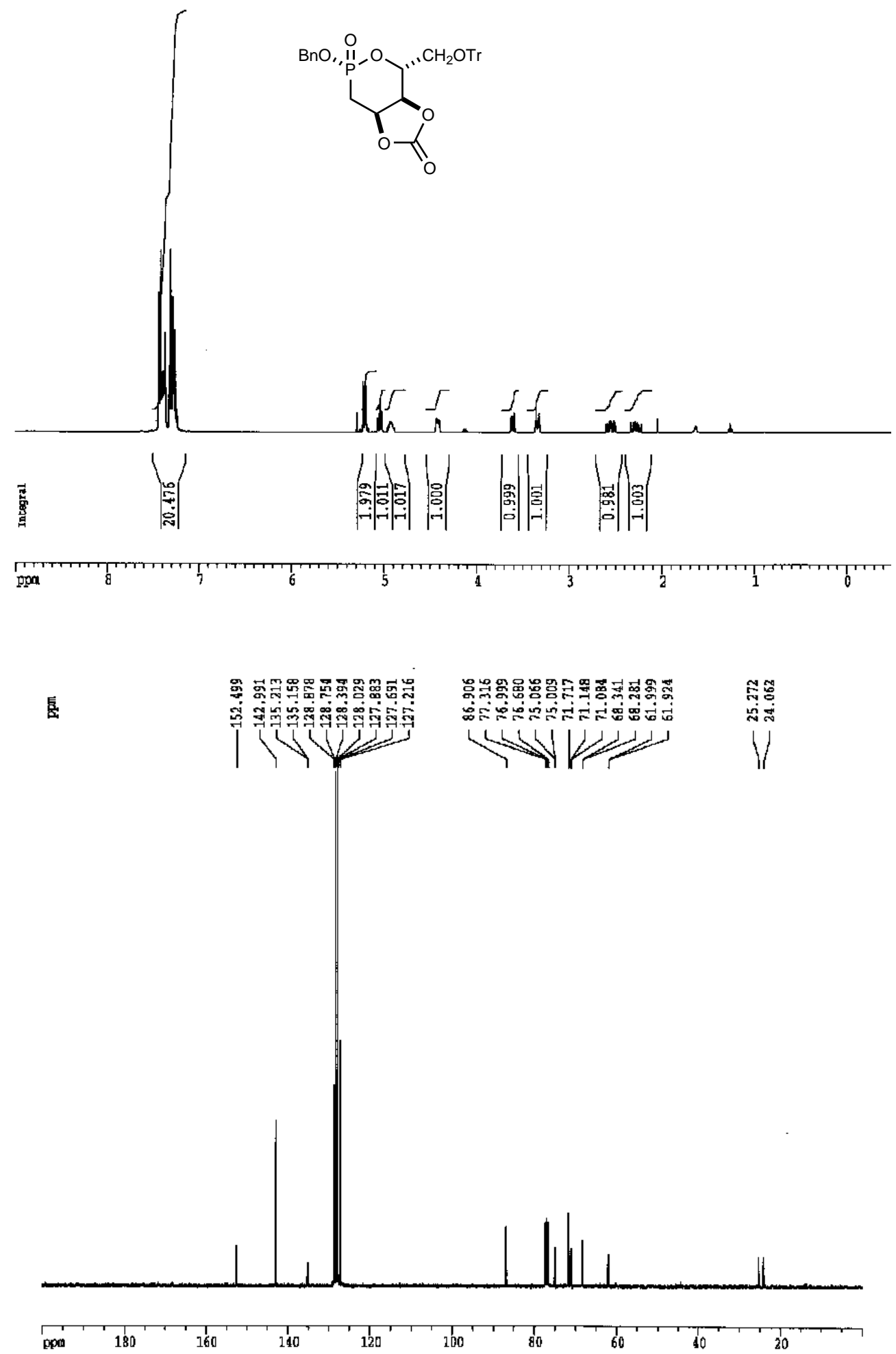

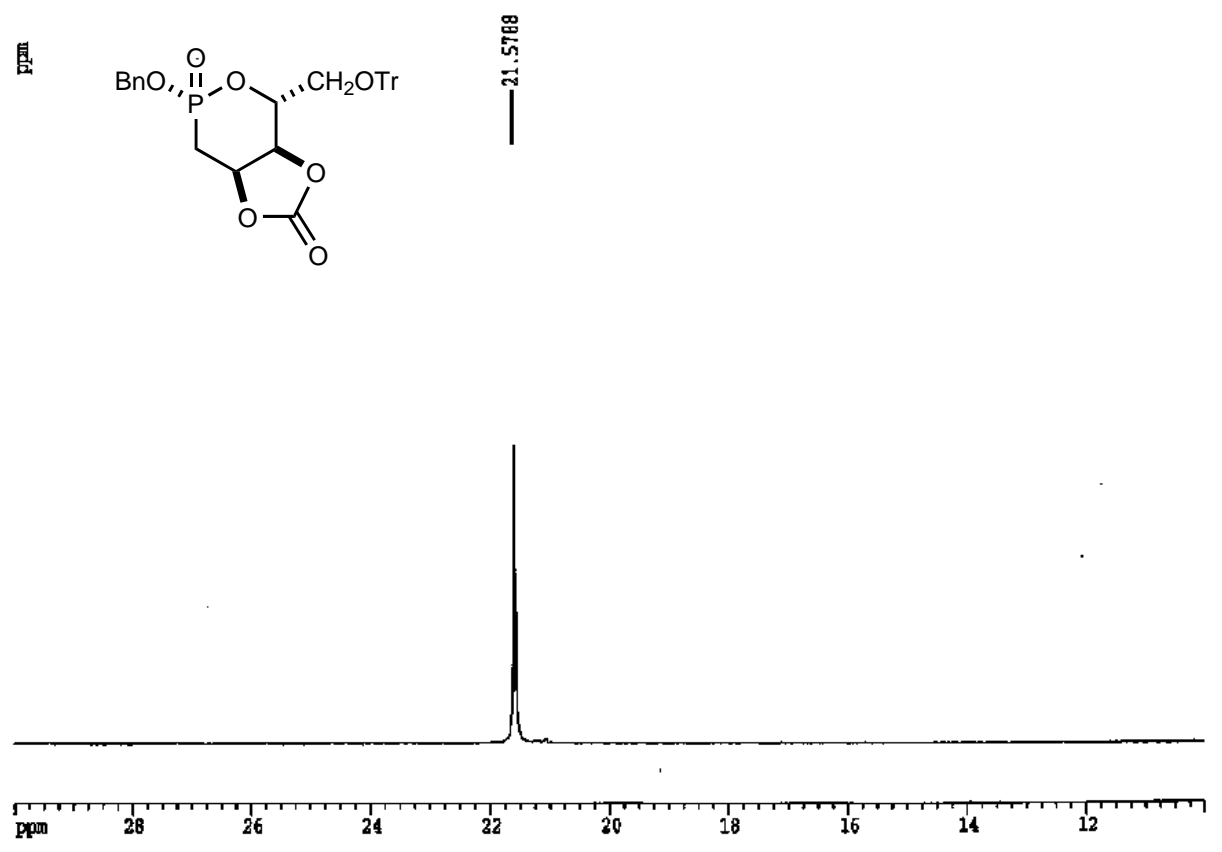


\section{Compound 37}

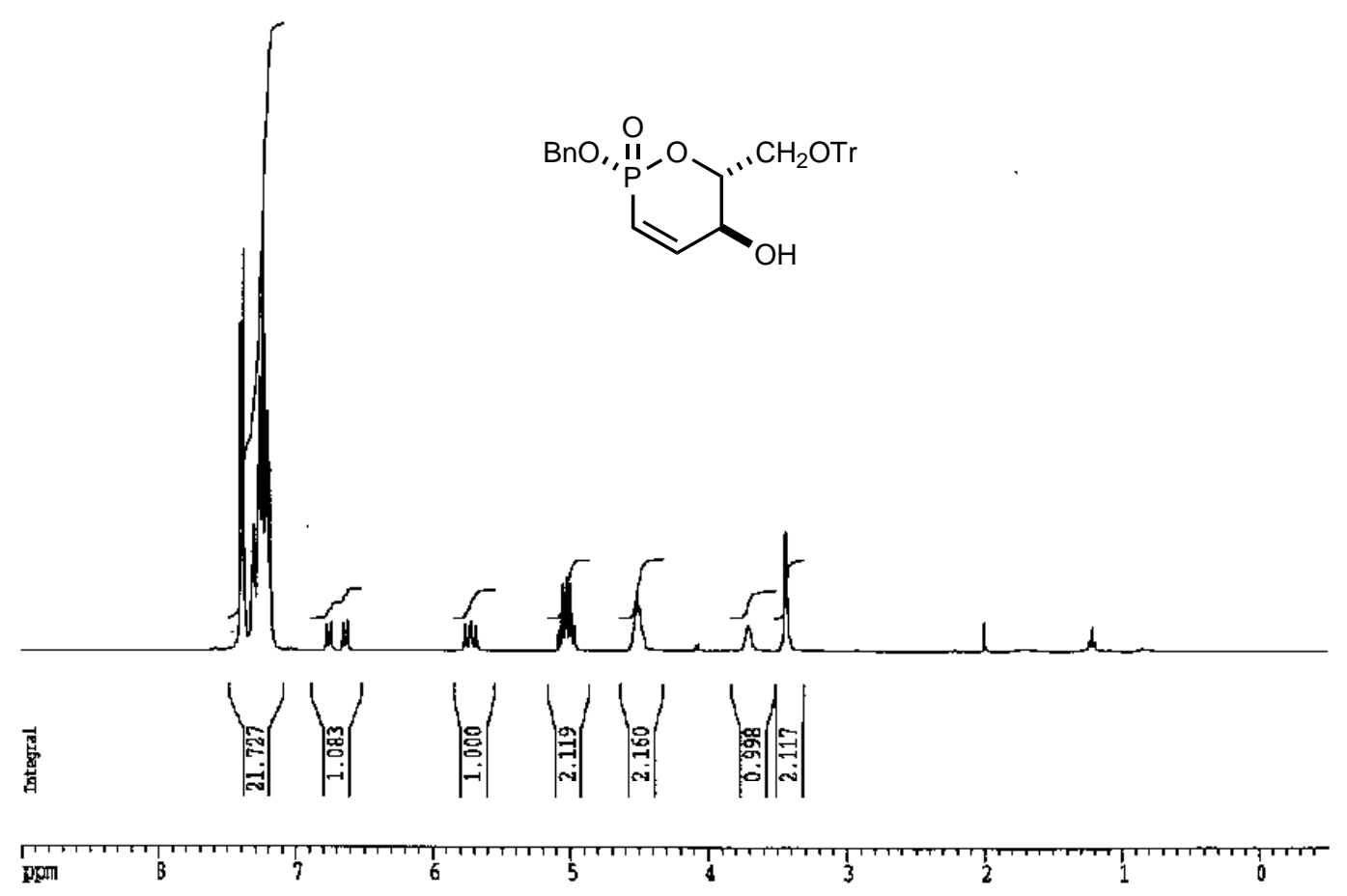

菅

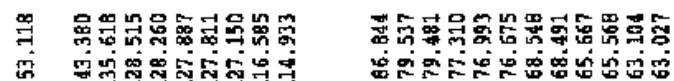

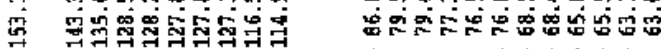

W Y V

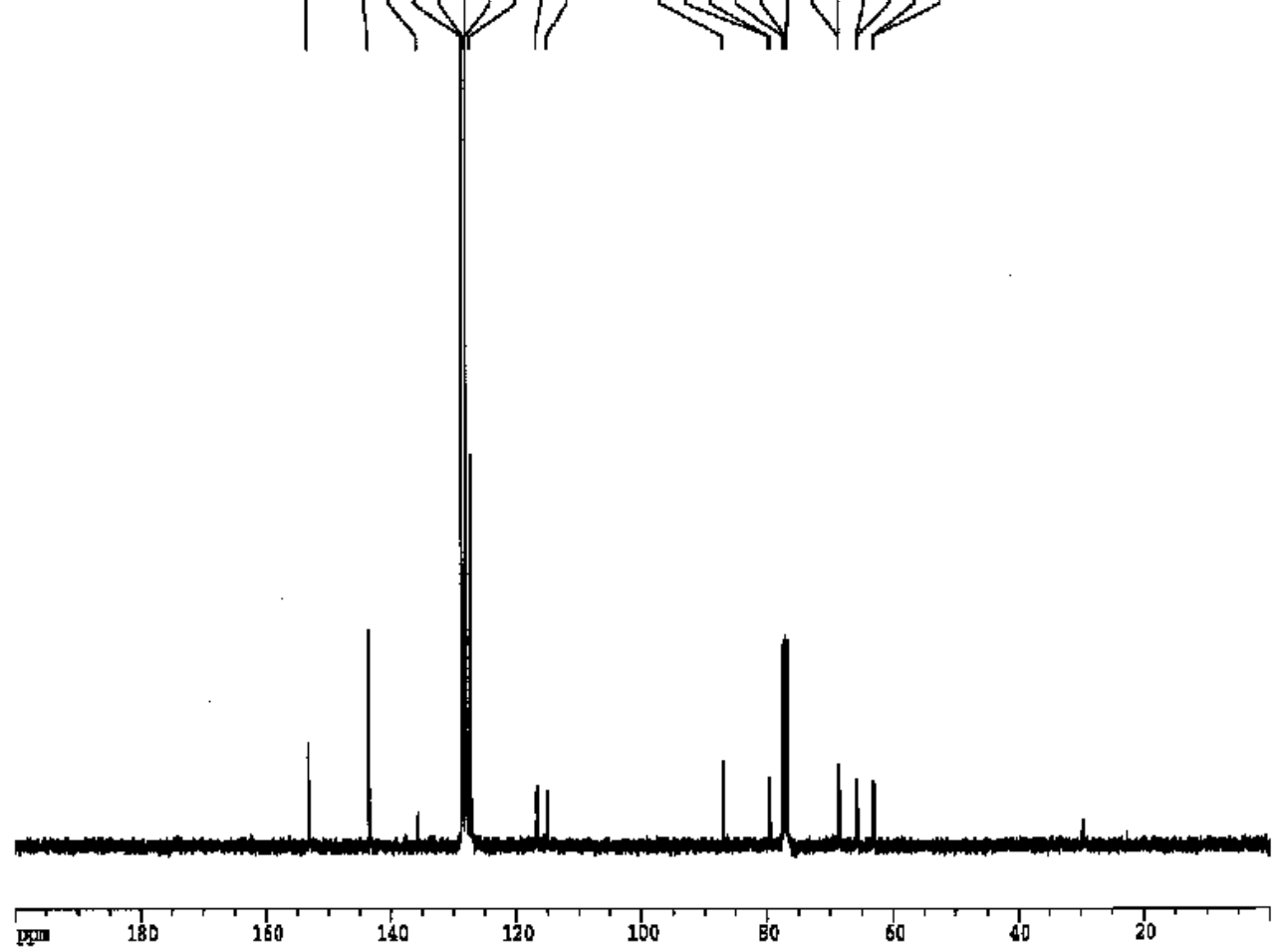


息
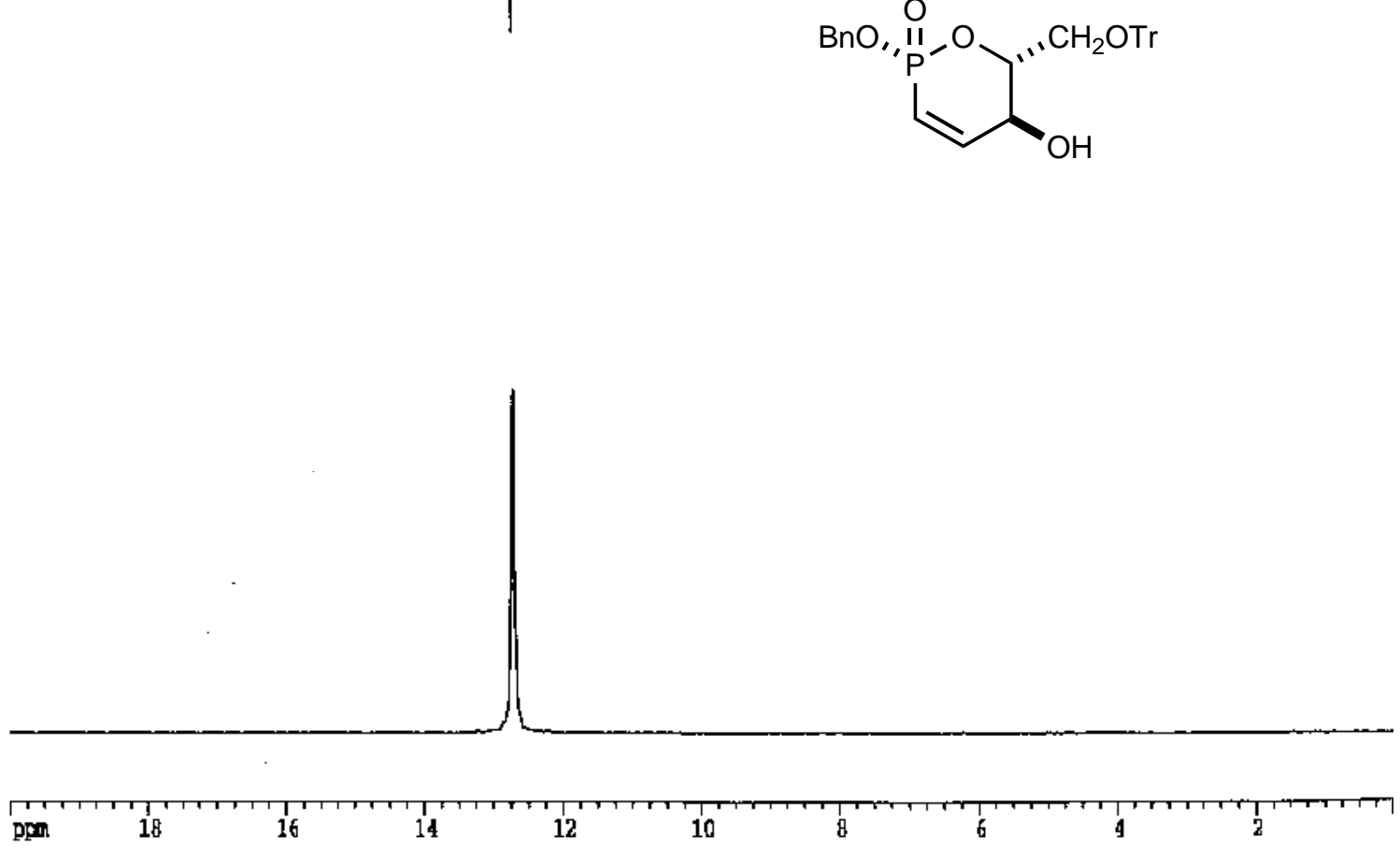


\section{Compound 38}

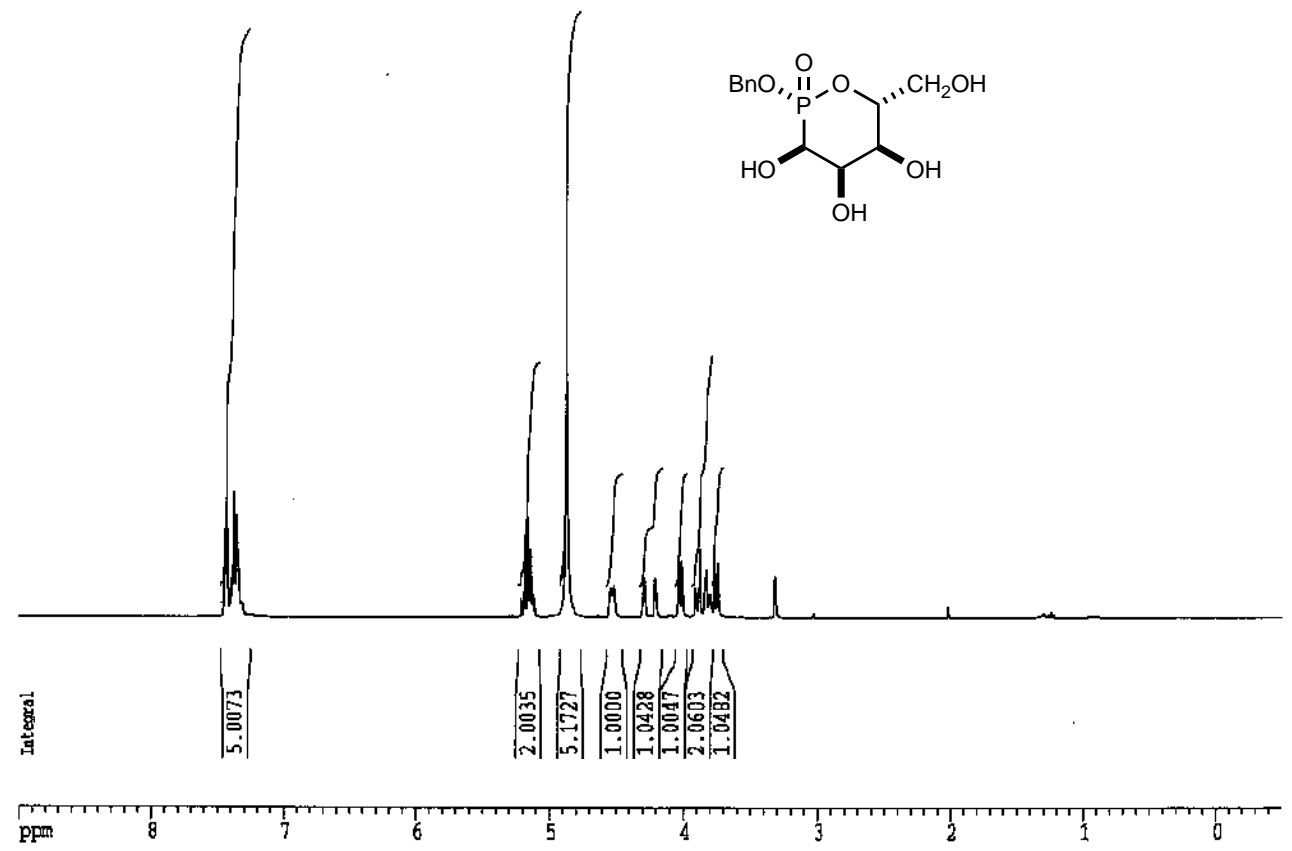

區

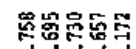

둥ํㅇ

Vर

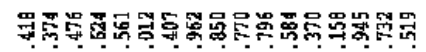

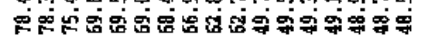

4 His

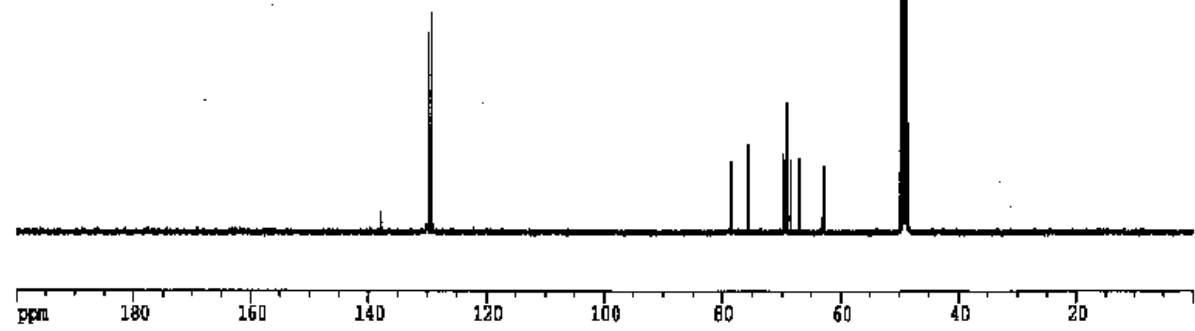


息
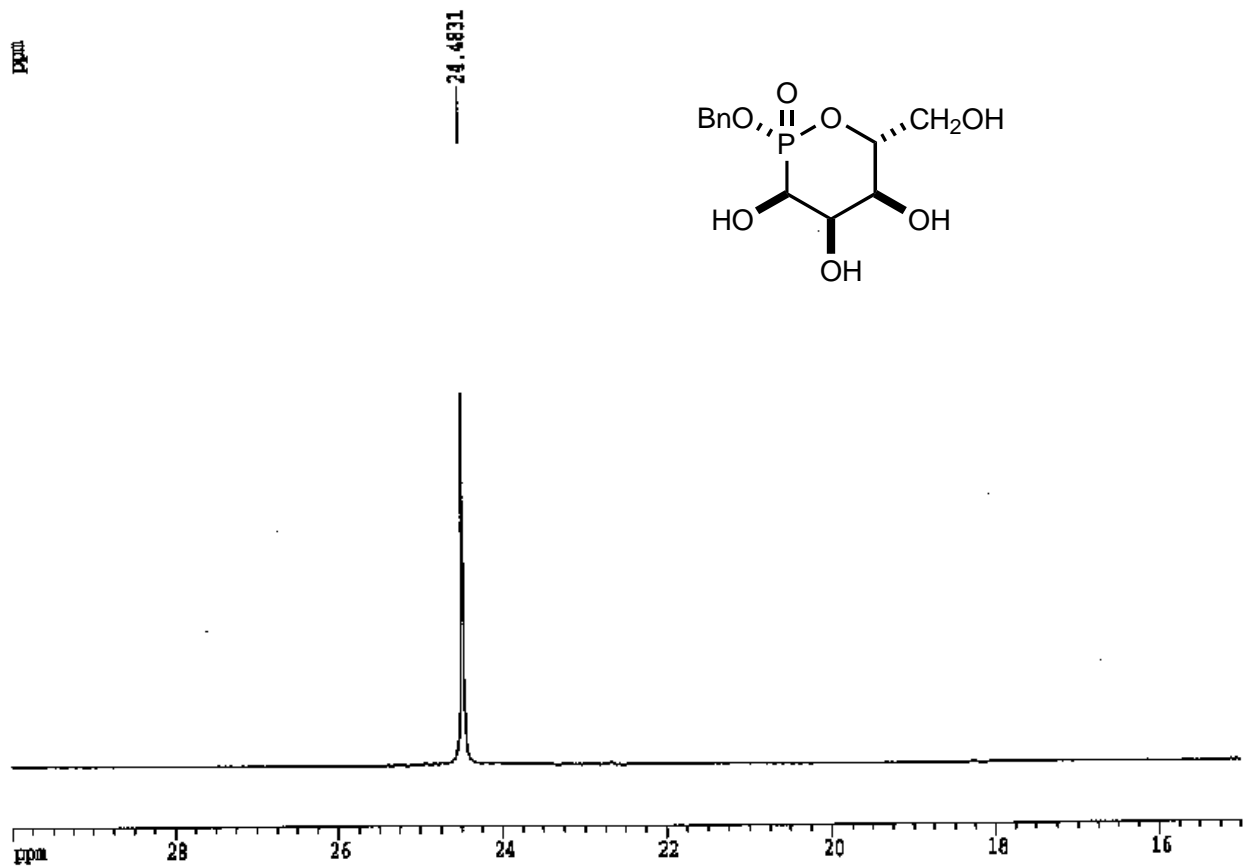


\section{Compound 39}

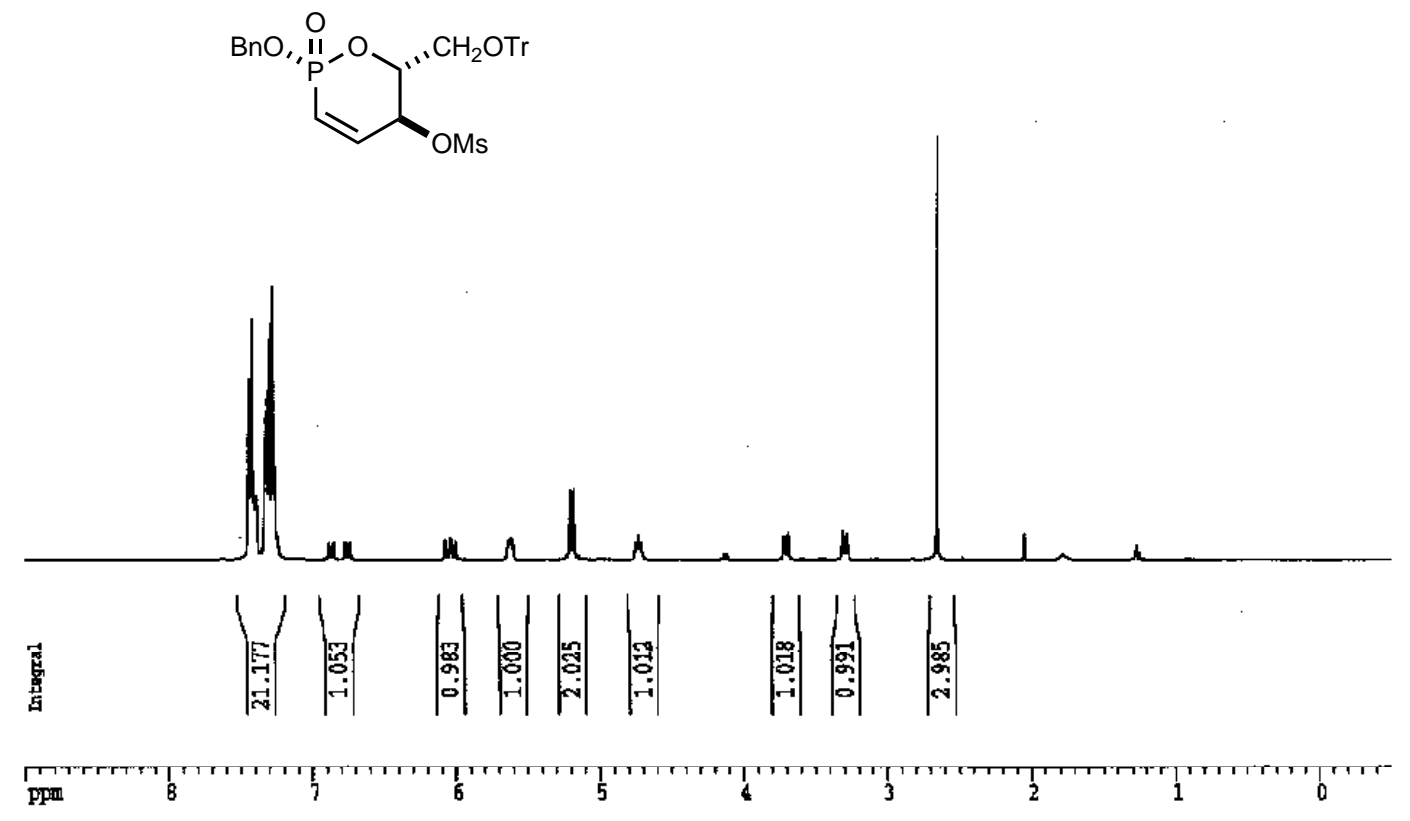

g
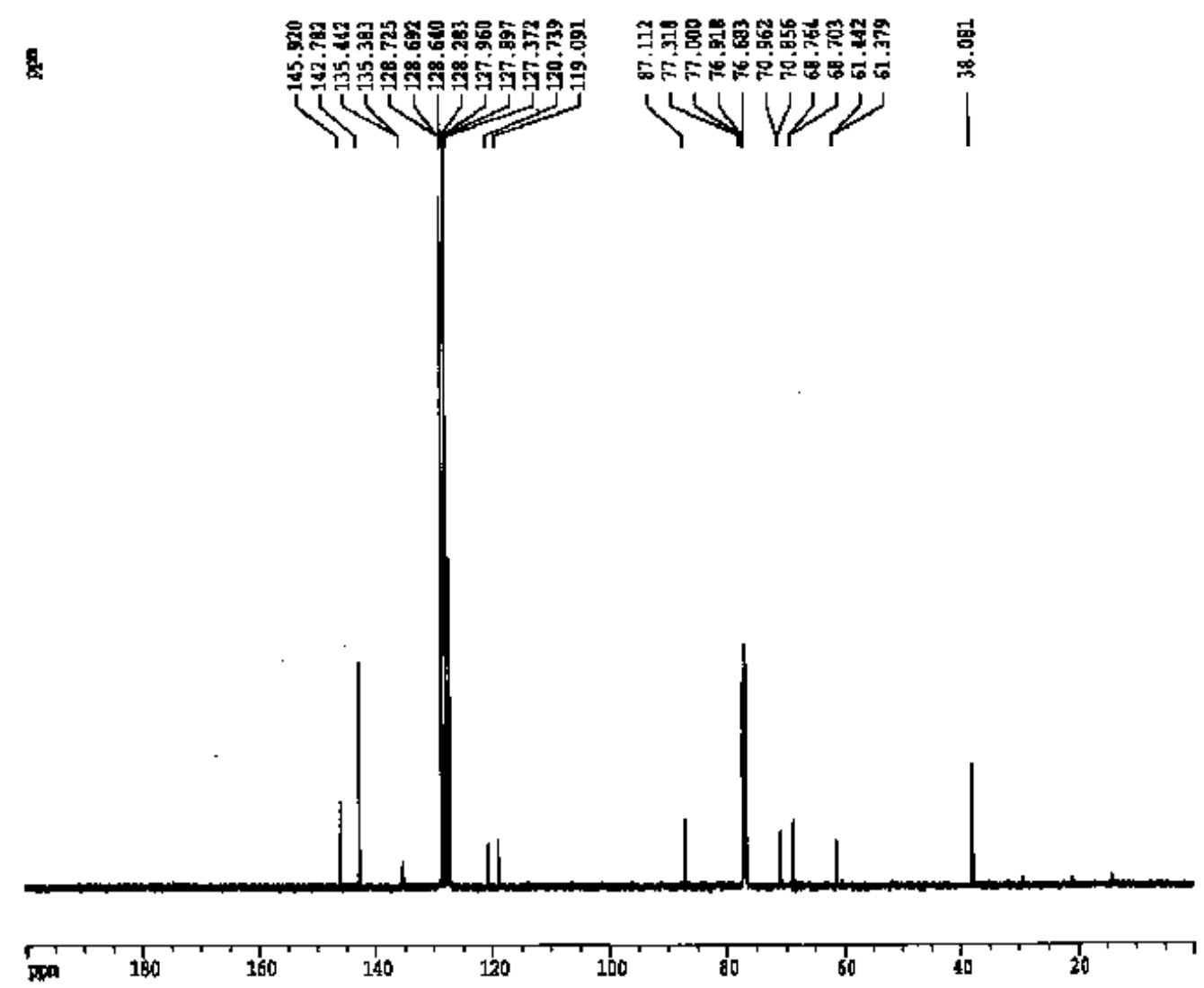


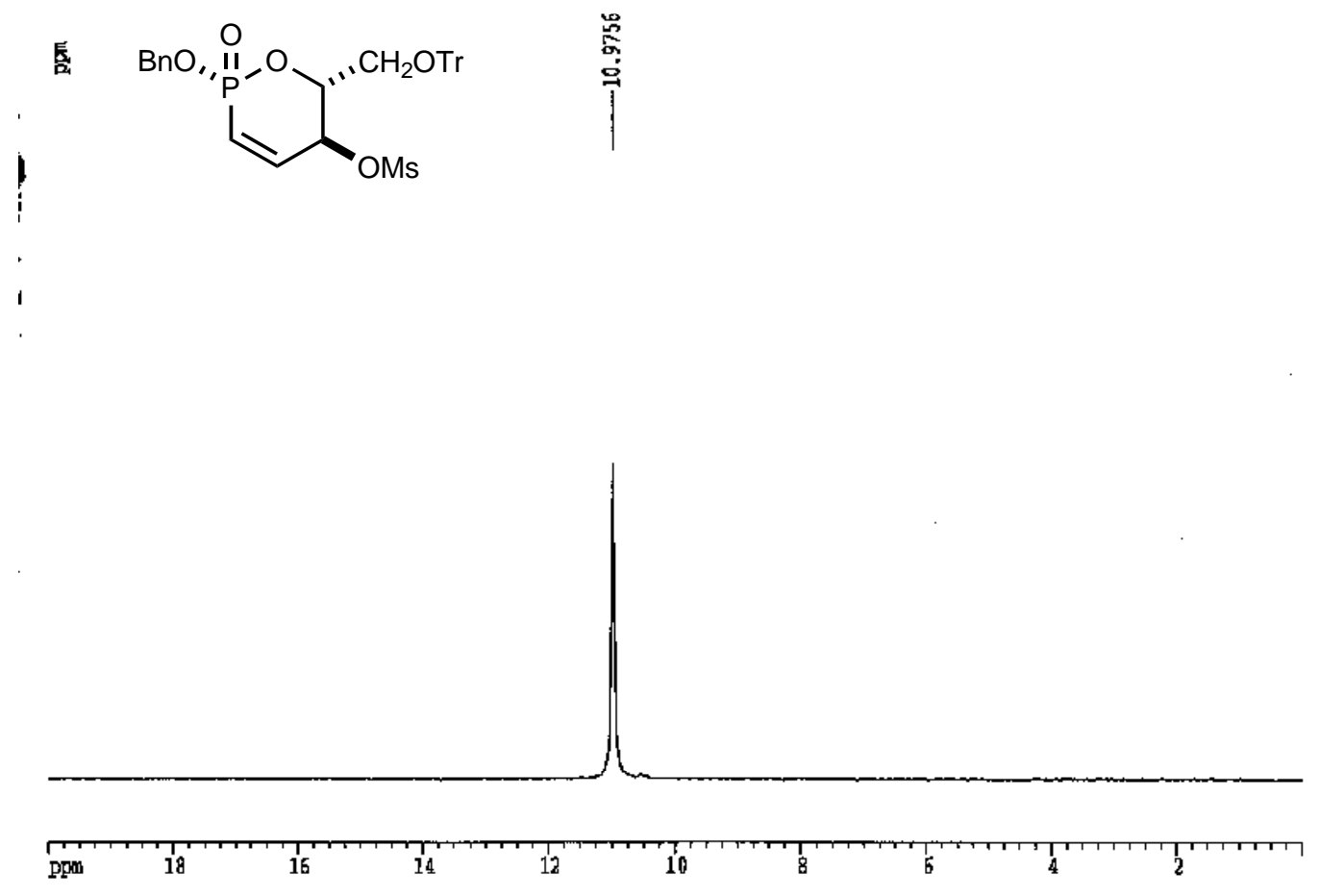




\section{Compound 40}

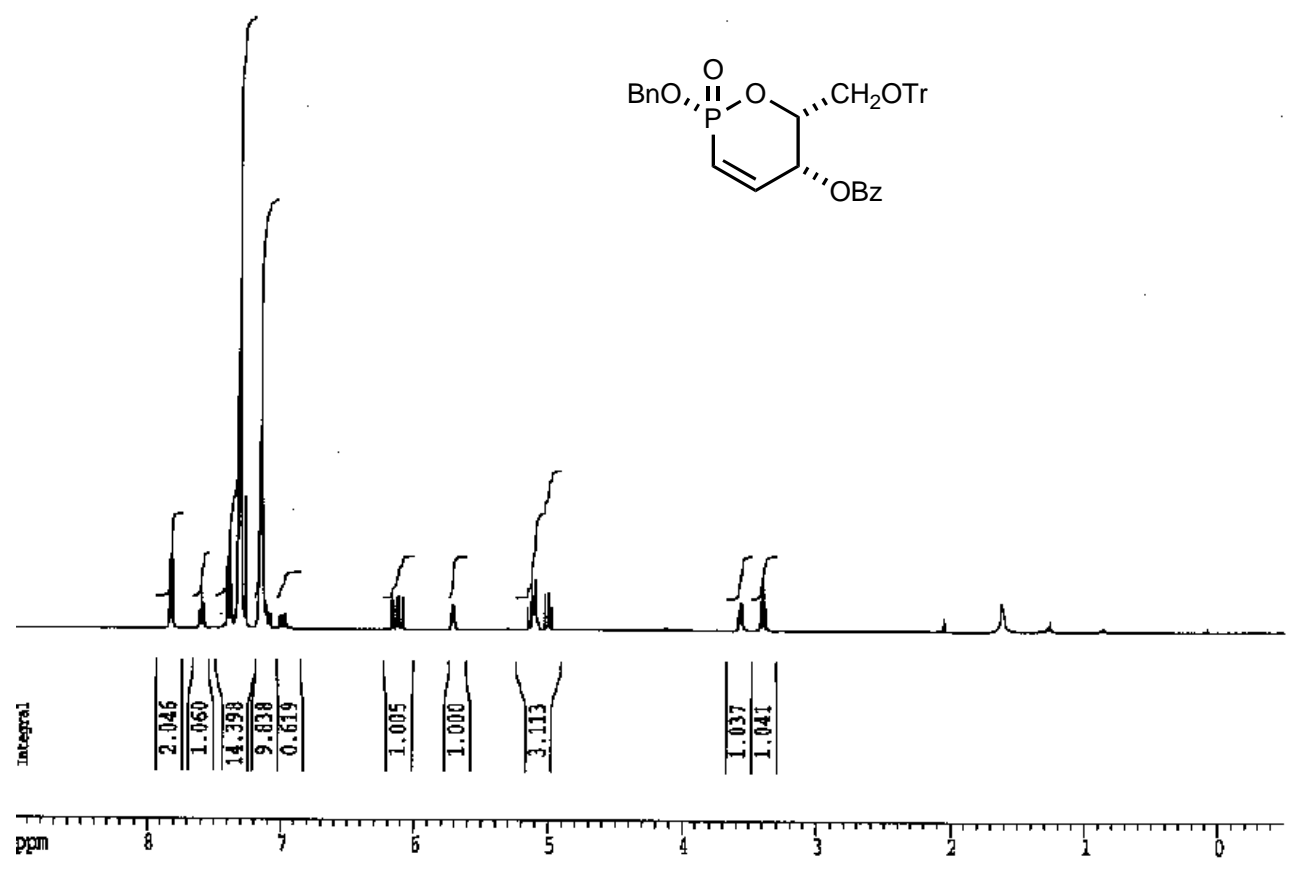

具

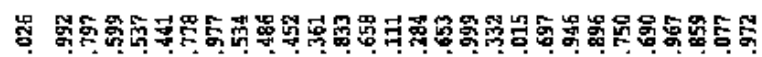

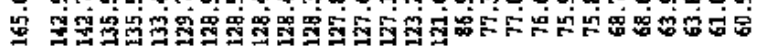

i

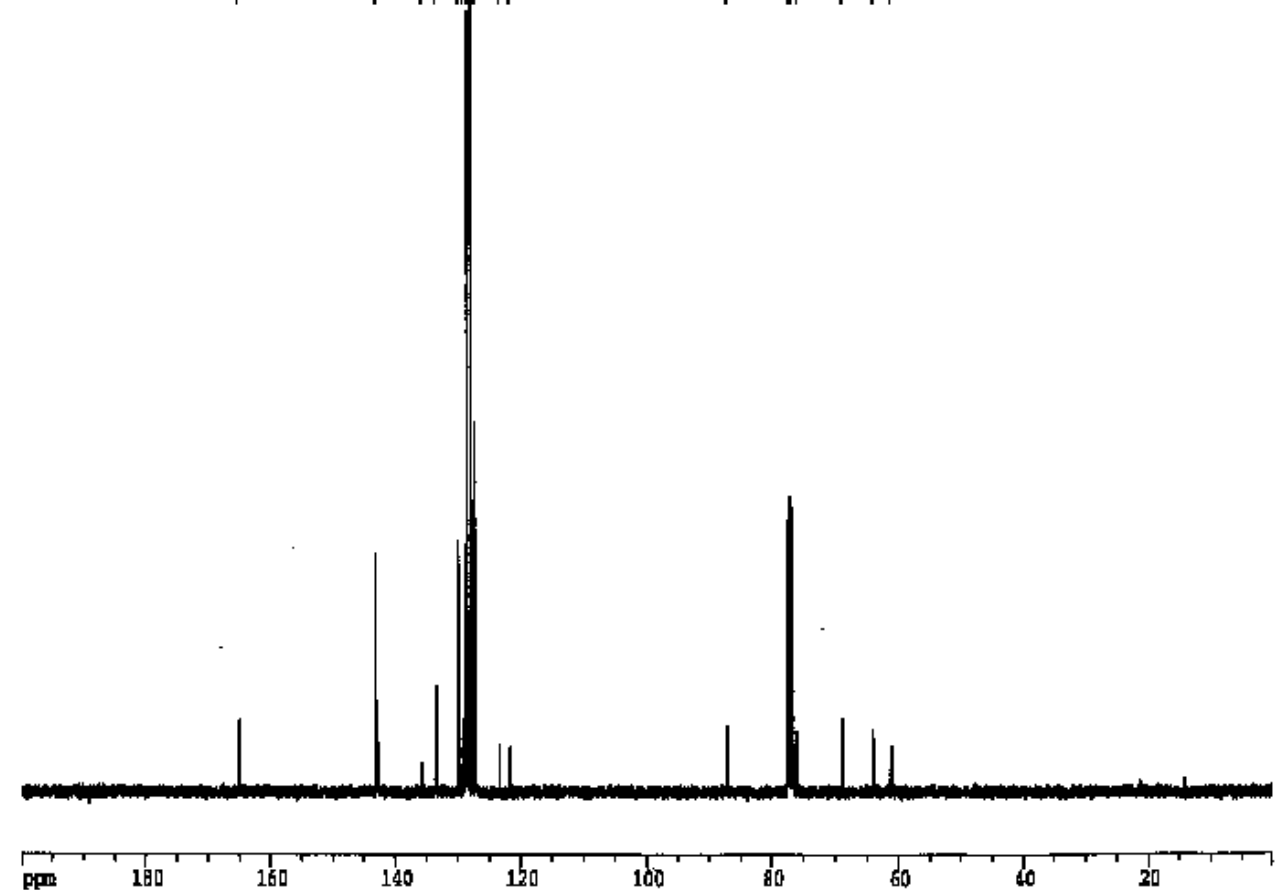

S 51 
镸<smiles>O=C(O)[C@H]1C=CP(=O)(Cc2ccccc2)O[C@@H]1C[O+]</smiles>

|

" "OBz
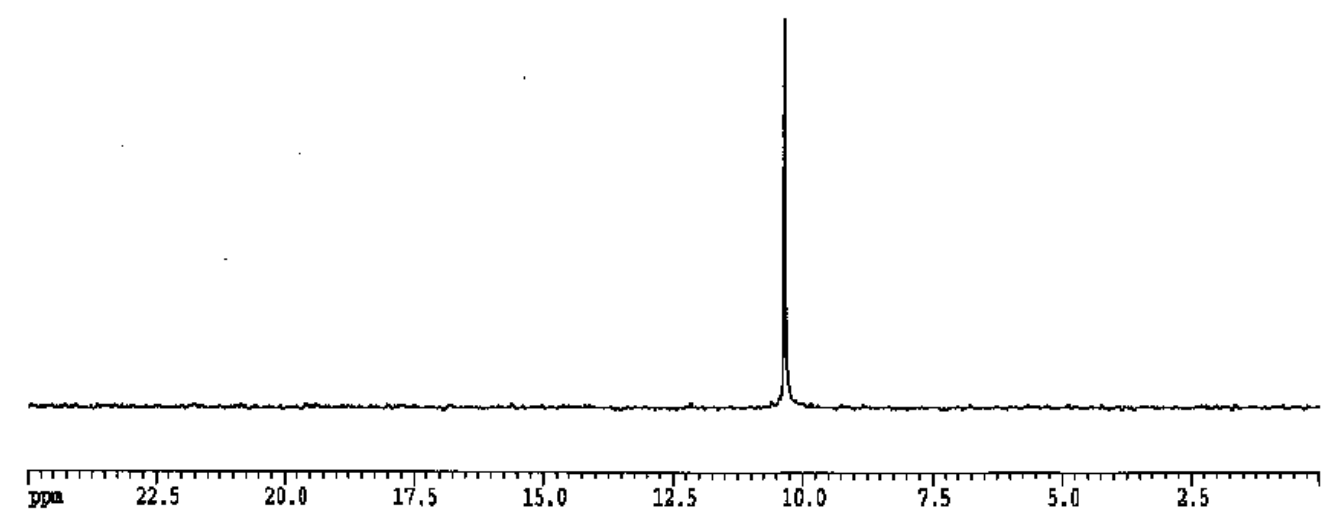


\section{Compound 41}

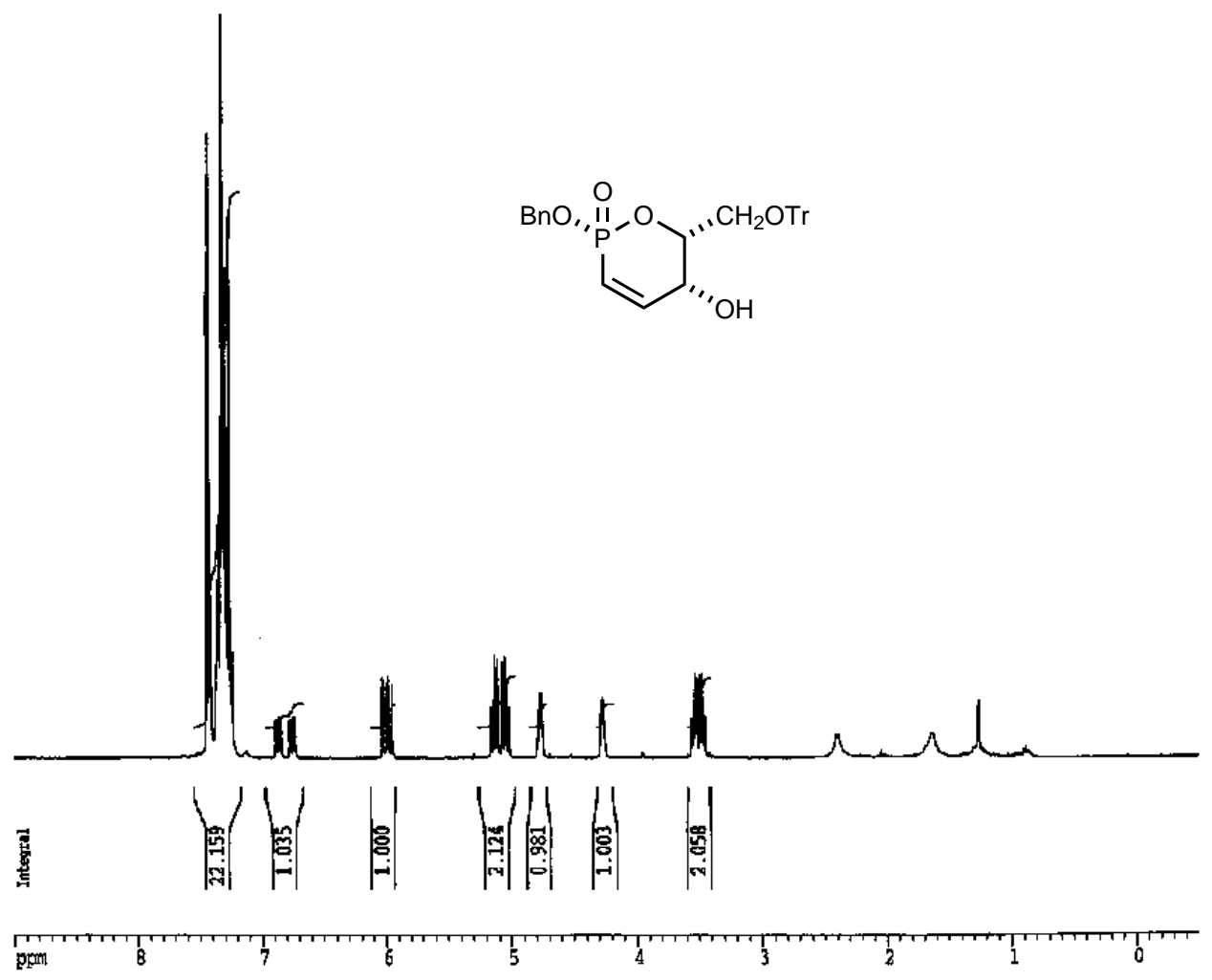

鼠

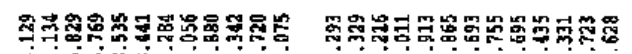

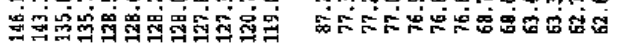

Tी

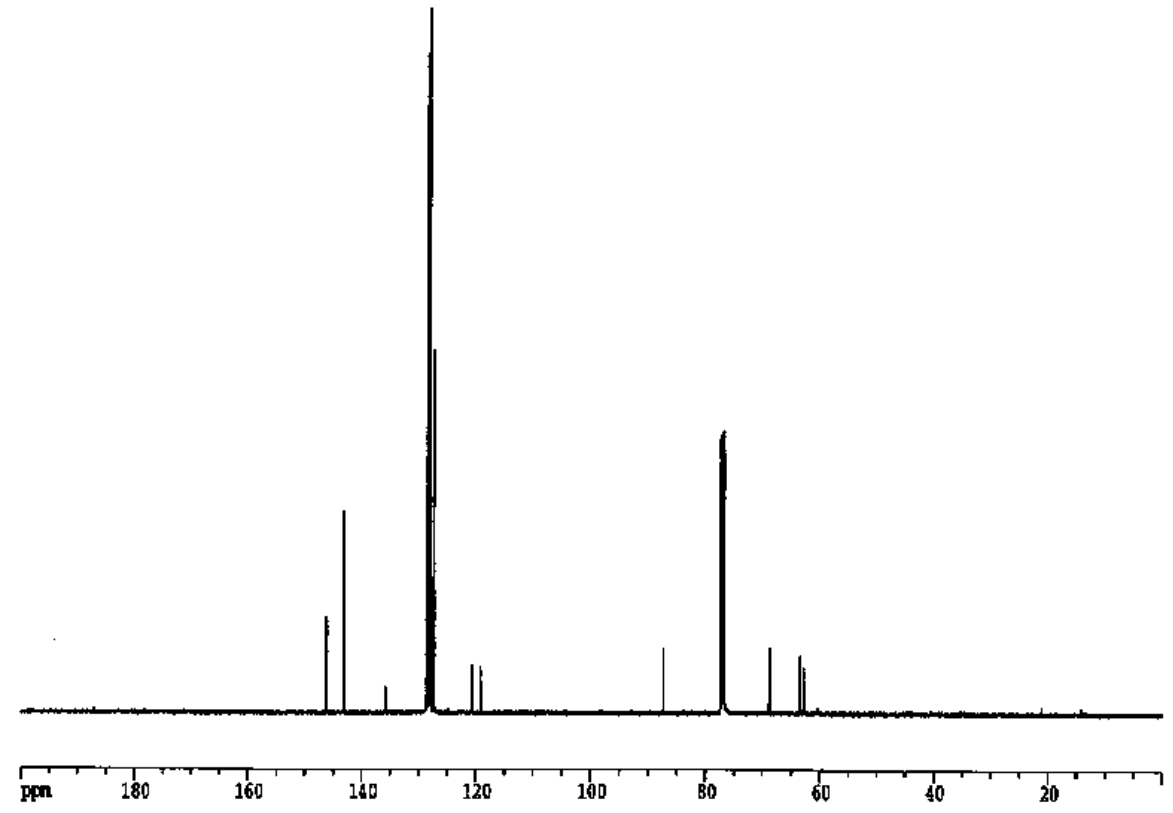


E

$\stackrel{5}{5}$

$\underbrace{\mathrm{O}}_{\text {" } \mathrm{BHO}}$

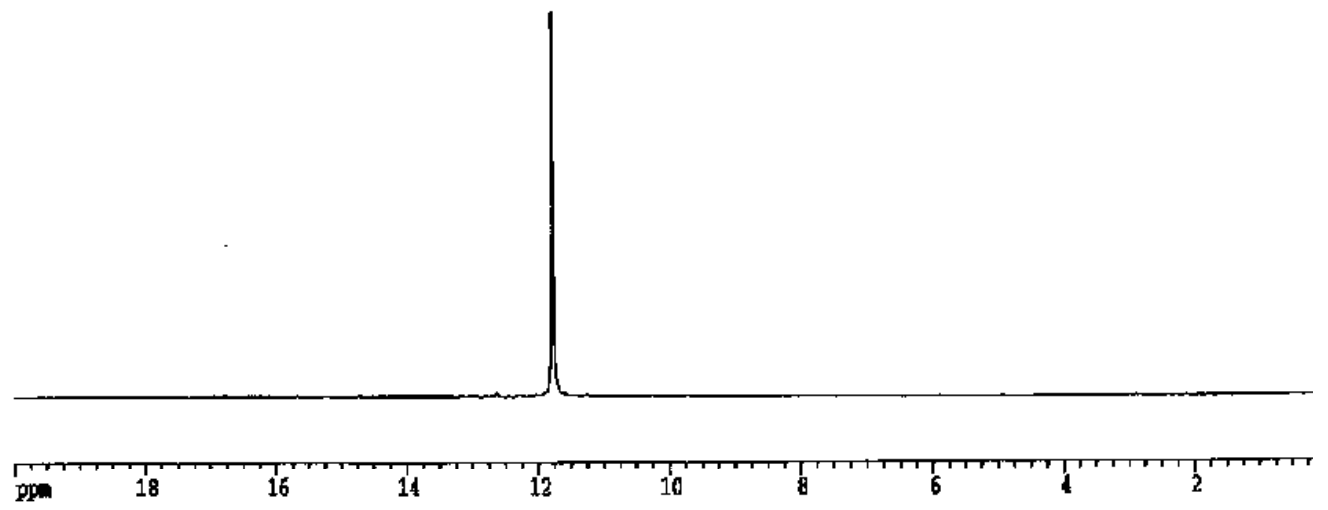




\section{Compound 42}<smiles></smiles>
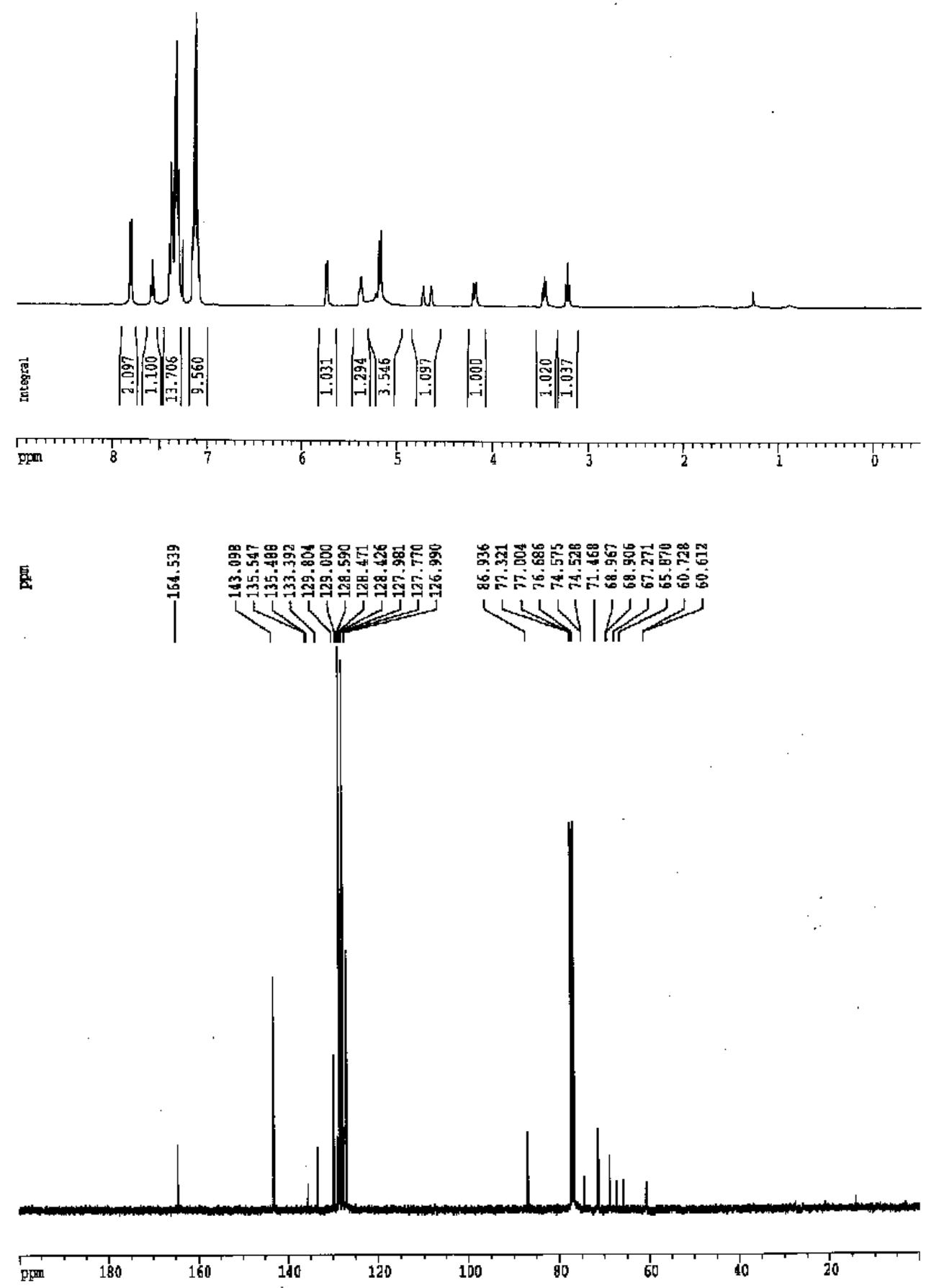

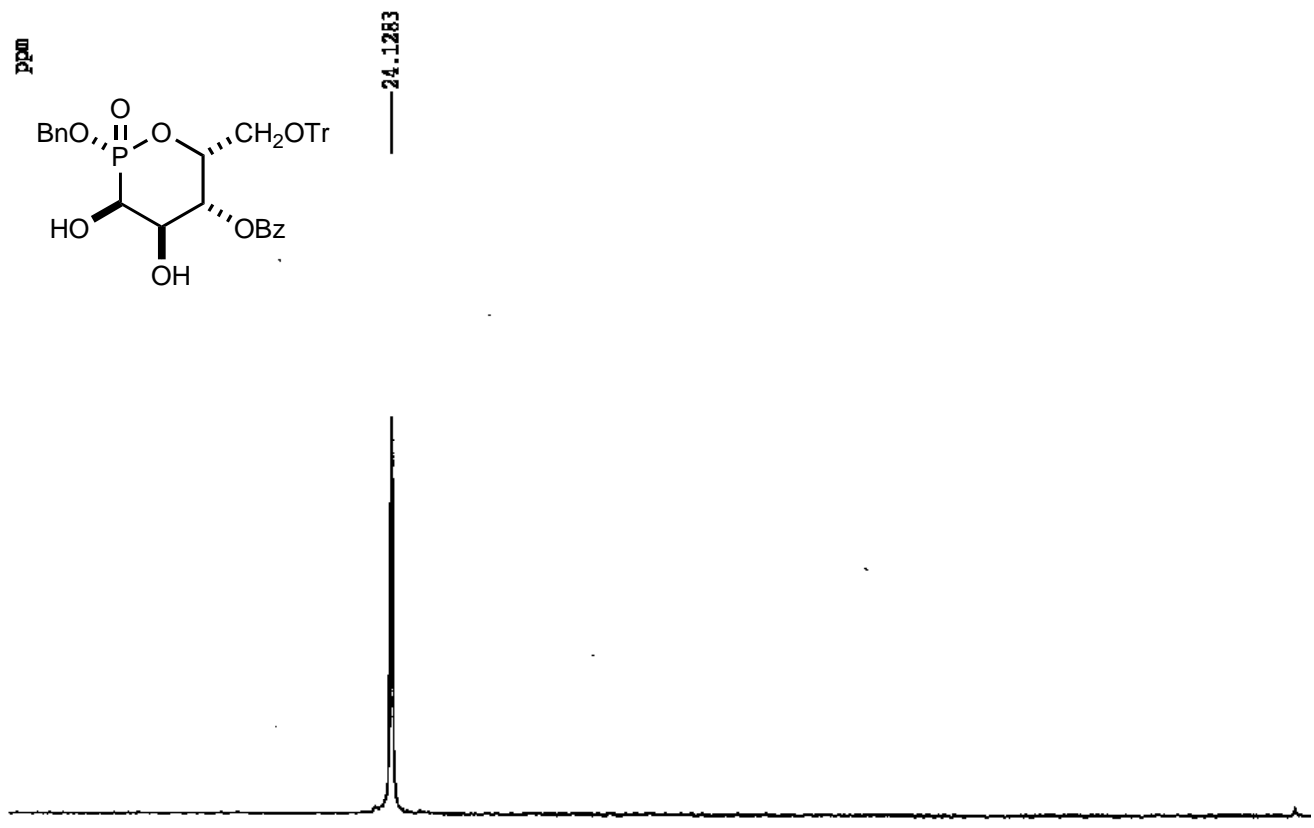

齿

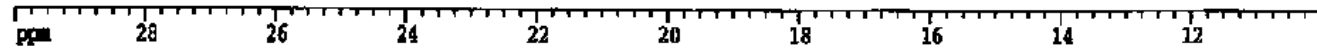




\section{Compound 43}

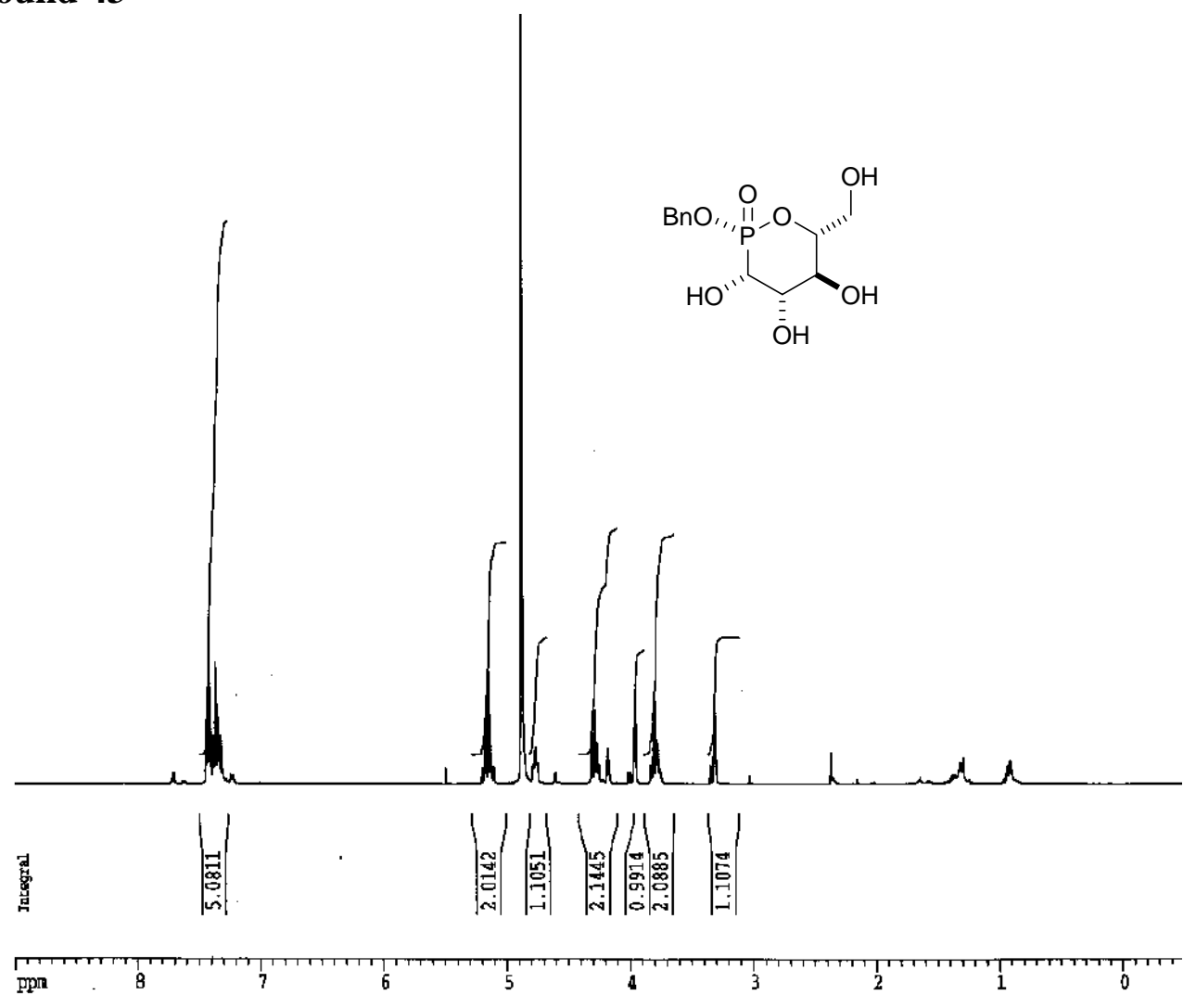

蒝

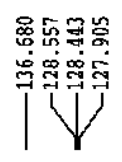

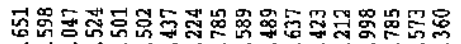

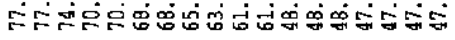
Lil

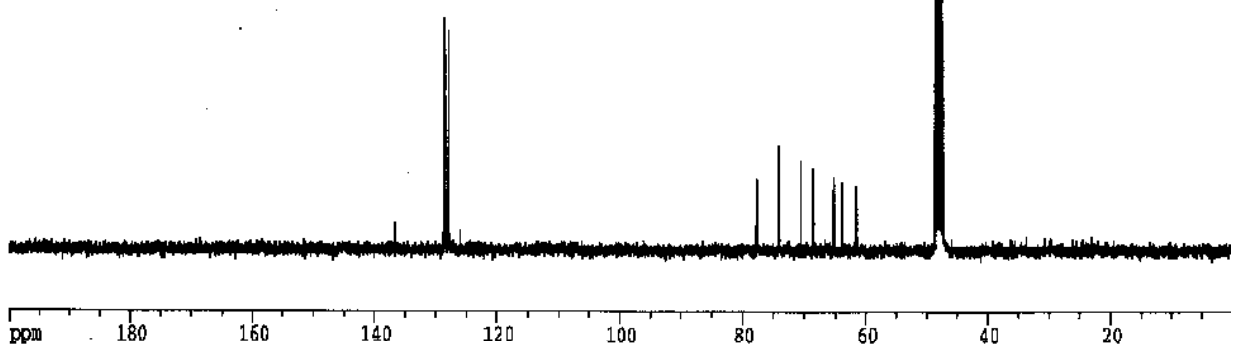




\section{$\underline{\text { X-ray Data: }}$}

X-ray Data for azide $\mathbf{2 3}$

\section{Comment}

The displacement ellipsoids were drawn at the $50 \%$ probability level.

\section{Experimental}

A colorless prism-shaped crystal of dimensions $0.21 \times 0.17 \times 0.05 \mathrm{~mm}$ was selected for structural analysis. Intensity data for this compound were collected using a Bruker APEX ccd area detector(1) mounted on a Bruker D8 goniometer using graphitemonochromated Mo Ka radiation $(1=0.71073 \AA)$. The data were collected at $100(2) \mathrm{K}$. The intensity data were measured as a series of $\mathrm{w}$ oscillation frames each of $0.25^{\circ}$ for $30 \mathrm{sec} /$ frame. The detector was operated in $512 \times 512$ mode and was positioned $5.04 \mathrm{~cm}$ from the sample. Coverage of unique data was $99.5 \%$ complete to 25.99 degrees in q. Cell parameters were determined from a least squares fit of 2072 peaks in the range $2.61<\mathrm{q}<$ $30.54^{\circ}$. From 52 peaks that were measured both at the beginning and end of data collection, the crystal showed a decay of $0.08 \%$. The data were corrected for absorption by the semiempirical method (2) from equivalent reflections giving minimum and maximum transmission factors of 0.9539 and 0.9888 . Lorentz and polarization corrections were applied. The data were merged to form a set of 2635 independent data with $\mathrm{R}$ (int) $=0.0337$.

The triclinic space group $P \overline{1}$ was determined by statistical tests and verified by subsequent refinement. The structure was solved by direct methods and refined by fullmatrix least-squares methods on $F^{2}$ (3). Hydrogen atom positions were initially determined by geometry and refined by a riding model. Non-hydrogen atoms were refined with anisotropic displacement parameters. Hydrogen atom displacement parameters were set to 1.2 (1.5 for methyl) times the displacement parameters of the bonded atoms. A total of 181 parameters were refined against 2635 data to give $w R\left(F^{2}\right)=0.1570$ and $\mathrm{S}=1.022$ for weights of $w=1 /\left[\mathrm{s}^{2}\left(F^{2}\right)+(0.1100 \mathrm{P})^{2}\right]$, where $\mathrm{P}=\left[F_{\mathrm{o}}^{2}+2 F_{\mathrm{c}}^{2}\right] / 3$. The final $R(F)$ was 0.0553 for the 2141 observed, $[F>4 \mathrm{~s}(F)]$, data. The largest shift/s.u. was 0.000 in the final refinement cycle. The final difference map had maxima and minima of 0.741 and -0.636 $\mathrm{e} / \AA^{3}$, respectively. 


\section{Acknowledgment}

The authors thank the National Science Foundation (grant CHE-0079282) and the University of Kansas for funds to purchase of the X-ray instrument and computers. This structure was determined by Douglas R. Powell.

\section{References}

(1) (a) Data Collection: SMART Software Reference Manual (1994). Bruker-AXS, 6300 Enterprise Dr., Madison, WI 53719-1173, USA. (b) Data Reduction: SAINT Software Reference Manual (1995). Bruker-AXS, 6300 Enterprise Dr., Madison, WI 53719-1173, USA.

(2) G. M. Sheldrick (1996). SADABS. Program for Empirical Absorption Correction of Area Detector Data. University of Göttingen, Germany.

(3) (a) G. M. Sheldrick (1994). SHELXTL Version 5 Reference Manual. Bruker-AXS, 5465

E. Cheryl Parkway, Madison, WI 53711-5373, USA. (b) International Tables for Crystallography, Vol C, Tables 6.1.1.4, 4.2.6.8, and 4.2.4.2, Kluwer: Boston (1995).

Table 1. Crystal data and structure refinement for 02038.

$\begin{array}{lll}\text { Empirical formula } & \mathrm{C}_{11} \mathrm{H}_{14} \mathrm{~N}_{3} \mathrm{O}_{5} \mathrm{P} & \\ \text { Formula weight } & 299.22 & \\ \text { Crystal system } & \text { Triclinic } & \\ \text { Space group } & P \overline{1} & \mathrm{a}=79.409(4)^{\circ} \\ \text { Unit cell dimensions } & a=8.1636(13) \AA \quad \mathrm{b}=74.124(4)^{\circ} \\ & b=8.7184(14) \AA & \mathrm{g}=81.613(4)^{\circ} \\ & c=10.1021(16) \AA & \\ \text { Volume } & 676.31(19) \AA^{3} & \\ \text { Z, Z } & 2,1 & \\ \text { Density (calculated) } & 1.469 \mathrm{Mg} / \mathrm{m}^{3} & \\ \text { Wavelength } & 0.71073 \AA \\ \text { Temperature } & 100(2) \mathrm{K} \\ F(000) & 312 \\ \text { Absorption coefficient } & 0.227 \mathrm{~mm}^{-1} & \\ \text { Absorption correction } & \text { Semi-empirical from equivalents } \\ \text { Max. and min. transmission } & 0.9888 \text { and } 0.9539 \\ \text { Theta range for data collection } & 2.12 \text { to } 25.99^{\circ}\end{array}$


Reflections collected

Independent reflections

Data / restraints / parameters

$w R$ (F $F^{2}$ all data)

$R$ ( $F$ obsd data $)$

Goodness-of-fit on $F^{2}$

Observed data [I $>2 \mathrm{~s}(\mathrm{I})]$

Largest and mean shift / s.u.

Largest diff. peak and hole
4187

2635 [R(int) $=0.0337]$

$2635 / 0 / 181$

$w R 2=0.1570$

$R 1=0.0553$

1.022

2141

0.000 and 0.000

0.741 and $-0.636 \mathrm{e} / \AA^{3}$

$w R 2=\left\{\mathrm{S}\left[w\left(F_{\mathrm{o}}^{2}-F_{\mathrm{c}}^{2}\right)^{2}\right] / \mathrm{S}\left[w\left(F_{\mathrm{o}}{ }^{2}\right)^{2}\right]\right\}^{1 / 2}$

$R 1=\mathrm{S}|| F_{\mathrm{o}}|-| F_{\mathrm{c}} \| / \mathrm{S}\left|F_{\mathrm{o}}\right|$ 
Table 2. Atomic coordinates and equivalent isotropic displacement parameters for 02038 . $\mathrm{U}(\mathrm{eq})$ is defined as one third of the trace of the orthogonalized $\mathrm{U}_{\mathrm{ij}}$ tensor.

\begin{tabular}{lllll}
\hline & \multicolumn{1}{c}{$\mathrm{x}$} & \multicolumn{1}{c}{$\mathrm{y}$} & $\mathrm{z}$ & $\mathrm{U}(\mathrm{eq})$ \\
& & & & \\
& & & & \\
$\mathrm{O}(1)$ & & & & \\
$\mathrm{P}(2)$ & $0.6230(2)$ & $0.69380(18)$ & $0.41110(16)$ & $0.0190(4)$ \\
$\mathrm{C}(3)$ & $0.72952(7)$ & $0.65339(7)$ & $0.52368(6)$ & $0.0170(2)$ \\
$\mathrm{C}(4)$ & $0.9197(3)$ & $0.7519(3)$ & $0.4389(2)$ & $0.0179(5)$ \\
$\mathrm{C}(5)$ & $0.8773(3)$ & $0.9184(3)$ & $0.3690(2)$ & $0.0181(5)$ \\
$\mathrm{C}(6)$ & $0.7669(3)$ & $0.9187(3)$ & $0.2681(2)$ & $0.0200(5)$ \\
$\mathrm{O}(7)$ & $0.5939(3)$ & $0.8554(3)$ & $0.3421(2)$ & $0.0199(5)$ \\
$\mathrm{O}(8)$ & $0.7570(2)$ & $0.48232(19)$ & $0.56259(18)$ & $0.0229(4)$ \\
$\mathrm{C}(9)$ & $0.6352(2)$ & $0.74187(18)$ & $0.65168(16)$ & $0.0188(4)$ \\
$\mathrm{C}(10)$ & $0.4900(3)$ & $0.6915(3)$ & $0.7535(2)$ & $0.0180(5)$ \\
$\mathrm{C}(11)$ & $0.3603(3)$ & $0.6350(3)$ & $0.7184(3)$ & $0.0237(5)$ \\
$\mathrm{C}(12)$ & $0.2172(3)$ & $0.5947(3)$ & $0.8236(3)$ & $0.0296(6)$ \\
$\mathrm{C}(13)$ & $0.2039(3)$ & $0.6109(3)$ & $0.9591(3)$ & $0.0302(6)$ \\
$\mathrm{C}(14)$ & $0.3351(4)$ & $0.6686(3)$ & $0.9923(3)$ & $0.0315(6)$ \\
$\mathrm{O}(15)$ & $0.4802(3)$ & $0.7085(3)$ & $0.8884(3)$ & $0.0244(6)$ \\
$\mathrm{O}(16)$ & $1.0246(2)$ & $0.74969(19)$ & $0.53117(17)$ & $0.0213(4)$ \\
$\mathrm{N}(17)$ & $0.7873(2)$ & $1.01513(19)$ & $0.46859(16)$ & $0.0209(4)$ \\
$\mathrm{N}(18)$ & $0.8673(3)$ & $0.8208(2)$ & $0.1610(2)$ & $0.0237(5)$ \\
$\mathrm{N}(19)$ & $0.8508(3)$ & $0.8680(3)$ & $0.0422(2)$ & $0.0269(5)$ \\
$\mathrm{C}(20)$ & $0.8462(3)$ & $0.8976(3)$ & $-0.0711(2)$ & $0.0422(7)$ \\
& $0.4831(3)$ & $0.8476(3)$ & $0.2470(3)$ & $0.0264(6)$ \\
& & & &
\end{tabular}


Table 3. Bond lengths $[\AA]$ and angles $\left[{ }^{\circ}\right]$ for 02038 .

\begin{tabular}{|c|c|c|c|}
\hline $\mathrm{O}(1)-\mathrm{C}(6)$ & $1.469(3)$ & $\mathrm{C}(9)-\mathrm{C}(10)$ & $1.383(3)$ \\
\hline $\mathrm{O}(1)-\mathrm{P}(2)$ & $1.5742(17)$ & $\mathrm{C}(10)-\mathrm{C}(11)$ & $1.386(3)$ \\
\hline $\mathrm{P}(2)-\mathrm{O}(7)$ & $1.4712(17)$ & $\mathrm{C}(10)-\mathrm{H}(10)$ & 0.9500 \\
\hline $\mathrm{P}(2)-\mathrm{O}(8)$ & $1.5838(16)$ & $C(11)-C(12)$ & $1.375(4)$ \\
\hline$P(2)-C(3)$ & $1.809(2)$ & $\mathrm{C}(11)-\mathrm{H}(11)$ & 0.9500 \\
\hline $\mathrm{C}(3)-\mathrm{O}(15)$ & $1.424(3)$ & $\mathrm{C}(12)-\mathrm{C}(13)$ & $1.389(4)$ \\
\hline$C(3)-C(4)$ & $1.528(3)$ & $\mathrm{C}(12)-\mathrm{H}(12)$ & 0.9500 \\
\hline $\mathrm{C}(3)-\mathrm{H}(3)$ & 1.0000 & $\mathrm{C}(13)-\mathrm{C}(14)$ & $1.390(3)$ \\
\hline $\mathrm{C}(4)-\mathrm{O}(16)$ & $1.411(3)$ & $\mathrm{C}(13)-\mathrm{H}(13)$ & 0.9500 \\
\hline$C(4)-C(5)$ & $1.534(3)$ & $\mathrm{C}(14)-\mathrm{H}(14)$ & 0.9500 \\
\hline $\mathrm{C}(4)-\mathrm{H}(4)$ & 1.0000 & $\mathrm{O}(15)-\mathrm{H}(15)$ & 0.8400 \\
\hline $\mathrm{C}(5)-\mathrm{N}(17)$ & $1.491(3)$ & $\mathrm{O}(16)-\mathrm{H}(16)$ & 0.8400 \\
\hline$C(5)-C(6)$ & $1.535(3)$ & $\mathrm{N}(17)-\mathrm{N}(18)$ & $1.232(3)$ \\
\hline $\mathrm{C}(5)-\mathrm{H}(5)$ & 1.0000 & $\mathrm{~N}(18)-\mathrm{N}(19)$ & $1.136(3)$ \\
\hline$C(6)-C(20)$ & $1.505(3)$ & $\mathrm{C}(20)-\mathrm{H}(20 \mathrm{~A})$ & 0.9800 \\
\hline $\mathrm{C}(6)-\mathrm{H}(6)$ & 1.0000 & $\mathrm{C}(20)-\mathrm{H}(20 \mathrm{~B})$ & 0.9800 \\
\hline $\mathrm{O}(8)-\mathrm{C}(9)$ & $1.405(3)$ & $\mathrm{C}(20)-\mathrm{H}(20 \mathrm{C})$ & 0.9800 \\
\hline$C(9)-C(14)$ & $1.376(3)$ & & \\
\hline $\mathrm{C}(6)-\mathrm{O}(1)-\mathrm{P}(2)$ & $121.37(14)$ & $\mathrm{N}(17)-\mathrm{C}(5)-\mathrm{H}(5)$ & 108.9 \\
\hline $\mathrm{O}(7)-\mathrm{P}(2)-\mathrm{O}(1)$ & $110.01(9)$ & $\mathrm{C}(4)-\mathrm{C}(5)-\mathrm{H}(5)$ & 108.9 \\
\hline $\mathrm{O}(7)-\mathrm{P}(2)-\mathrm{O}(8)$ & $113.37(9)$ & $\mathrm{C}(6)-\mathrm{C}(5)-\mathrm{H}(5)$ & 108.9 \\
\hline $\mathrm{O}(1)-\mathrm{P}(2)-\mathrm{O}(8)$ & 109.01(9) & $\mathrm{O}(1)-\mathrm{C}(6)-\mathrm{C}(20)$ & $105.74(18)$ \\
\hline $\mathrm{O}(7)-\mathrm{P}(2)-\mathrm{C}(3)$ & $116.05(10)$ & $\mathrm{O}(1)-\mathrm{C}(6)-\mathrm{C}(5)$ & $109.41(18)$ \\
\hline $\mathrm{O}(1)-\mathrm{P}(2)-\mathrm{C}(3)$ & $102.49(10)$ & $C(20)-C(6)-C(5)$ & $114.5(2)$ \\
\hline $\mathrm{O}(8)-\mathrm{P}(2)-\mathrm{C}(3)$ & $105.18(10)$ & $\mathrm{O}(1)-\mathrm{C}(6)-\mathrm{H}(6)$ & 109.0 \\
\hline $\mathrm{O}(15)-\mathrm{C}(3)-\mathrm{C}(4)$ & $111.64(18)$ & $\mathrm{C}(20)-\mathrm{C}(6)-\mathrm{H}(6)$ & 109.0 \\
\hline $\mathrm{O}(15)-\mathrm{C}(3)-\mathrm{P}(2)$ & $111.92(15)$ & $\mathrm{C}(5)-\mathrm{C}(6)-\mathrm{H}(6)$ & 109.0 \\
\hline $\mathrm{C}(4)-\mathrm{C}(3)-\mathrm{P}(2)$ & $112.13(15)$ & $\mathrm{C}(9)-\mathrm{O}(8)-\mathrm{P}(2)$ & $123.43(14)$ \\
\hline $\mathrm{O}(15)-\mathrm{C}(3)-\mathrm{H}(3)$ & 106.9 & $C(14)-C(9)-C(10)$ & $122.0(2)$ \\
\hline $\mathrm{C}(4)-\mathrm{C}(3)-\mathrm{H}(3)$ & 106.9 & $\mathrm{C}(14)-\mathrm{C}(9)-\mathrm{O}(8)$ & $116.6(2)$ \\
\hline $\mathrm{P}(2)-\mathrm{C}(3)-\mathrm{H}(3)$ & 106.9 & $\mathrm{C}(10)-\mathrm{C}(9)-\mathrm{O}(8)$ & $121.4(2)$ \\
\hline $\mathrm{O}(16)-\mathrm{C}(4)-\mathrm{C}(3)$ & 111.11(18) & $C(9)-C(10)-C(11)$ & $118.1(2)$ \\
\hline $\mathrm{O}(16)-\mathrm{C}(4)-\mathrm{C}(5)$ & $108.09(18)$ & $\mathrm{C}(9)-\mathrm{C}(10)-\mathrm{H}(10)$ & 120.9 \\
\hline$C(3)-C(4)-C(5)$ & $111.06(18)$ & $\mathrm{C}(11)-\mathrm{C}(10)-\mathrm{H}(10)$ & 120.9 \\
\hline $\mathrm{O}(16)-\mathrm{C}(4)-\mathrm{H}(4)$ & 108.8 & $C(12)-C(11)-C(10)$ & $121.1(2)$ \\
\hline $\mathrm{C}(3)-\mathrm{C}(4)-\mathrm{H}(4)$ & 108.8 & $\mathrm{C}(12)-\mathrm{C}(11)-\mathrm{H}(11)$ & 119.5 \\
\hline $\mathrm{C}(5)-\mathrm{C}(4)-\mathrm{H}(4)$ & 108.8 & $\mathrm{C}(10)-\mathrm{C}(11)-\mathrm{H}(11)$ & 119.5 \\
\hline$N(17)-C(5)-C(4)$ & $107.11(18)$ & $\mathrm{C}(11)-\mathrm{C}(12)-\mathrm{C}(13)$ & $120.0(2)$ \\
\hline $\mathrm{N}(17)-\mathrm{C}(5)-\mathrm{C}(6)$ & 110.67(19) & $\mathrm{C}(11)-\mathrm{C}(12)-\mathrm{H}(12)$ & 120.0 \\
\hline$C(4)-C(5)-C(6)$ & $112.33(19)$ & $\mathrm{C}(13)-\mathrm{C}(12)-\mathrm{H}(12)$ & 120.0 \\
\hline
\end{tabular}




$\begin{array}{ll}\mathrm{C}(12)-\mathrm{C}(13)-\mathrm{C}(14) & 119.7(2) \\ \mathrm{C}(12)-\mathrm{C}(13)-\mathrm{H}(13) & 120.1 \\ \mathrm{C}(14)-\mathrm{C}(13)-\mathrm{H}(13) & 120.1 \\ \mathrm{C}(9)-\mathrm{C}(14)-\mathrm{C}(13) & 119.1(2) \\ \mathrm{C}(9)-\mathrm{C}(14)-\mathrm{H}(14) & 120.5 \\ \mathrm{C}(13)-\mathrm{C}(14)-\mathrm{H}(14) & 120.5 \\ \mathrm{C}(3)-\mathrm{O}(15)-\mathrm{H}(15) & 109.5 \\ \mathrm{C}(4)-\mathrm{O}(16)-\mathrm{H}(16) & 109.5 \\ \mathrm{~N}(18)-\mathrm{N}(17)-\mathrm{C}(5) & 115.1(2) \\ \mathrm{N}(19)-\mathrm{N}(18)-\mathrm{N}(17) & 172.8(3) \\ \mathrm{C}(6)-\mathrm{C}(20)-\mathrm{H}(20 \mathrm{~A}) & 109.5 \\ \mathrm{C}(6)-\mathrm{C}(20)-\mathrm{H}(20 \mathrm{~B}) & 109.5 \\ \mathrm{H}(20 \mathrm{~A})-\mathrm{C}(20)-\mathrm{H}(20 \mathrm{~B}) & 109.5 \\ \mathrm{C}(6)-\mathrm{C}(20)-\mathrm{H}(20 \mathrm{C}) & 109.5 \\ \mathrm{H}(20 \mathrm{~A})-\mathrm{C}(20)-\mathrm{H}(20 \mathrm{C}) & 109.5 \\ \mathrm{H}(20 \mathrm{~B})-\mathrm{C}(20)-\mathrm{H}(20 \mathrm{C}) & 109.5\end{array}$


Table 4. Anisotropic displacement parameters $\left(\AA^{2} \times 10^{3}\right)$ for 02038 . The anisotropic displacement factor exponent takes the form:

$-2 \mathrm{p}^{2}\left[\mathrm{~h}^{2} a * 2 \mathrm{U}_{11}+\ldots+2 \mathrm{~h} \mathrm{k} a^{*} b^{*} \mathrm{U}_{12}\right]$

\begin{tabular}{lcccccc}
\hline & $\mathrm{U}_{11}$ & $\mathrm{U}_{22}$ & $\mathrm{U}_{33}$ & $\mathrm{U}_{23}$ & $\mathrm{U}_{13}$ & \multirow{2}{*}{$\mathrm{U}_{12}$} \\
\cline { 1 - 5 } & & & & & \\
$\mathrm{O}(1)$ & $13(1)$ & $18(1)$ & $23(1)$ & $-3(1)$ & $0(1)$ & $-4(1)$ \\
$\mathrm{P}(2)$ & $10(1)$ & $16(1)$ & $22(1)$ & $-3(1)$ & $0(1)$ & $-2(1)$ \\
$\mathrm{C}(3)$ & $12(1)$ & $20(1)$ & $20(1)$ & $-3(1)$ & $0(1)$ & $-2(1)$ \\
$\mathrm{C}(4)$ & $13(1)$ & $17(1)$ & $22(1)$ & $-3(1)$ & $2(1)$ & $-4(1)$ \\
$\mathrm{C}(5)$ & $15(1)$ & $19(1)$ & $22(1)$ & $-2(1)$ & $1(1)$ & $-1(1)$ \\
$\mathrm{C}(6)$ & $14(1)$ & $19(1)$ & $24(1)$ & $-4(1)$ & $-2(1)$ & $-1(1)$ \\
$\mathrm{O}(7)$ & $13(1)$ & $20(1)$ & $32(1)$ & $-3(1)$ & $0(1)$ & $-3(1)$ \\
$\mathrm{O}(8)$ & $13(1)$ & $18(1)$ & $22(1)$ & $-3(1)$ & $3(1)$ & $-6(1)$ \\
$\mathrm{C}(9)$ & $12(1)$ & $15(1)$ & $24(1)$ & $-1(1)$ & $1(1)$ & $-2(1)$ \\
$\mathrm{C}(10)$ & $21(1)$ & $26(1)$ & $24(1)$ & $-6(1)$ & $-2(1)$ & $-6(1)$ \\
$\mathrm{C}(11)$ & $17(1)$ & $36(2)$ & $36(1)$ & $-9(1)$ & $1(1)$ & $-11(1)$ \\
$\mathrm{C}(12)$ & $20(1)$ & $35(2)$ & $30(1)$ & $-4(1)$ & $7(1)$ & $-11(1)$ \\
$\mathrm{C}(13)$ & $31(2)$ & $40(2)$ & $21(1)$ & $-2(1)$ & $1(1)$ & $-11(1)$ \\
$\mathrm{C}(14)$ & $19(1)$ & $28(1)$ & $26(1)$ & $-2(1)$ & $-4(1)$ & $-6(1)$ \\
$\mathrm{O}(15)$ & $11(1)$ & $22(1)$ & $30(1)$ & $-6(1)$ & $-4(1)$ & $0(1)$ \\
$\mathrm{O}(16)$ & $16(1)$ & $18(1)$ & $28(1)$ & $-8(1)$ & $1(1)$ & $-3(1)$ \\
$\mathrm{N}(17)$ & $20(1)$ & $28(1)$ & $21(1)$ & $-6(1)$ & $0(1)$ & $-1(1)$ \\
$\mathrm{N}(18)$ & $21(1)$ & $33(1)$ & $25(1)$ & $-4(1)$ & $2(1)$ & $-8(1)$ \\
$\mathrm{N}(19)$ & $45(2)$ & $54(2)$ & $23(1)$ & $0(1)$ & $-2(1)$ & $-10(1)$ \\
$\mathrm{C}(20)$ & $22(1)$ & $29(1)$ & $29(1)$ & $-2(1)$ & $-8(1)$ & $-5(1)$ \\
& & & & & & \\
\hline & & & & & &
\end{tabular}


Table 5. Hydrogen coordinates and isotropic displacement parameters for 02038 .

\begin{tabular}{lcccc}
\hline & $x$ & $y$ & $z$ & \\
& & & & \\
& & & & \\
& & & & \\
$H(3)$ & 0.9881 & 0.6916 & 0.3633 & 0.021 \\
$H(4)$ & 0.9865 & 0.9633 & 0.3158 & 0.022 \\
$H(5)$ & 0.7459 & 1.0286 & 0.2214 & 0.024 \\
$\mathrm{H}(6)$ & 0.5299 & 0.9223 & 0.4140 & 0.024 \\
$\mathrm{H}(10)$ & 0.3690 & 0.6242 & 0.6248 & 0.028 \\
$\mathrm{H}(11)$ & 0.1269 & 0.5552 & 0.8018 & 0.036 \\
$\mathrm{H}(12)$ & 0.1050 & 0.5826 & 1.0300 & 0.036 \\
$\mathrm{H}(13)$ & 0.3257 & 0.6808 & 1.0857 & 0.038 \\
$\mathrm{H}(14)$ & 0.5713 & 0.7469 & 0.9101 & 0.029 \\
$\mathrm{H}(15)$ & 1.1065 & 0.6793 & 0.5165 & 0.026 \\
$\mathrm{H}(16)$ & 0.8468 & 1.0867 & 0.4669 & 0.025 \\
$\mathrm{H}(20 \mathrm{~A})$ & 0.5412 & 0.7752 & 0.1812 & 0.040 \\
$\mathrm{H}(20 \mathrm{~B})$ & 0.4623 & 0.9523 & 0.1955 & 0.040 \\
$\mathrm{H}(20 \mathrm{C})$ & 0.3737 & 0.8104 & 0.3023 & 0.040 \\
& & & & \\
\end{tabular}


Table 6. Torsion angles $\left[{ }^{\circ}\right]$ for 02038.

\begin{tabular}{lr}
\hline $\mathrm{C}(6)-\mathrm{O}(1)-\mathrm{P}(2)-\mathrm{O}(7)$ & $-172.95(15)$ \\
$\mathrm{C}(6)-\mathrm{O}(1)-\mathrm{P}(2)-\mathrm{O}(8)$ & $62.16(17)$ \\
$\mathrm{C}(6)-\mathrm{O}(1)-\mathrm{P}(2)-\mathrm{C}(3)$ & $-48.94(18)$ \\
$\mathrm{O}(7)-\mathrm{P}(2)-\mathrm{C}(3)-\mathrm{O}(15)$ & $-68.64(18)$ \\
$\mathrm{O}(1)-\mathrm{P}(2)-\mathrm{C}(3)-\mathrm{O}(15)$ & $171.46(15)$ \\
$\mathrm{O}(8)-\mathrm{P}(2)-\mathrm{C}(3)-\mathrm{O}(15)$ & $57.52(17)$ \\
$\mathrm{O}(7)-\mathrm{P}(2)-\mathrm{C}(3)-\mathrm{C}(4)$ & $165.01(14)$ \\
$\mathrm{O}(1)-\mathrm{P}(2)-\mathrm{C}(3)-\mathrm{C}(4)$ & $45.12(17)$ \\
$\mathrm{O}(8)-\mathrm{P}(2)-\mathrm{C}(3)-\mathrm{C}(4)$ & $-68.83(17)$ \\
$\mathrm{O}(15)-\mathrm{C}(3)-\mathrm{C}(4)-\mathrm{O}(16)$ & $-60.6(2)$ \\
$\mathrm{P}(2)-\mathrm{C}(3)-\mathrm{C}(4)-\mathrm{O}(16)$ & $65.9(2)$ \\
$\mathrm{O}(15)-\mathrm{C}(3)-\mathrm{C}(4)-\mathrm{C}(5)$ & $179.05(17)$ \\
$\mathrm{P}(2)-\mathrm{C}(3)-\mathrm{C}(4)-\mathrm{C}(5)$ & $-54.4(2)$ \\
$\mathrm{O}(16)-\mathrm{C}(4)-\mathrm{C}(5)-\mathrm{N}(17)$ & $177.90(17)$ \\
$\mathrm{C}(3)-\mathrm{C}(4)-\mathrm{C}(5)-\mathrm{N}(17)$ & $-60.0(2)$ \\
$\mathrm{O}(16)-\mathrm{C}(4)-\mathrm{C}(5)-\mathrm{C}(6)$ & $-60.4(2)$ \\
$\mathrm{C}(3)-\mathrm{C}(4)-\mathrm{C}(5)-\mathrm{C}(6)$ & $61.7(2)$ \\
$\mathrm{P}(2)-\mathrm{O}(1)-\mathrm{C}(6)-\mathrm{C}(20)$ & $-177.99(15)$ \\
$\mathrm{P}(2)-\mathrm{O}(1)-\mathrm{C}(6)-\mathrm{C}(5)$ & $58.3(2)$ \\
$\mathrm{N}(17)-\mathrm{C}(5)-\mathrm{C}(6)-\mathrm{O}(1)$ & $60.3(2)$ \\
$\mathrm{C}(4)-\mathrm{C}(5)-\mathrm{C}(6)-\mathrm{O}(1)$ & $-59.4(2)$ \\
$\mathrm{N}(17)-\mathrm{C}(5)-\mathrm{C}(6)-\mathrm{C}(20)$ & $-58.2(3)$ \\
$\mathrm{C}(4)-\mathrm{C}(5)-\mathrm{C}(6)-\mathrm{C}(20)$ & $-177.86(19)$ \\
$\mathrm{O}(7)-\mathrm{P}(2)-\mathrm{O}(8)-\mathrm{C}(9)$ & $-45.47(19)$ \\
$\mathrm{O}(1)-\mathrm{P}(2)-\mathrm{O}(8)-\mathrm{C}(9)$ & $77.43(18)$ \\
$\mathrm{C}(3)-\mathrm{P}(2)-\mathrm{O}(8)-\mathrm{C}(9)$ & $-173.26(17)$ \\
$\mathrm{P}(2)-\mathrm{O}(8)-\mathrm{C}(9)-\mathrm{C}(14)$ & $142.29(19)$ \\
$\mathrm{P}(2)-\mathrm{O}(8)-\mathrm{C}(9)-\mathrm{C}(10)$ & $-40.7(3)$ \\
$\mathrm{C}(14)-\mathrm{C}(9)-\mathrm{C}(10)-\mathrm{C}(11)$ & $-0.1(4)$ \\
$\mathrm{O}(8)-\mathrm{C}(9)-\mathrm{C}(10)-\mathrm{C}(11)$ & $-176.9(2)$ \\
$\mathrm{C}(9)-\mathrm{C}(10)-\mathrm{C}(11)-\mathrm{C}(12)$ & $0.3(4)$ \\
$\mathrm{C}(10)-\mathrm{C}(11)-\mathrm{C}(12)-\mathrm{C}(13)$ & $0.1(4)$ \\
$\mathrm{C}(11)-\mathrm{C}(12)-\mathrm{C}(13)-\mathrm{C}(14)$ & $-0.6(4)$ \\
$\mathrm{C}(10)-\mathrm{C}(9)-\mathrm{C}(14)-\mathrm{C}(13)$ & $-0.4(4)$ \\
$\mathrm{O}(8)-\mathrm{C}(9)-\mathrm{C}(14)-\mathrm{C}(13)$ & $176.5(2)$ \\
$\mathrm{C}(12)-\mathrm{C}(13)-\mathrm{C}(14)-\mathrm{C}(9)$ & $0.7(4)$ \\
$\mathrm{C}(4)-\mathrm{C}(5)-\mathrm{N}(17)-\mathrm{N}(18)$ & $-143.3(2)$ \\
$\mathrm{C}(6)-\mathrm{C}(5)-\mathrm{N}(17)-\mathrm{N}(18)$ & $94.0(2)$ \\
$\mathrm{C}(5)-\mathrm{N}(17)-\mathrm{N}(18)-\mathrm{N}(19)$ & $-176(2)$ \\
& \\
& \\
& \\
&
\end{tabular}


Table 7. Hydrogen bonds for $02038\left[\AA\right.$ and $\left.^{\circ}\right]$.

\begin{tabular}{lcccc}
\hline D-H...A & d(D-H) & $d(H \ldots A)$ & $d(D \ldots A)$ & $<($ DHA $)$ \\
\cline { 1 - 4 } O(15)-H(15)...O(7)\#1 & 0.84 & 1.83 & $2.626(2)$ & \\
O(16)-H(16)...O(15)\#2 & 0.84 & 1.90 & $2.736(2)$ & 178.0
\end{tabular}

Symmetry transformations used to generate equivalent atoms:

$\# 1-\mathrm{x}+2,-\mathrm{y}+1,-\mathrm{z}+1 \quad \# 2-\mathrm{x}+2,-\mathrm{y}+2,-\mathrm{z}+1$ 


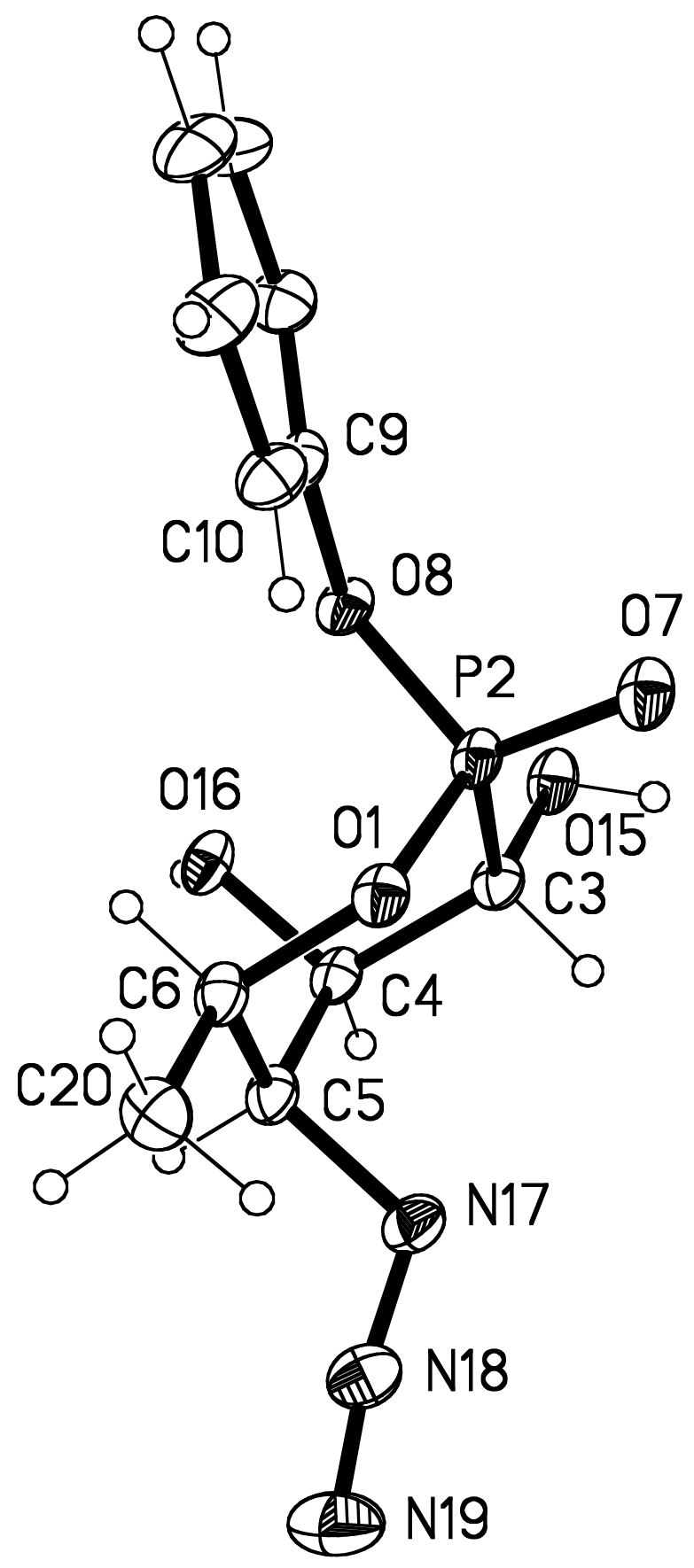




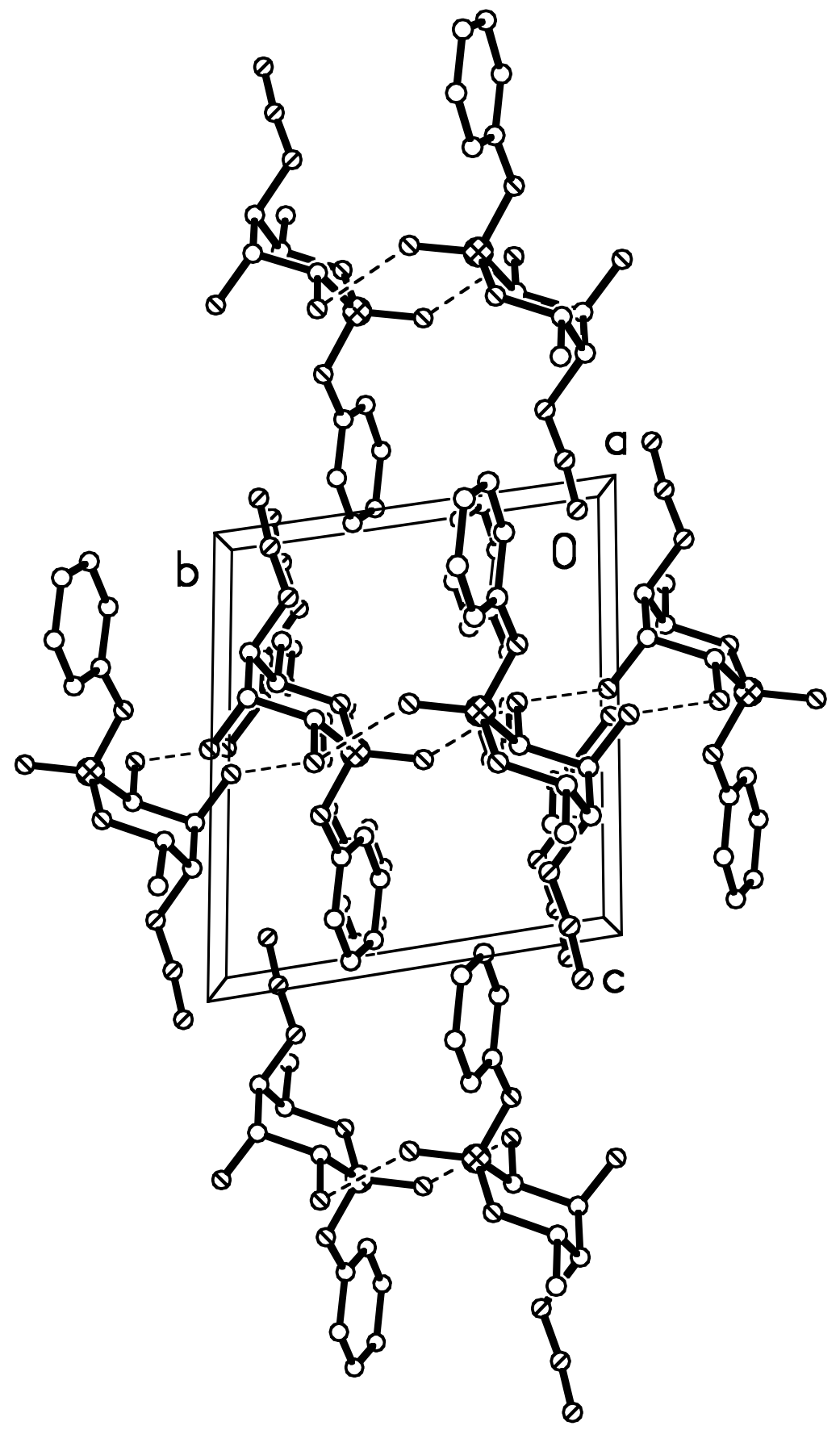

